\title{
"CARACTERISTICAS EPIDEMIOLÓGICAS DA CÁRIE DENTAL NA DENTIÇĀO PERMANENTE DE ESCOLARES DO GRUPO ETÁRIO DE 7 A 14 ANOS NO ESTADO DE SĀO PAULO"
}

ANTONIO GALVĀO FORTUNA ROSA

Tese apresentada ao Departamento de Prātica de Saūde Pública, da Facul dade de Saūde Pública da Universidāa de de São Paulo, para obtenção do Grau de Doutor em Saúde Pública.

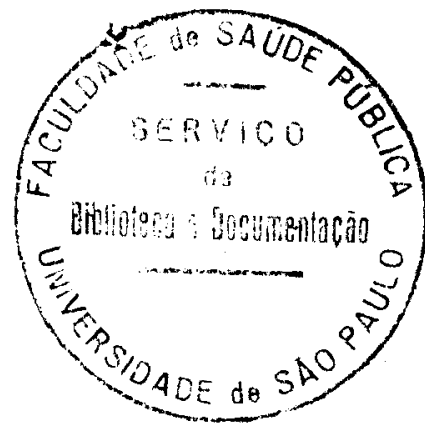

Orientador: Prof. Dr. Alfredo Reis Viegas 
I minha esposa

THEREZINHA 
Aos meus filhos

DENISE

e

RUBENS (IN MEMORIAM) 


\section{MEUS AGRADECIMENTOS}

Ao Prof. Dr. AlfRedo REIS VIEgAs, Professor Titular do De partamento de Prática de Saúde Pública, pela segura e zelo sa orientação, pelas observações que permitiram o aperfei çoamento deste trabalho e pelo tempo inestimāvel que nos de dicou, embora sobrecarregado com inümeras atividades admi nistrativas e didäticas, nossa sincera gratidão.

AOS Prof'. SABINA LEA DAVIDSON GOTLIEB e JOSE MARIA PACHECO DE SOUZA, respectivamente, Professor. Assistente Doutor e. Professor Adjunto do Departamento de Epiderniologia, pelas sugestões apresentadas por ocasião da anälise do Pro tocolo de Pesquisa.

Ao prezado amigo VITOR GOMES PINTO, Cirungião Dentista, Mes tre em Saúde Püblica, pela valiosa colaboração e fornecimen to de dados das regiões nordeste, sul e Distrito Federal.

Ao Prof. Dr. JAIR M. S. ROCHA, da Universidade Federal do Amazonas, pelo fornecimento de dados da região norte do Bra sil. 
Aos Cirurgiões Dentistas MERCEDO MAIALLE e EMIL ADIB RAZUK, respectivamente, Diretor da Divisão de Estudos, Normas e Programas em Assistência Odontológica e Diretor do Departa mento de Assistência ao Escolar por ocasião da execução dos levantamentos, pelo estímulo e apoio administrativo sem os quais não teria sido possivel a execução do presente estu do.

Aos Cirurgiões Dentistas Sanitaristas da DENPAO/DAE, mem bros da Equipe Técnica de Estudos e Normas, com os quais ti ve a satisfação de trabalhar no nível central, pela identifica ção das fichas de levantamento epidemiológico, posteriormente encaminhadas à PRODESP para processamento dos dados.

Aos Cirurgiões Dentistas Sanitaristas da DENPAO/DAE, com exercício nas Regionais de Ensino, pela revisão das fichas encaminhadas pelo nivel de operações.

Aos Cirurgiões Dentistas da DENPAO/DAE e contratados por Prefeituras Municipais, com exercicio nas escolas da rede estadual de ensino, pelos exames realizados.

À DAISY PIRES NORONHA, Bibliotecāria Chefe e ANGELA MARIA BELLONI CUENCA, Bibliotecária de Referência, pela revisão das referências bibliográficas. 
Ao Programa de Apoio à Pós-Graduação executado pelo Serviço de Biblioteca e Documentação da Faculdade de Saúde Pública, pelas cópias xerográficas utilizadas na revisão da literatú ra.

Á MARINEI CAMILLO CAMARGo, Secretária do Departamento de Prática de Saúde Pública, pelos serviços datilogräficos.

Finalmente, agradecemos sensibilizados a todos os que, com seu apoio e estímulo, ou de qualquer outra forma, coopera ram na realização deste trabalho. 
SUMĀRIO

Página

1. INTRODUÇÃO. . . . . . . . . . . . . . . . . . . . I

2. REVISÃO DA LITERATURA . . . . . . . . . . . . . . 5

2.1 Quadro epidemiológico no grupo etário de 7 a 14 anos de idade em outros países. . . . .

2.2 Quadro epidemiolögico no grupo etărio de 7 a 14 anos, no Brasil. . . . . . . . .

2.3 Quadro epidemiológico no grupo etârio de 7 a 14 anos, no Estado de São Paulo. . . . .

3. MATERIAL E MEtodos............... 60

3.1 Amostra. . . . . . . . . . . . . 60

3.2 Registro dos dados ............ 61

3.3 Indice................ . 62

3.4 Material . . . . . . . . . . . 65

3.5 Processamento de dados . . . . . . . . . 65

4. RESUltadoS E DiSCUSSÃO. . . . . . . . . . 69

5. CONCLUSÕES ........................... II6

6. REFERENCIAS BIBLIOGRAFICAS. . . . . . . . . 118 ANEXOS 
INDICE DE TABELAS

Tabela

Pägina

I CPo médio do grupo etário de 7 a 14 anos, de ambos os sexos, segundo a idade em Minnesota (Estados Unidos) em 1947. . .

2 CPO médio do grupo etário de 7 a 14 anos, de ambos os sexos, segundo a idade em New York (USA) em 1947. . . . . . . .

3 CPO médio de escolares do grupo etário de 7 a 14 anos de idade, de ambos os sexos, segundo a idade em Nova Jersey (Estados Unidos) em 1948 . . . . . . . . . . . . .

4 CPo médio aos 11 anos de idade, segundo o sexo e o teor de flüor presente na água de abastecimento público, na Finlândia em

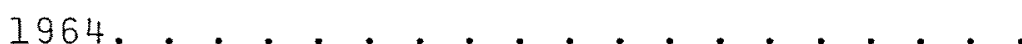

$5 \quad$ CPO médio de escolares de 7 a 13 anos de idade, de ambos os sexos, em regiões com baixo teor de flúor na água de abasteci mento público, segundo a idade, na Dina marca, em 1967. . . . . . . . . .

6 CPO médio do grupo etário de 7 a 14 anos, de ambos os sexos, segundo a idade, na Ma lásia, em 1975. . . . . . . . . . . .

7 CPos médio do grupo etário de 7 a 14 anos, de ambos os sexos, na Dinamarca, em 1979. • . . . . . . . . . . . . 
8 CPO médio de escolares de 9 a 13 anos de idade, de ambos os sexos, segundo a idade, em Newark (EUA), 1978-79. . . . . . .

9 CPO médio de escolares de 7, 9 e 11 anos de idade, de ambos os sexos, segundo a idade e a época do levantamento, na Holan da, de 1969 a 1978 . . . . . . . . .

10 Percentual de escolares de 7, 9 e 11 anos de idade, livres de cāries, de ambos os sexos, segundo a idade e a época do levan tamento, na Holanda, de 1969 a 1978 . . .

11 Número de indivíduos examinados, do grupo etário de 7 a 14 anos, segundo a idade e o sexo, nos Estados Unidos, 1971-74. . .

12 CPo médio e componentes, do grupo etário de 7 a 14 anos, do sexo masculino, segun do a idade, nos Estados Unidos, em 1971-74 . . . . . . . . . . . . . .

13 CPO médio e componentes, do grupo etärio de 7 a 14 anos, do sexo feminino, segundo a idade, nos Estados Unidos, em 1971-74.

14 CPO médio e componentes do grupo etário de 7 a 14 anos, de ambos os sexos, segun do a idade, nos Estados Unidos, em 197174 . . . . . . . . . . . . .

15 CPO médio e componentes de escolares com 12 anos de idade, segundo a região e a época do levantamento, na Inglaterra. . . 
Redução da prevalência de cảrie após 10 anos de aplicação de métodos preventivos, segundo a idade, em Cuba, 1970-1980. . . . . . . . .

Nümero de escolares examinados, segundo a idade e a época do levantamento, na Austrá lia, 1977-1982. . . . . . . . . . . .

CPO médio de escolares de 7 a 13 anos, segun do a idade e a época do levantamento, na Aus trālia, 1977-82. . . . . . . . . . . .

19 CPo médio para escolares de 7 a 14 anos, se gundo a idade, na Finlândia, em 1983 . . .

CPO mëdio de escolares de 7 a 12 anos, segun do a idade, na Bélgica, em 1983. . . . . .

Percentual de escolares livres de cáries, se gundo a idade, nos Estados Unidos, em 1979$-80$

CPo médio aos 12 anos de idade e consumo mé dio de açücar "per capita", segundo o país, em 13 países. . . . . . . . . . . . . .

23 CPO mẻdio do grupo etário de 7 a 14 anos, se gundo a idade e a época do levantamento, em Baixo Guandu, 1953-67. . . . . . . . . .

Composição percentual do Índice CPO em 2.904 crianças brasileiras de 7 a 14 anos, segundo a idade, em 1955 . . . . . . . . . . . 
Média dos dentes cariados, perdidos e obtura dos, em 36.543 escolares pertencentes ao gru po etario de 6 a 14 anos de idade, em comuni dades brasileiras trabalhadas pelo Ministê rio de saúde (FSESP). . . . . . . . . .

26 CPO médio e componentes em escolares de 7 a 12 anos, segundo a idade, em Natal, 1972.. .

27 CPO médio e componentes, de escolares de 7 a 13 anos, segundo a idade, em Porto Alegre, 1974 . . . . . . . . . . . . . . . . . . .

28 CPO mẻdio do grupo etärio de 7 a 14 anos, se gundo a idade, em Vitōria, 1975. . . . . .

29 CPO médio de escolares de 7 a 14 anos, segun do a idade, em Manaus, 1976. . . . . . . 40

$30 \quad$ CPO médio de 4.068 escolares do grupo etärio de 7 a 14 anos, segundo a idade, em Porto Velho (Rondônia), 1976 . . . . . . . . .

31 CPo médio do grupo etário de 7 a 14 anos, se gundo a idade, em Petrolina e Juazeiro, 1977

32 Prevalência da cárie dental em escolares de 7 a 12 anos, segundo a idade, em Brasília, 1979 . . . . . . . . . . . . . . .

33 CPo médio do grupo etärio de 7 a 14 anos, se gundo a idade, em Salvador, 1979. . . . .

34 CPo médio para escolares de 7 a 14 anos, se gundo a idade em Jõ̃o Pessoa, 1979. . . . . 
35 CPo médio do grupo etärio de 7 a 14 anos, se gundo a idade, em Boa Vista, 1980 . . . . .

CPO médio de escolares do grupo etärio de 7 a 14 anos, segundo a idade, em Triunfo (PE), 1980 . . . . . . . . . . . . . . .

CPO médio de escolares de 7 a 14 anos, segun do a idade, em Teresina, 1980. . . . . . .

Nưmero mẻdio de dentes atacados pela cárie nas idades de 7 a 14 anos, segundo a idade, em Uberaba, em 1981. . . . . . . . . .

CPO médio e componentes, número de escolares examinados, número médio de dentes irrompi dos do grupo etário de 7 a 12 anos, segundo o sexo e a idade, em Uberlândia, 1981. . .

CPo médio e componentes do grupo etário de 7 a 14 anos, segundo a idade, em Porto Alegre, 1982 . . . . . . . . . . . . . .

$41 \quad$ CPO médio e componentes e número de escola res examinados, do grupo etário de 7 a 14 a nos, segundo a idade no Bnasil, em 1983. .

42 Indice CPO e componentes, número mëdio de dentes irrompidos e número de escolares de 7 a 14 anos examinados, segundo a idade, em Campinas, 1961 . . . . . . . . . .

43 CPo médio e componentes, número mëdio de den tes irrompidos e número de escolares de 7 a 14 anos examinados, segundo a idade, em Campinas, 1972. . . . . . . . . . . . . 
44 CPO médio e componentes, número de escolares de 7 a 14 anos examinados, segundo a idade, en Campinas, 1976. . . . . . . . . . . . . .

45 CPO médio e componentes, nümero de escolares de 7 a 14 anos examinados e nümero mëdio de dentes inrompidos, segundo a idade, em Guai ra, 1975 . . . . . . . . . . . . .

CPo médio do grupo etário de 7 a 14 anos, se gundo a idade, em Santa Fé do Sul (SP), em 1978 . . . . . . . . . . . . . .

CPo médio dos escolares de 7 a 12 anos, se gundo a idade e a época do levantamento, em Garça, 1973-78 . . . . . . . . . . .

48 CPO mëdio e componentes, número mëdio de den tes irrompidos, do grupo etário de 7 a 14 a nos, segundo a idade, em são José dos Campos (SP), em 1979. . . . . . . . . . . . .

49 CPo mëdio e componentes, número médio de den tes irrompidos, do grupo etário de 7 a 14 a nos, em São José dos Campos (SP), em 1984. •

50 Nủmero de escolares examinados, do grupo etá rio de 7 a 14 anos, segundo a idade, sexo e época do levantamento, no Estado de São Pau Io, 1980-82. . . . . . . . . . . . .

51 CPO médio de escolares de 7 a 14 anos, segun do a idade e o sexo, no Estado de São Paulo, em 1982. • . . . . . . . . . . . . . 
CPO médio de escolares de 7 a 14 anos, segun do a idade e o sexo, no Estado de São Paulo, em 1982. • . . . . . . . . . . . . . .

53 CPO médio, segundo a idade, local e época do levantamento, em 8 cidades brasileiras e no Brasil . . . . . . . . . . . . . . . .

54 Prevalência de cārie dental nos primeiros mo lares permanentes, segundo a idade e o sexo, no Estado de São Paulo, em 1980-82 . . . .

55 CPO médio e componentes, dos primeiros mola res permanentes, segundo a idade, no Estado de São Paulo, em 1980. . . . . . . . . . . .

CPO médio e componentes, dos primeiros mola res permanentes, segundo a idade, no Estado de São Paulo, em 1982. . . . . . . . . . . .

Nümero mêdio de dentes irrompidos, segundo a idade, o sexo e a ëpoca do levantamento, no Estado de São Paulo, em 1980-82. . . . . .

CPo mẻdio e componentes, segundo a idade no Estado de São Paulo, em 1980.. . . . . . .

59 CPO mëdio e componentes, segundo a idade no Estado de São Paulo, em 1982 . . . . . . . .

CPO médio e componentes do grupo etário de 7 a 14 anos, após 14 anos de fluoretação, se gundo a idade, em Campinas, 1976. . . . . 
61 CPo médio dos lados direito e esquerdo, se gundo a idade e o sexo no Estado de São Pau lo, em 1980. . . . . . . . . . . . . . . . .

62 CPO mêdio das arcadas superior e inferior em escolares de 7 a 14 anos, segundo a idade, no Estado de São Paulo, em 1980-82. . . . . .

Número médio de dentes anteriones atacados pela cărie, segundo a idade e a ëpoca do le vantamento, no Estado de São Paulo, 1980-82.

CPO mëdio e componentes dos dentes anterio res, segundo a idade, no Estado de São PauIo, em 1980. • . . . . . . . . . . . . .

CPO médio e componentes dos dentes anterio res, segundo a idade, no Estado de São Paulo, em 19.82.

Percentual de participação dos dentes ante riores em relação ao CPO mêdio, segundo a $\underline{i}$ dade e a época do levantamento, no Estado de São Paulo, 1980-82 . . . . . . . . . . .

$67 \quad$ CPo médio e componentes dos dentes posterio res, segundo a idade e a época do levantamen to, no Estado de São Paulo . . . . . . . .

Número de escolares examinados, CPO médio, componentes, necessidades de tratamento ( $\mathrm{C}+$ EI), serviços executados $(O+E)$ e desvio pa drão, segundo a idade, na região Metropolita na de São Paulo, em 1980 . . . . . . . . . 
Nümero de escolares examinados, CPO médio, componentes, necessidades de tratamento ( + $E I)$, serviços executados $(O+E)$ e desvio pa drão, segundo a idade, na região Metropolitana de São Paulo, em 1982 . . . . . . . 109

Número de escolares examinados, cPo médio, componentes, necessidades de tratamento ( $\mathrm{C}+$ $E I)$, serviços executados $(O+E)$ e desvio pa drão, segundo a idade, no Interior, em 1980. 110

71 Nümero de escolares examinados, CPo médio, componentes, necessidades de tratamento ( $\mathrm{C}+$ $E I)$, serviços executados $(O+E)$ e desvio $\mathrm{pa}$ drão, segundo a idade, no Interior, em 1982 . Ill 
RESUMO

Em 1980 e 1982 foram realizados estudos epide miológicos da cârie dental abrangendo a ârea geográfica do Estado de São Paulo. Os levantamentos foram realizados em to das escolas da rede estadual de ensino que possuíam assistên cia odontológica. Os examinadores receberam por escrito as instruções sobre critérios de exame e preenchimento das fi chas. No primeiro levantamento foram examinados 270.736 esco lares do grupo etārio de 7 a 14 anos e em 1982 foram examina dos 144.480 escolares do mesmo grupo etário, sendo utilizado - Indice CPOD nos dois levantamentos. Fonam coletados dados apenas referentes aos dentes permanentes e o processamento foi executado pela PRODESP (Processamento de Dados do Estado de São Paulo).

Foram tabulados o número médio de dentes ataca dos pela cárie, segundo a idade e o sexo considerando - se: prevalência de cárie no grupo etário de 7 a 14 anos, dentes anteriores e posteriores, lado direito e lado esquerdo, den tes superiores e inferiores, primeiros molares e quadrantes. Foram também avaliados o nümero médio de dentes irrompidos, hígidos e necessidades de tratamento.

Os resultados encontrados em 1982 são simila res aos de 1980 e também semelhantes aos resultados obtidos em alguns estudos realizados em outras regiões do Brasil. 0 CPOD médio aos doze anos de idade foi 7,24 em 1980 e 7,13 em 1982, sendo mais do que o dobro da meta da Organização Mun dial de saúde para o ano $2.000\left(\mathrm{CPOD}_{12} \leq 3\right)$. 
SUMMARY

Epidemiological studies on dental caries were carried out covering a geographical area of the state of São Paulo, Brazil, in 1980 and 1982. All the schools belonging to the state teaching network, which had odontological assistance, took part in the surveys. The examiners received written instructions on the examination criteria as well as on how to fill out the charts. At the first survey, 270.7 .36 school children of the 7-14 years age-group were examined and, in 1982, 144.480 school children of the same age-group were examined, being used in both surveys the DMFT index. The data collected refer only to permanent teeth; the processing was worked out by the PRODESP (Data Processing of the State of São Pauıo).

The average number of teeth attaked by caries was computed according to age and sex, taking into account: caries prevalence in the 7-14 years age-group, anterior and posterior teeth, right and left sides, upper and lower teeth, first molars and quadrants. The average number of erupted, sound teeth, as well as the needs for treatment, were also estimated.

The results found out for 1982 are similar to those of 1980, being also similan to the results of some studies carried out in other regions of Brazil. The average DMFT for the age of 12 years was 7.24 in 1980 and 7.13 in 1982 , being more than the double of the value of the World Health Organization goal for the year of 2.000 (DMFT $\left._{12} \leq 3\right)$ 


\section{INTRODUÇÃO}

Uma das mais importantes äreas de atividade hu mana ê, por certo, a administração, ciência que tem como es sência o estabelecimento de condições adequadas para que as pessoas tenham um desempenho eficiente em suas atividades. A eficácia do trabalho no sentido de alcançar os objetivos pro postos depende diretamente do planejamento que envolve na área da saüde entre outras, o dimensionamento dos problemas e a racionalização do trabalho. No setor odontolögico, o co nhecimento das condições de saüde bucal, ou seja, quais pro blemas e respectivas necessidades de tratamento, bem como os recursos e sistemas de trabalho, são dados essenciais a con. siderar por parte de quem tem como objetivo agir no sentido de propiciar melhores condições de saúde para a comunidade.

Países desenvolvidos como Suécia, Dinamarca e Noruega, oferecem assistência odontológica integral e gratui ta a todos os indivíduos, do nascimento até os dezoito anos de idade, quando passam a integrar a força de trabalho ati va. No Brasil, as precārias condições sōcio-econômicas da po pulação reduz o acesso da maioria das pessoas ao Cirurgião Dentista de clínica particular. Em decorrência desse fato, aumenta a responsabilidade do Estado no que tange à assistên cia odontológica, seja no nïvel municipal, estadual ou fede nal.

Para o planejamento das ações dos óngäos pübli 
cos, é essencial obter dados que permitam instituir priorida des, alocar recursos, ayaliar os resultados e introduzir as modificações eventualmente necessárias. Como diz FORATTINI (1976): "Ao se pretender compreender realmente qualquer agra vo à saủde, torna-se imprescindîvel o conhecimento de seus aspectos epidemiológicos; trata-se portanto, de estabelecer e interpretar o quadro completo da história natural da doen ça".

Estudos epidemiológicos sobre doenças da boca publicados no Brasil são em nümero reduzido e a maioria abran ge apenas a área geográfica de um município, tratando apenas do maion problema da odontologia brasileira no momento: a cá rie dental. Estimativas da magnitude da prevalēncia da cárie dental no Brasil foram apresentas por Viegas no CONSELHO CON SULTIVO DE ADMINISTRAÇÃO DA SAỦDE PREVIDENCIÂRIA (CONASP) (1983), com o objetivo de elaborar o programa de reorienta ção e assistência odontológica do INAMPS (Instituto Nacional de Assistência Médica e Previdência Social) e por PIJTO (1983) em seu trabalho - Saúde bucal no Brasil.

Em virtude da carência de dados a nível nacio nal, em 1985 o Ministério da Saúde com o apoio do IPEA (Ins tituto de Planejamento Econômico e Social) e do BNH (Banco Nacional de Habitação), coordenou uma investigação epidemio lögica: abrangendo a ärea metropolitana de 16 capitais, com

* Levantamento realizado com recursos do FINSOCIAL e alocados ao Progra ma Nacional de Fluoretação das Âguas de Abastecinento Püblico, insti tuído pela Exposição de Motivos no $217 / 83$. 
a finalidade de obter informações sobre cärie dental, doença periodontal, necessicades de prótese, demanda a serviços odontológicos e prätica de higiene bucal, envolvendo 4 gru. pos etários: 6 a 12 anos, 15 a 19 anos, 35 a 44 anos e 50 a 59 anos, cujos resultados não foram publicados até o fin de 1986.

No Estado de São Paulo a carência de dados tam bém era notöria. Apenas alguns municípios realizaram levanta mentos epidemiológicos de cárie dental com o objetivo de ve rificar a redução de cáries promovida pela fluoretação da água de abastecimento püblico. Com o objetivo de obter dados a nível estadual, coordenamos em 1980 e 1982 dois levantamen tos epidemiológicos de cárie dental, envolvendo todas as es. colas estaduais que contassem com assistência odontológica. Foi utilizado o indice CPO-Dente proposto por KLEIN \& PALMER (1937) cujos componentes são: cariados, perdidos e obtura dos, para avaliar algumas caracteristicas epidemiológicas da cárie dental na dentição permanente dos escolares do 19 grau ( 7 a 14 anos), descritas nos objetivos especificos deste tra balho. O levantamento de 1982 teve também o objetivo de veri ficar os efeitos do treinamento geral dos recursos humanos, em todos os niveis, desenvolvido pelo óngão prestador de as sistência odontológica na nede estadual de ensino - DENPAO (Divisão de Estudos, Normas e Programas em Assistência Odon tológica) do Departamento de Assistência ao Escolar que faz parte da Secretaria de Estado da Educação.

Este estudo tem como objetivo geral analisar a 
histónia natural da cárie dental no Estado de Säo Paulo, na dentição permanente do grupo etărio 7 a 14 anos, atravess de dois levantamentos epidemiológicos realizados em 1980 e 1982 .

objetivos específicos:

a - analisar o CPO médio e componentes do gru po etário 7 a 14 anos, segundo a idade e o sexo em 1980 e 19.82 .

b - analisar o ataque de cárie nos primeiros molares, nos dois levantamentos.

c - analisar a prevalência de cárie dos lados direito e esquerdo em 1980 e 1982.

d - analisar a prevalência de cärie nos den tes superiores e inferiores em 1980 e 1982.

e - analisar a prevaléncia de cärie segundo os quadrantes superiores: direito e es querdo e os quadrantes inferiores: direi to e esquerdo nos dois levantamentos.

f - analisar o ataque de cárie em 1980 e 1982 nas duas macro regiões administrativas da Secretaria de Educação: Região Metropoli tana de São Paulo e Interior.

h - analisar o CPO médio ponderado do grupo etário 7 a 14 anos, segundo a Divisão Re gional de Educação em 1980 e 1982 . 


\section{REVISÃO DA LITERATURA}

A cärie dental passou a ser vista como um pro. blema importante de saúde pública em época recente na histó ria da humanidade. Citada em tempos remotos, mas praticamen te desconhecida quanto à história natural da doença, a ocor rência de cárie aumentou com o passar do tempo em consequén cia da industrialização acompanhada de aumento do consumo de sacarose, ocupando lugar de destaque no conjunto de proble mas de saủde da boca que aflige o homem modenno.

Atualmente a tendëncia nos países desenvolvi dos, com exceção do Japão, è uma significativa redução do ataque de cárie em virtude da Odontologia utilizar mëtodos preventivos em larga escala, principalmente com a utilização de flúor e controle da placa bacteriana dental.

o aparecimento da cárie ocorre geralmente logo após a erupção dos dentes e a incidência de novas lesões é mais alta na primeira infância com relação aos dentes tempo rários e na idade escolar e adolescência com relação aos den tes permanentes. Por esta razão o Comitê de Peritos da ORGA NIZAÇÃO MUNDIAL DE SAŨDE (1965) classificou o grupo etário de 7 a 14 anos como a primeira prioridade para tratamento odontológico e considerando ainda os dentes permanentes como primeira opção. Por essa razão, os dados disponíveis na lite. ratura, em sua maioria, referem-se a esse grufo, consideran do ainda que levantamentos epidemiológicos podem ser planeja dos e executados facilmente em ambientes fechados como são 
as escolas.

Procurando facilitar a exposição das investi gações epidemiológicas sobre cânie dental analisadas, a re visão da literatura foi ordenada em 3 partes: a prineira, voltada ao estudo epidemiológico da cárie em outros países, a segunda, dirigida a estudos realizados no Brasil e a ter ceira, expondo a prevalência da cárie em alguns municípios do Estado de São Paulo. Ressaltamos que, dos trabalhos ana lisados, utilizamos apenas os dados referentes ao grupo etá rio objeto deste estudo -7 a 14 anos de idade.

2.1 Quadro Epidemiológico no Grupo Etário 7 a 14 anos de Idade em outros Países

ODENTHAL (1887) examinou 987 escolares na Ale manha, encontrando cárie dental nos dentes de 429 indiví duos, o que corresponde a $43,5 \%$ do total.

Um artigo do Comitê Escolar da BRITISH DENTAL ASSOCIATION (1891) versando sobre as condições dentais de escolares ingleses informou que $84 \%$ dos individuos examina dos apresentaram um ou mais dentes cariados.

FENCHEL (1893) examinou 335 escolares na Ale manha, sendo 135 do sexo feminino e 200 do sexo masculino, encontrando 2.471 dentes cariados o que corresponde a uma média de 7,37 dentes cariados por indivíduo, enquanto ape nas 12 estavam livres de cáries. 
BESTEN (1894) yenificou que em algumas regiões da Alemanha apenas $17 \%$ dos 3.347 escolares examinados, esta vam livres de cāries.

GUILLERMIN (1895), examinando 2.222 escolares em Genebra (Suíça), observou que 69\% apresentavam dentes ata cados pela cârie.

FRICKE (1900) examinou 19.725 escolares de am bos os sexos em uma província germânica, constatando que 18.739 ( $95 \%$ ) estavam com dentes cariados.

BILLETER (1901), examinando 300 escolares de 12 e 13 anos de idade na Alemanha, observou que apenas 10\% não apresentavam dentes atacados pela cārie.

CUNINGHAM (1908) examinou 1.403 escolares em Cambridge (Inglaterra), verificando que $96,5 \%$ apresentavam um ou mais dentes cariados.

SCHWARZ (1930) examinou 19.027 escolares na Alemanha, encontrando dentes cariados em $94 \%$ deles.

CAMPATELLI (1931) observou uma média de 2,3 dentes cariados por indivíduo, depois de examinar 10.758 den tes em 4.640 escolares italianos.

FRANCI (1932) examinou 758 escolares na Itá lia, constatando que $89 \%$ apresentavam dentes cariados.

TORO-FREILE (1933), apôs investigação epidemio lógica sobre cárie nas escolas no Equador, encontrou 93\% dos escolares com um ou mais dentes cariados. 
KROHN (1935), examinando cerca de 7.000 esco lares em Copenhagen. (Dinamarca), verificou que $98 \%$ apresen tavam dentes cariados.

Atê esta época, a falta de um indice padrão levava a avaliações obtidas com critérios individuais, ton nando difíceis as comparações e análise dos resultados, di ficultando sobremaneira o estudo da história natural da cá rie dental. KLEIN \& PALMER (1937) propuseram o indice CPO (cariados, perdidos e obturados) utilizando-o no levantamen to epidemiológico de cárie dental realizado em jovens in dios de 35 tribos americanas. Este indice veio preencher uma lacuna existente na aferição de dados epidemiológicos sobre cárie dental e preenche os requisitos estabelecidos por JONHSON (1950):

- Pertinência - deve haver uma relação entre a doença e o indice utilizado

- Confiança - é preciso que o índice mantenha sua validade quando submetido a tratamento estatístico

- Significado - o Indice deve ser capaz de despertar uma idéia significativa daquilo que se pretende medir.

Desta época em diante, os estudos epidemioló gicos sobre cárie dental passaram a dispor de registro e critérios adequados para a análise da histónia natural da doença, possibilitando obter dados, quer em relação ao ata que global da cárie - CPO no indivíduo ou grupo de indiví 
duos, quer em relação a seus componentes: cariados, perdi dos e obturados.

KNUTSON (1947), em Minnesota (Fstados Uni dosl, examinando 2.627 escolares de 6 a 18 anos de idade, ve rificou que o ataque de cárie era crescente, acompanhando a idade. Na Tabela 1 podemos observar o CPo médio do grupo etário 7 a 14 anos.

TABELA 1 - CPO MEDIO DO GRUPO ETARIO DE 7 A 14 ANOS, DE AMBOS os SEXOS, SEgUNDO A IDADE EM MINNESOTA ( ESTADOS UNIDOS) EM. 1947 .

\begin{tabular}{lcccccccc}
\hline Idades & 7 & 8 & 9 & 10 & 11 & 12 & 13 & 14 \\
\hline$\underline{\mathrm{CPO}} *$ & 1,43 & 2,30 & 2,86 & 3,39 & 4,16 & 5,50 & 6,32 & 7,69 \\
\hline
\end{tabular}

Fonte: KNUTSON, J.W. (1947)

FINN (1947) examinou 5.824 escolares obtendo resultados que podem ser analisados na Tabela 2.

$* \overline{\mathrm{CPO}}=$ CPO médio 
TABELA 2 - CPO MEDIO DO GRUPO ETARIO DE 7 A 14 ANOS, DE AMBOS OS SEXOS, SEGUNDO A IDADE EM NEW YORK (USA) EM 1947.

\begin{tabular}{lcccccccc}
\hline Idades & 7 & 8 & 9 & 10 & 11 & 12 & 13 & 14 \\
\hline$\overline{\mathrm{CPO}}$ & 1,07 & 1,98 & 2,90 & 3,86 & 4,85 & 6,36 & 7,83 & 8,55 \\
\hline
\end{tabular}

Fonte: FINN, S.B. (1947)

WISAN \& CHILTON (1948) examinaram 61.612 esco lares em Nova Jersey (Estados Unidos) cujos resultados são apresentados na Tabela 3 .

TABELA 3 - CPO MEDIO DE ESCOLARES DO GRUPO ETARIO DE 7 A 14 ANOS DE IDADE, DE AMBOS OS SEXOS, SEGUNDO A IDA DE EM NOVA JERSEY (ESTADOS UNIDOS) EM 1948.

\begin{tabular}{lcccccccc}
\hline Idades & 7 & 8 & 9 & 10 & 11 & 12 & 13 & 14 \\
\hline$\overline{\mathrm{CPO}}$ & 1,54 & 2,32 & 2,90 & 3,62 & 4,42 & 5,68 & 7,11 & 8,12 \\
\hline
\end{tabular}

Fonte: WISAN, J.M. \& CHILTON, N.W. (1948)

SCHEININ e col. (1964) ao estudar a relação entre teor de flüor presente na ägua de abastecimento püblico e cárie dental na Finlândia, encontrou indices de prevalência de cárie aos 11 anos de idade que podem ser observados na Tabela 4. 
TABELA 4 - CPO MEDIO AOS 11 ANOS DE IDADE, SEGUNDO O SEXO E O TEOR DE FLUOR PRESENTE NA ÄGUA DE ABASTECI MENTO PUBBLICO, NA FINLÂNDIA EM 1964.

ppm* de flũor

$\overline{\mathrm{CPO}}$

Masculino

Feminino

\begin{tabular}{llll} 
& 0,10 & 6,90 & 6,90 \\
0,11 a 0,39 & 6,00 & 6,20 \\
0,40 a 0,99 & 4,50 & 4,80 \\
\hline
\end{tabular}

Fonte: SCHEININ, A. et al (1964)

o número de dentes erupcionados, segundo o au tor, variou de 19 a 21 em média. Quando o teor de flūor é menor do que 0,10 ppm 33\% dos dentes estavam atacados pela cárie.

BENTZ (1965) realizou um levantamento epide miológico de cárie dental na República Dominicana encontran do um cPo médio 1,51 aos 7 anos, 2,52 aos 8 anos e 3,18 aos 9. anos de idade.

* ppr $=$ partes por milhão. 
LIND \& LARSEN (1967), analisando äreas com al to e baixo teor de flüor nas águas de abastecimento püblico na Dinamarca, encontraram nas äreas de baixo teor de flíor os resultados apresentados na Tabela 5 .

TABELA 5 - CPO MEDIO DE ESCOLARES DE 7 A 13 ANOS DE IDADE, DE AMBOS OS SEXOS, EM REGIÕES COM RAIXO TEOR DE

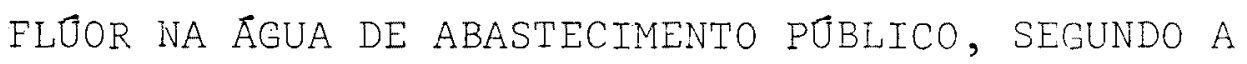
IDADE, NA DINAMARCA, EM 1967.

\begin{tabular}{llllllll}
\hline Idades & 7 & 8 & 9 & 10 & 11 & 12 & 13 \\
\hline$\overline{\mathrm{CPO}}$ & 2,80 & 3,60 & 4,50 & 5,60 & 6,60 & 8,40 & 10,80 \\
\hline
\end{tabular}

Fonte: LIND, P.O. \& LARSEN, M.J. (1967)

CHUNG e col. (1970) examinando. 17.772 escolares de 12 a 14 anos de idade nas escolas püblicas do Haway constą tou um CPO mëdio 5,69 aos 12 anos, 6,67 aos 13 anos e 8,00 aos 14 anos de idade.

BAGRAMIAN \& RUSSELL (1971) examinaram 1.486 jovens nas cidades de Detroit e Colúmbia (EUA), encontrando um CPO mëdio 9,17 aos 14 anos de idade em Detroit e 10,30 em Colúmbia na mesma faixa de idade.

TAMARI (1974), realizando uma revisão básica para determinar as necessidades de tratamento acumuladas nas escolas públicas do Líbano, observou um CPO inëdio 1,67 aos 
7 anos $e I, 74$ aos 8 anos de idade.

YASSIN \& LOW (1975), realizando estudos epide miológicos sobre cärie dental na Maläsia, examinaram 15.197 escolares de 6 a 18 anos de idade em 47 escolas, obtendo re sultados para o grupo etário 7 a 14 anos que estão assinala dos na Tabela 6 .

TABELA 6 - CPO MEDIO DO GRUPO ETÄRIO DE 7 A 14 ANOS, DE AMBOS OS SEXOS, SEGUNDO A IDADE, NA MALASIA EM 1975.

\begin{tabular}{lcccccccc} 
Idades & 7 & 8 & 9 & 10 & 11 & 12 & 13 & 14 \\
\hline$\overline{\mathrm{CPO}}$ & 1,40 & 2,70 & 3,80 & 4,90 & 6,10 & 7,60 & 9,30 & 10,80
\end{tabular}

Fonte: YASSIN, I. \& LOW, T. (1975)

SCHWARZ \& HANSEN (1979) realizaram um levanta mento epidemiológico de cârie dental na Dinamarca, utilizan do o Indice CPO-S*, ocasião em que foram examinados 507.485 individuos de 2 a 14 anos de idade. Os resultados referentes aos grupo etário de 7 a 14 anos podem ser analisados na Ta bela 7 .

* Superficies dentais atacadas pela cârie. 
TABELA 7 - CPO-S MEDIO DO GFUPO ETARIO DE 7 A 14 ANOS, DE AM BOS OS SEXOS, NA DINAMARCA EM 1979.

\begin{tabular}{lccccccccc}
\hline Idades & 7 & 8 & 9 & 10 & 11 & 12 & 13 & 14 \\
\hline$\overline{\mathrm{CPO}} * \overline{5}$ & 1,40 & 2,70 & 3,80 & 4,90 & 6,10 & 7,60 & 9,30 & 10,80 \\
\hline
\end{tabular}

Fonte: SCHWARZ, E. \& HANSEN, E.R. (1979)

HAUSEN e colaboradores (1979) compararam a pre valência de cārie na Finlândia, após 4 anos ca implanta̧̧ão de programas curativos e preventivos com os exames anteriores à implantação. O CPO médio aos 8 anos de idade foi reduzido de 2,70 para 1,70, o que significa um dente a menos, enquanto aos 12 anos de idade a redução foi de um dente e meio: 6,70 para 5,20. Os autores salientaram que essa redução foi devi da à ação local do flúor utilizado nos programas preventivos.

HOUPT e colaboradores (1979) realizaram um es tudo epidemiológico sobre cárie dental em escolares de Newark (EUA) durante 2 anos. Foram examinadas 3.766 crianças com idades de 9 a 13 anos, cujos resultados podem ser vistos na Tabela 8 .

* $\overline{\mathrm{CPO}-\mathrm{S}}-\mathrm{CPO}-\mathrm{S}$ médio 
TARELA 8 - CPO MEDIO DE ESCOLARES DE 9 A 13 ANOS DE IDADE, DE AMBOS OS SEXOS, SEGUNDO A IDADE, EM INEWARK (EUA), 1978-79.

\begin{tabular}{llllll}
\hline Idades & 9 & 10 & 11 & 12 & 13 \\
\hline$\overline{\mathrm{C}} \overline{\mathrm{PO}}$ & 1.39 & 1,98 & 2,42 & 3,15 & 3,35 \\
\hline
\end{tabular}

Fonte: HOUPT, M. et al (1979)

AMARATUNGE e col. (1980) realizando estudos epidemio lógicos de cárie dental no sri Lanka, observou que as cáries vestibulares nos dentes anteriores se iniciam praticamente ao redor dos 12 anos de idade, recomendando que medidas pre ventivas devem ser aplicadas antes dessa idade para evitar a ocorrência dessas cäries. Observou ainda diferenças no ata que de cárie em relação ao sexo. As meninas apresentavam maior número de cáries do que os meninos da mesma idade. o autor explicou a prevalência de cárie maion no sexo femini no, em virtude do maion número de dentes irrompidos apresen tado pelas meninas.

O'MULlane (1980), avaliando a redução de cá ries após 19 anos de fluoretação na Irlanda, apresentou redu ções que variaram de $54 \%$ aos 8 e 9 anos $\left(\overline{\mathrm{CPO}}_{61}=2,80 \mathrm{e}\right.$ $\left.\overline{\mathrm{CPO}}_{80}=1,30\right)$ para $45 \%$ aos 13 e 14 anos $\left(\overline{\mathrm{CPO}}_{61}=8,00 \mathrm{e}\right.$ $\left.\overline{\mathrm{CPO}}_{80}=4,40\right)$.

TRUIN e col. (1981) realizaram um estudo na Holanda no período de 1969 a 1978, constando de educação em saúde da bo 
ca para os pais, "check up" nas clinicas do bom bebê aos 6 e 10 meses de idade e ação educativa junto aos escolares de 4 a 6 anos de idade, utilizando professores devidamente treinados como pessoal auxiliar e posteriormente, a partir de 1972, estendendo o processo educativo até 9 anos de ida de e até 11 anos a partir de 1974. Em paralelo foi desenvol vido um programa curativo em todas as escolas. Os resulta dos estão apresentados na Tabela 9.

TABELA 9 - CPO MEDIO DE ESCOLARES DE 7,9 E 11 ANOS DE IDADE, DE AMBOS OS SEXOS, SEGUNDO A IDADE E A EPOCA DO LEVANTAMENTO, NA HOLANDA, DE 1969 A 1978.

\begin{tabular}{ccccc}
\hline Idades & \multicolumn{4}{c}{$\overline{\mathrm{C} \overline{\mathrm{PO}}}$} \\
\hline 1969 & 1972 & 1975 & 1978 \\
\hline 7 & 3,26 & 2,78 & 2,15 & 1,77 \\
9 & 6,95 & 6,75 & 4,87 & 3,94 \\
& - & 10,30 & 9,75 & 8,18 \\
\hline
\end{tabular}

Fonte: TRUIN, G.J. et aI (198I)

o percentual de escolares sem nenhuma cárie encontrado nesse estudo pode ser observado na Tabela 10. 
TABELA 10 - PERCENTUAL DE ESCOLARES DE 7,9 I 11 ANOS DE IDA DE LIVRES DE CARIES, DE AMBOS OS SEXOS, SEGUNDO A IDADE E A EPOCA DO LEVANTAMENTO, NA HOLANDA,DE 1969 A 1978 .

\begin{tabular}{ccccc}
\hline & \multicolumn{2}{c}{ Percentual de escolares livres de cäries } \\
\cline { 2 - 3 } & 1969 & 1972 & 1975 & 1978 \\
\hline 7 & $2 \%$ & $6 \%$ & $14 \%$ & $52 \%$ \\
9 & $0 \%$ & $1 \%$ & $3 \%$ & $21 \%$ \\
\hline
\end{tabular}

Fonte: TRUIN, G.J. et al. (I98I)

HARVEY \& KELLY (1981), analisando o primeiro "National Health and Nutrition Examination Survey" realizado entre 1971 e 1974 nos Estados Unidos, durante o qual foram examinadas 20.749 pessoas de ambos os sexos, de 1 a 74 anos de idade, selecionaram entre outros dados o CPO médio para medir a prevalência de cärie dental. Os resultados em rela ção ao grupo etário 7 a 14 anos podem ser analisados nas Ta belas 11, 12, 13 e 14. 
TABELA 11 - NÜMERO DE INDIVIDUOS EXAMINADOS, DO GRUPO ETARIO DE 7 A 14 ANOS, SEGUNDO A IDADE E O SEXO, NOS ESTADOS UNIDOS, $1971-74$.

\begin{tabular}{|c|c|c|c|}
\hline \multirow{2}{*}{ Idades } & \multicolumn{3}{|c|}{ Nümero de indivíduos examinados } \\
\hline & Masculino & Feminino & Total \\
\hline 7 & 164 & 169 & 333 \\
\hline 8 & 152 & 152 & 304 \\
\hline 9 & 169 & 171 & 340 \\
\hline 10 & 184 & 197 & 381 \\
\hline 11 & 178 & 166 & 344 \\
\hline 12 & 200 & 177 & 377 \\
\hline 13 & 174 & 198 & 372 \\
\hline 14 & 174 & 184 & 358 \\
\hline
\end{tabular}

Fonte: HARVEY, C. \& KELLY, J.E. (1981) 
TABELA 12 - CPO MEDIO E COMPONENTES, DO GRUPO ETẢRIO DE 7 A 14 ANOS, DO SEXO MASCULTNO, SEgUNDO A IDADE, NOS ESTADOS UNIDOS, EM 1971 - 74 .

\begin{tabular}{ccccc}
\hline Idades & $\overline{\mathrm{C}}^{*} \mathrm{\sigma ^{* } *}$ & $\overline{\mathrm{P}}^{* * *}$ & $\overline{\mathrm{CPO}}$ \\
\hline 7 & 0,40 & 0,20 & 0,00 & 0,60 \\
9 & 0,60 & 0,60 & 0,00 & 1,20 \\
10 & 0,90 & 1,40 & 0,10 & 2,40 \\
11 & 0,90 & 1,50 & 0,20 & 2,60 \\
12 & 1,10 & 1,70 & 0,30 & 3,10 \\
13 & 1,00 & 2,60 & 0,30 & 3,90 \\
14 & 1,90 & 2,40 & 0,50 & 4,80 \\
\hline 1,70 & 3,00 & 0,50 & 5,20 \\
\hline
\end{tabular}

Fonte: HARVEY, C. \& KELLY, J.E. (1981)

$* \overline{\mathrm{C}}=$ nümero médio de dentes cariados

$* \overline{0}=$ número médio de dentes obturados

$* *: \overrightarrow{\mathrm{P}}=$ nümero mëdio de dentes perdidos 
TABELA 13 - CPO MEDIO E COMPONENTES, DO GRUPO EIARIO DE 7 A'14 $^{\prime}$ ANOS, DO SEXO FEMININO, SEGUNDO A IDADE, NOS ES TADOS UNIDOS, EM 1971 - 74 .

\begin{tabular}{|c|c|c|c|c|}
\hline Idades & $\bar{C}$ & 0 & $\overline{\mathrm{P}}$ & $\overline{\mathrm{CPO}}$ \\
\hline 7 & 0,30 & 0,10 & 0,10 & 0,50 \\
\hline 8 & 0,60 & 0,60 & 0,10 & 1,30 \\
\hline 9 & 1,00 & 0,60 & 0,30 & 1,90 \\
\hline 10 & 0,90 & 1,40 & 0,20 & 2,50 \\
\hline 11 & $1,10$. & 1,10 & 0,40 & 2,60 \\
\hline 12 & 1,40 & 1,90 & 0,40 & 3,70 \\
\hline 13 & 1,70 & 3,00 & 0,50 & 5,20 \\
\hline 14 & 2,00 & 3,70 & 0,90 & 6,60 \\
\hline
\end{tabular}

Fonte: HARVEY, C. \& KELLY, J.E. (I981) 
TABELA 14 - CPO MEDIO E COMPONENTES DO GRUPO ETARIO DE 7 A 14 ANOS, DE AMBOS OS SEXOS, SEGUNDO A IDADE, NOS ESTADOS UNIDOS, EM 1971 - 74 .

\begin{tabular}{|c|c|c|c|c|}
\hline Idades & $\overline{\mathrm{C}}$ & $\overline{0}$ & $\overline{\mathrm{P}}$ & $\overline{\mathrm{CPO}}$ \\
\hline 7 & 0,40 & 0,10 & 0,00 & 0,50 \\
\hline 8 & 0,60 & 0,60 & 0,10 & 1,30 \\
\hline $\mathrm{g}$ & 0,90 & 1,00 & 0,20 & 2,10 \\
\hline 10 & $0,9 a$ & 1,40 & 0,20 & 2,50 \\
\hline 11 & 1,10 & 1,40 & 0,30 & 2,80 \\
\hline 12 & 1,20 . & 2,30 & 0,30 & 3,80 \\
\hline 13 & 1,80 & 2,70 & 0,50 & 5,00 \\
\hline 14 & 1,80 & 3,30 & 0,70 & 5,80 \\
\hline
\end{tabular}

Fonte: HARVEY, C. \& KELLY, J.E. (1981) 
KALSBEEK (1981) realizou um estudo epidemioló gico na Holanda abrangendo seis localidades, inclusive a ca pital Amsterdam, observando uma variação do CPO médios dos escolares com 12 anos de idade - 7,70 em Amsterdam e 9,30 nas outras regiōes.

HUNTER \& HENDERSON (1982) aO analisarem os efeitos da fluoretação da âgua de abastecimento público em Timaru (Nova Zelândia), durante o período de 1973 a 1981 , ve rificaram uma redução de $72 \%$ no CPO médio aos 8 anos de ida de, passando de 3,16 para 0,89 .

HESSESLGREN \& THYLSTRUP (1982) analisaram os efeitos do programa de atendimento odontológico a escolares de Frederikssund (Dinamarca), situada a apenas $50 \mathrm{~km}$ da capi tal - Copenhagen, com uma população de cerca de 17.000 habi tantes. O levantamento de Iinha de base realizado em 1961 re velou um cPo médio 2,30 aos oitos anos de idade para os meni nos e 3,20 para as meninas na mesma idade. Apös 15 anos de implantação do programa preventivo, no qual foram utilizados métodos combinados de prevenção extensivos a todos os indiví duos de 0 a 16 anos de idade, os resultados encontrados fo ram: CPO médio aos 8 anos de idade 1,40 para os meninos e 1,70 para as meninas, portanto, uma significativa redução da prevalência de cárie.

VON DER FEHR (1982), comparando o resultado de programas de assistência odontológica em 5 paises, verifi cou que Nova Zelânaia e Noruega apresentavam maion número de dentes tratados, portanto um bom programa curativo, embora 
esses 2 países apresentassem prevalência de cárie maior do que os demais, significando maiores recursos para cobertura das necessidades de tratamento e consequentemente custos operacionais mais dispendiosos.

FIGURA 1 - CPO MEDIO E COMPONENTES DA AUSTRÁLIA, NORUEGA, NO VA ZELÃNDIA, JAPÃO E REP.FED. DA ALEMANHA.

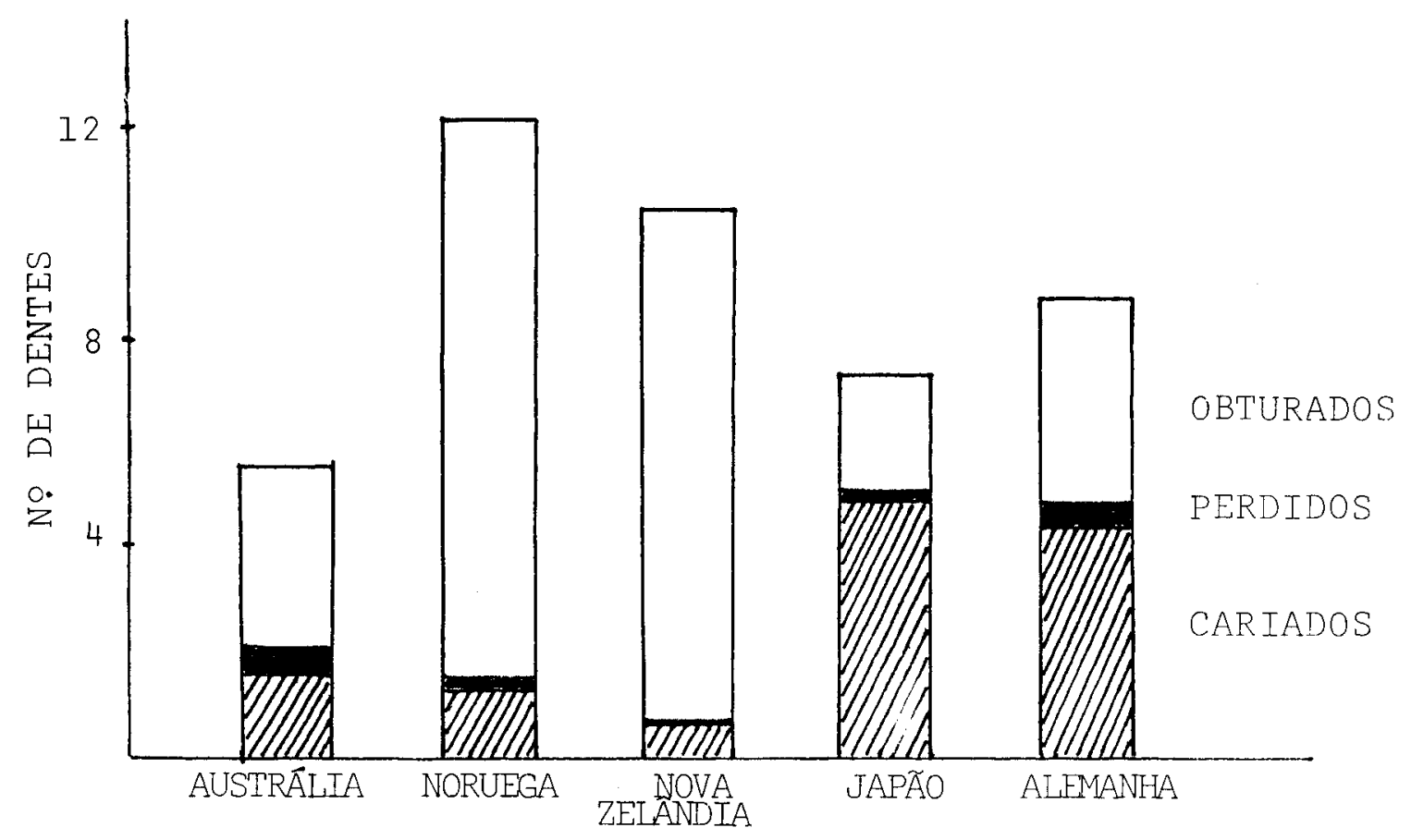

Fonte: VON DER FEHR, F.R. (1982)

De 1969 em diante, os responsáveis pela saūde pública na Noruega passaram a investin mais nos programas preventivos e atualmente a prevaléncia da cárie é bem menor do que a apresentada na Figura 1. Algumas considerações fo 
ram feitas pelo Prof. Gunnar Rolla para explicar a redução de cáries e o sucesso da assistência odontológica na Norue ga. *

"A Noruega tinha grandes problemas com a cá rie dental, mas com grandes investimentos, principalmente na prevenção, o problema foi resolvido. o Serviço Dentário Escolar atendia em 1982 cerca de 95\% dos escolares. As clî nicas püblicas são tão atraentes quanto as clínicas particu lares. O poder püblico presta assistēncia odontológica gra tuita a todos os indivíduos de 0 a 18 anos de idade, desde que estejam matriculados no programa desde o nascimento, par ticipando portanto de todos os programas preventivos. A par tir de 1971 ocorreu grande aumento no consumo de dentifrí. cios fluorados e em 1982 dominavam 70\% do mercado. Comprimi. dos fluorados têm sido sistematicamente introduzidos atra vés das clínicas do bom bebê. Pessoal auxiliar tem sido uti lizado amplamente na execução dos programas preventivos e a motivação para Iimpeza dos dentes é executada a partir da pré-escola."

BROWN (1982), em estudos realizados na Nova Zelândia, observou que o CPO mëdio no país para as idades 12 e 13 anos ena 7,00 em 1977, passando a 5,1 em 1980, apös 3 anos de fluoretação da āgua de abastecimento pūblico.

* Comunicação pessoal durante curso de prevenção de cárie e moléstias periodontais, realizado na Universidade de Oslo em 1982. 
EEJERSKOV e colaboradores (1982) em levanta mentos epidemiológicos realizados em 1972 e 1979 na Dinamar ca, assinalaram uma redução de cärie cada vez maior, ano a ano, graças à implantação de métodos combinados de preven ção. No ültimo levantamento, $56 \%$ dos escolares com 7 anos de idade estayam livres de cáries, enquanto $44 \%$ apresen tavam cáries apenas nas superficies oclusais.

ANDERSON e colaboradores (1982), estudando 0 ataque de cárie em escolares com 12 anos de idade, em 4 re giões rurais da Inglaterra, verificaram que depois de 10 ou 15 anos de introdução de métodos preventivos, ocorreram re duções de $32 \%$ a $51 \%$. O CPO médio e componentes pode ser ana lisado na Tabela 15 .

TABELA 15 - CPO MEDIO E COMPONENTES DE ESCOLARES COM 12 A NOS DE IDADE, SEGUNDO A REGIÃO E A EPOCA DO LE VANTAMENTO, NA INGLATERRA.

\begin{tabular}{lccccc}
\hline Idades & Epoca & $\overline{\mathrm{C}}$ & $\overline{\mathrm{P}}$ & $\overline{\mathrm{O}}$ & $\overline{\mathrm{C}} \overline{\mathrm{PO}}$ \\
\hline \multirow{2}{*}{ Somerset } & 1963 & 1,67 & 1,00 & 2,68 & 5,36 \\
\multirow{2}{*}{ Shoropshire } & 1978 & 0,31 & 0,20 & 2,93 & 3,44 \\
\multirow{2}{*}{ Devon } & 1980 & 1,30 & 0,53 & 2,69 & 4,53 \\
& 1980 & 0,31 & 0,32 & 2,45 & 3,08 \\
\multirow{2}{*}{ Fairford } & 1971 & 1,52 & 0,38 & 3,42 & 5,32 \\
& 1981 & 0,24 & 0,17 & 2,29 & 2,70 \\
& 1964 & 1,20 & 0,48 & 2,80 & 4,48 \\
& 1979 & 0,11 & 0,11 & 1,97 & 2,19 \\
\hline
\end{tabular}

Fonte: ANDERSON, R.J. et al (1982) 
MARTIN (1982), analisando o "Programa incremen to de la atencion estomatológica a escolares de primaria (1970 a 1980) "em Cuba, discorreu sobre as atividades desen volvidas com os objetivos de reduzir as necessidades de tra tamento atravës do programa preventivo e aumentar a cobertu ra por meic do programa curativo. No programa preventivo atuaram Assistentes dentais e professores devidamente treina dos para execução de bochechos fluorados a 0,2\% a cada 15 dias. As atividades curativas estiveram a cargo de Estomato logistas (Cirurgiões Dentistas)e Técnicos de estomatologia. Instruções sobre saúde da boca foram ministradas aos escola. res, pais e mestres. Depois de 10 anos foram alcançadas redu ções da ordem de $31 \%$ na prevalência da cârie e um aumento significativo na cobertura. Os resultados podem ser observa dos na Tabela 16 .

TABELA 16 - REDUÇÃO NA PREVALENCIA DA CARIE APÓS 10 ANOS DE APLICAÇÃO DE METODOS PREVENTIVOS, SEGUNDO A IDA DE, EM CUBA, $1970-1980$.

\begin{tabular}{cccc}
\hline Idades & & \multicolumn{1}{c}{ CPO } & Redução \\
\hline 7 & 1970 & 1980 & $40,6 \%$ \\
8 & 1,28 & 0,76 & $28,5 \%$ \\
9 & 1,96 & 1,40 & $27,0 \%$ \\
10 & 2,55 & 1,86 & $29,8 \%$ \\
11 & 3,55 & 2,49 & $27,9 \%$ \\
12 & 4,36 & 3,14 & $29,8 \%$ \\
13 & 5,72 & 4,01 & $27,4 \%$ \\
\hline
\end{tabular}

Fonte: MARTIN, B.V.M. (1982) 
MOSHA \& IANGEBAEK (1983) DUbIicaram um estudo sobre as condiçōes bucais de escolares na Tanzânia, cujas idades variaram de 5 a 19 anos. A prevalência de cárie en contrada foi muito baixa: 0,60 para o grupo etário de 5 a 9 anos e 0,82 para o grupo etário de 10 a 12 anos. A maio ria das lesöes de cárie estavam situadas nas superfícies oclusais e a quantidade de flūor existente na água de abas tecimento público (flūor natural) era tão alta que a maio ria das crianças apresentavam fluorose. A higiene da boca estava em péssimo nível: $75 \%$ dos indivíduos examinados apre sentavam cálculos e todos estavam com inflamação gengival.

CARR (1983) realizou uma avaliação da preva lência da cärie na Austrália durante 6 anos. 0 nümero de es colares examinados pode ser observado na Tabela 17 e os re sultados do primeino e ūltimo levantamento na Tabela 18.

TABELA 17 - NUMERO DE ESCOLARES EXAMINADOS, SEGUNDO A IDADE E A EPOCA DO LEVANTAMENTO, NA AUSTRALIA, $1977-$ -1982 .

\begin{tabular}{ccc}
\hline & & $\overline{\mathrm{CPO}}$ \\
\cline { 2 - 3 } Idades & 1977 & 1982 \\
\hline 7 & 35.808 & 107.575 \\
9 & 33.188 & 110.848 \\
10 & 30.113 & 114.745 \\
11 & 28.993 & 115.186 \\
12 & 28.721 & 110.882 \\
13 & 17.586 & 54.608 \\
Total & 3,822 & 10.144 \\
\hline Fonte: CARR, L.M. (1983) & 623.988 \\
\hline
\end{tabular}


TABELA 18 - CPO MEDIO DE ESCOLARES DE 7 A 13 ANOS, SEGUNDO A IDADE E A EPOCA DO LEVANTAMENTO, NA AUSTRA LIA, 1977 - 1982 .

$\overline{\mathrm{CPO}}$

Idades

1977

1982

0,47

0,92

1,34

1,82

2,35

3,01

3,85

Fonte: CARR, L.M. (1983)

Segundo o autor, diversos fatores contribui ram para a redução de cáries observadas nesse período, sen do o mais evidente o aumento da população abastecida com ägua fluoretada. Outro fator importante apontado pelo autor foi a utilização de dentifricios fluorados em larga escala em todo país, pois $95 \%$ dos dentifrícios comercializados con tinham flüor. A introdução de medidas educativas nos servi ços odontológicos escolares, no que tange a adoção e manu tenção de bons häbitos de higiene da boca, foi assinalada como fator importante para a melhoria da saúde bucal nas es. colas. 
JARVINEN (1983), na Finlândia, relatou dados de prevalência de cárie dental em escolares de 7 a 14 anos que podem ser observados na Tabela 19.

TABELA 19 - CPO MEDIO PARA ESCOLARES DE 7 A 14 ANOS, SEGUN DO A IDADE, NA FINLÂNDIA EM 1983.

\begin{tabular}{lcccccccc}
\hline Idades & 7 & 8 & 9 & 10 & 11 & 12 & 13 & 14 \\
\hline$\overline{\mathrm{CPO}}$ & 0,80 & 1,40 & 2,20 & 2,60 & 3,40 & 4,30 & 7,20 & 10,80
\end{tabular}

Fonte: JARVINEN, S. (1983)

BUTTNER \& KOHL (1983) examinaram setecentos e trinta e cinco escolares de 7 a 12 anos na Bélgica, anali sando o ataque de cárie na dentição permanente, com resultą dos que estão assinalados na Tabela 20 .

TABELA 20 - CPO MEDIO DE ESCOLARES DE 7 A 12 ANOS, SEGUNDO A IDADE, NA BELGICA, EM 1983.

\begin{tabular}{lcccccc}
\hline Idades & 7 & 8 & 9 & 10 & 11 & 12 \\
\hline$\overline{\mathrm{CPO}}$ & 0,70 & 1,40 & 2,00 & 2,50 & 3,00 & 3,90
\end{tabular}

Fonte: BUTTNER, M. \& KOHL, J. (1.983) 
BOHANNAN (1983), analisando os dados do levanta mento nacional de cárie dental nos Estados Unidos em 1979- 80, enfatizou a redução de cáries no país, assinalando o percentual de indivíduos livres de cáries que pode ser ob servado na Tabela 21.

TABELA $2 I$ - PERCENTUAL DE ESCOLARES LIVRES DE CARIES, SEGUN DO A IDADE, NOS ESTADOS UNIDOS, EM 1979 - 80.

Fonte: BOHANNAN, H.M. (1983)

ADENUBI (1984), avaliando a prevalência da cé rie em escolares com 8 anos de idade na Nigéria, encontrou um CPO mêdio muito baixo: 0,40, após examinar 860 indiví duos, constatando que $52 \%$ estavam livres de cáries. 
Iizado em escolares de Granada por GONZALEZ e colaboradores (1984) envolveu 781 indiyíduos com idades de 6 a 14 anos, sendo 516 meninas e 275 meninos, dos quais 347 moravam no meio urbano e 444 no meio rural. A prevalência de cárie en contrada foi maior no meio urbano: 5,84 do que 3,42 no meio rural. Os autores salientaram o fato de que os habitantes do meio urbano apresentavam nivel söcioeconônico melhor do que os moradores do meio rural, mas não relacionaram o fato com as concentrações de flúor natural na água de abasteci mento, embora tenham informado as concentrações: 0,2 ppm pa ra a população urbana e de 0,6 a 0,7 ppm para a população rural.

Uma relação entre o CPO aos 12 anos e o consu mo de açücar por dia foi apresentada por Pinto* conforme Ta Dela 22 .

* Dados fornecidos em palestra proferida pelo Cirurgião Dentista Sanitarista Vitor Gomes Pinto do IPEA, na Fa culdade de Saúde Pública - USP em 1986. 
TABELA 22 - CPO MEDIO AOS 12 ANOS DE IDADE E CONSUMO MEDIO DE AÇOCAR "PER CAPITA", SEGUNDO O PAIS, EM 13 PAISES.

\begin{tabular}{lcc}
\hline \multicolumn{1}{c}{ Pais } & $\overline{\mathrm{C}} \overline{\mathrm{PO}} \mathrm{I2}$ & Consumo açúcar/dia \\
\hline Polinésia Francesa & 10,70 & $160 \mathrm{~g}$ \\
Costa Rica & 8,30 & $161 \mathrm{~g}$ \\
Islandia & 7,70 & $139 \mathrm{~g}$ \\
Panamá & 7,60 & $112 \mathrm{~g}$ \\
Repüblica Dominicana & 7,60 & $111 \mathrm{~g}$ \\
Brasil & 7,30 & $125 \mathrm{~g}$ \\
Uruguai & 7,00 & $85 \mathrm{~g}$ \\
Barbados & 6,50 & $172 \mathrm{~g}$ \\
Bolivia & 1,70 & $76 \mathrm{~g}$ \\
China & 1,60 & $15 \mathrm{~g}$ \\
Uganda & 1,50 & $4 \mathrm{~g}$ \\
Bangladesh & 1,50 & $7 \mathrm{~g}$ \\
Etiópia & 0,70 & $14 \mathrm{~g}$ \\
\hline
\end{tabular}

Fonte: PINTO, V.G. - Comunicação Pessoal

WALDMAN (1984) relatou que inferindo os resul tados do levantamento nacional de cärie dental nos Estados Unidos realizado em 1979 - 80 para a população, 37\% dos 48 milhões de indivíduos do grupo etārio de 5 a 17 anos, esta vam livres de cáries. 
O "MORBIDITY AND MORTALITY WEEKLY REPORT" (1985) complementa a informação anterior salientando que $40 \%$ do mesmo grupo etārio apresentavan de 1 a 4 dentes ata cados pela cárie, o que significa uma prevalência baixa.

2.2 Quadro epidemiológico do grupo etário de 7 a 14 ANOS NO BRASIL.

No Brasil, somente no início da década de 50 é que surgiram levantamentos epidemiológicos da cárie den tal e o primeiro que temos notícia foi executado pelo SESP (Serviço Especial de Saúde Pública), óngão subordinado ao Ministério da Saúde. Foi o levantamento de linha de base executado em Baixo Guandu (ES), antes da fluoretação da ägua de abastecimento püblico, implantação pioneira no Bra sil em 1953. Na Tabela 23 podemos comparar os resultados do primeiro levantametno publicados por FREIRE (1957) e apös 14 anos de fluoretação em 1967.:

* Dados fornecidos pelo Prof. Alfredo Reis Viegas. 
TABELA 23 - CPO MEDIO DO GRUPO ETARIO DE 7 A 14 ANOS, SEGUNDO A IDADE E A EPOCA DO LEVANTAMENTO, EM BAIXO GUANDU, EM 1953-67.

Idades

$\overline{\mathrm{CPO}}$

$1953 \quad 1967$

\begin{tabular}{ccc}
7 & 3,17 & 0,80 \\
8 & 3,86 & 1,73 \\
9 & 4,55 & 1,69 \\
10 & 6,29 & 1,89 \\
11 & 6,71 & 2,29 \\
12 & 8,61 & 2,66 \\
13 & 9,41 & 3,68 \\
14 & 11,02 & 4,33 \\
\hline
\end{tabular}

Fonte: FREIRE, P.S. (1957)

VIEGAS, A.R. Comunicação pessoal

FRANKEL \& CHAVES (1955) publicaram um traba Tho cujo objetivo principal foi a divulgação do indice CPO no Brasil, tendo em vista que segundo esses autores "sem a adoção de normas uniformes de aferição não é possível compa rar entre si dados de diversas localidades, diversos esta dos, ou diferentes paises." Foi a primeira vez que observa mos a decomposição do componente dentes perdidos em: dentes extraídos e dentes com extração indicada, o que permite a estimativa das necessidades de tratamento considerando os componentes: dentes cariados e dentes com extração indica. 
da, ou ainda a estimativa dos trabalhos executados: dentes obturados e dentes extraidos. Os resultados são apresenta dos na Tabela 24. FREIRE (1968) publicou resultados encontrados em 14 estados brasileiros que podem ser observados na Tabe la 25 .

TABELA 24 - COMPOSICÃO PERCENTUAL DO INDICE EM 2.904 CRIAN ÇAS BRASILEIRAS DE 6 A 14 ANOS, SEGUNDO A IDADE, EM 1955 .

\begin{tabular}{|c|c|c|c|c|c|c|c|c|c|}
\hline \multirow{2}{*}{$\begin{array}{l}\text { Composição per } \\
\text { centual do in } \\
\text { dice CPO }\end{array}$} & \multicolumn{9}{|c|}{ Idades } \\
\hline & 6 & 7 & 8 & 9 & 10 & 11 & 12 & .13 & 14 \\
\hline Inaice CPO & 100 & 100 & 100 & 100 & 100 & 100 & 100 & 100 & 100 \\
\hline dentes cariados & 95,7 & 86,6 & 83,7 & 71,7 & 80,5 & 79,1 & 79,5 & 80,2 & 75,1 \\
\hline $\begin{array}{l}\text { dentes obtura } \\
\text { dos }\end{array}$ & 1,2 & 4,6 & 3,8 & 12,3 & 4,4 & 5,9 & 5,1 & 5,2 & 8,8 \\
\hline ext. indicada & 0,8 & 7,1 & 9,5 & 12,0 & 10,1 & 10,1 & 10,5 & 9,9 & 11,8 \\
\hline $\begin{array}{l}\text { dentes extraí } \\
\text { dos }\end{array}$ & 2,3 & 1,7 & 3,0 & 4,0 & 5,0 & 4,9 & 4,9 & 4,7 & 4,3 \\
\hline $\begin{array}{l}\text { dentes perdi } \\
\text { dos }\end{array}$ & 3,1 & 8,8 & 12,5 & 16,0 & 15,1 & 15,0 & 15,4 & 14,6 & $3.6,1$ \\
\hline
\end{tabular}

Fonte: FRANKEL, J.M. \& CHAVES, M.M. (1955)

CASTRO \& ALBUQUERQUE (1974) examinaram 688 es lares de 7 a 12 anos de idade em Natal (RN) verificando que se trata praticamente de uma população desassistida em rela ção ao tratamento odontológico. Os resultados estão apresen tados na Tabela 26 . 
TABELA 25 - MEDIA DE DENTES CARIADOS, PERDIDOS E OBTURADOS, EM 36.543 ESCOLARES PERTENCENIES AO GRUPO ETÁRIO DE 6 A 14 ANOS DE IDADE, EM COMUNIDADES BRASILEIRAS TRABALHADAS PELO MINISTERIO DA SAODE (FSESP).

\begin{tabular}{|c|c|c|c|c|c|c|c|c|c|c|c|c|c|c|c|}
\hline \multirow{2}{*}{ Idades } & \multicolumn{14}{|c|}{ ESTADOS } & \multirow[b]{2}{*}{$\begin{array}{l}\text { Media do } \\
\text { brasil }\end{array}$} \\
\hline & AiM & PA & $\therefore A_{1}$ & EI & $C E$ & $\mathrm{RN}$ & PB & $\mathrm{PE}$ & AL & SE & $\mathrm{BA}$ & ES & MG & SC & \\
\hline 6 & 1,62 & - & 2,78 & 2,32 & 1,91 & 2,20 & 1,66 & 2,19 & - & 1,65 & 2,46 & - & - & 1,80 & 2,09 \\
\hline 7 & 3,10 & 2,86 & 3,31 & 3,18 & 2,83 & 2,59 & 2,48 & 2,85 & 3,12 & 2,88 & 3,55 & 3,12 & 2,93 & 2,54 & 3,02 \\
\hline 8 & 3,58 & 3,94 & 3,67 & 3,54 & 3,26 & 3,35 & 3,17 & 3,37 & 3,42 & 3,50 & 4,06 & 3,74 & 3,58 & 3,84 & 3,59 \\
\hline 9 & 4,68 & 4,64 & 4,46 & 4,27 & 3,85 & 3,64 & 4,00 & 4,04 & 4,82 & 4,36 & 4,67 & 4,68 & 4,71 & 4,78 & 4,37 \\
\hline 10 & 5,83 & 6,06 & 5,53 & 5,47 & 5,17 & 4,80 & 4,98 & 4,82 & 5,65 & 4,99 & 5,70 & 5,99 & 6,14 & 4,64 & 5,54 \\
\hline 11 & 8,66 & 6,91 & 7.00 & 6,75 & 5,90 & 5,68 & 6,64 & 6,39 & 8,20 & 6,24 & 7,22 & 6,74 & 8,02 & 7,08 & 6,90 \\
\hline 12 & 10,30 & 9,35 & 8,50 & 7,72 & 7,55 & 6,59 & 7,36 & 7,40 & 9,95 & 7,32 & 9,42 & 8,66 & 9,16 & 10,16 & 8,31 \\
\hline 13 & 10,35 & 10,75 & 10,03 & 8,94 & 8,43 & 8,00 & 9,75 & 9,31 & - & 7,96 & 10,77 & 8,91 & 11,99 & 12,10 & 9,71 \\
\hline 14 & $12,9.9$ & 12,59 & 10,53 & 9,30 & 9,16 & 8,74 & 8,31 & 9,62 & - & 9,40 & 11,82 & 9,88 & 11,35 & 13,22 & 10,45 \\
\hline
\end{tabular}


TABELA 26 - CPO MEDIO E COMPONEIJES EM ESCOLARES DE 7 A 12 ANOS, SEGUNDO A IDADE, EM NATAL, 1972.

\begin{tabular}{ccccccc}
\hline Idades & $\bar{N} *$ & $\bar{C}$ & $\overline{0}$ & $\bar{E} * *$ & $\overline{E I * * *}$ & $\overline{C P O}$ \\
\hline 7 & 175 & 2,97 & 0,00 & 0,07 & 0,22 & 3,26 \\
9 & 103 & 2,59 & 0,01 & 0,30 & 0,46 & 3,36 \\
10 & 110 & 4,01 & 0,06 & 0,29 & 0,74 & 5,10 \\
11 & 106 & 4,96 & 0,01 & 0,48 & 1,08 & 6,53 \\
12 & 103 & 5,32 & 0,24 & 0,53 & 1,53 & 7,62 \\
\hline
\end{tabular}

Fonte: CASTRO, O.L. \& ALBUQUERQUE, A.J. (1974)

PINTO (1974) coordenou um levantamento epide miolögico na rede municipal de ensino de Porto Alegre, com - objetivo de avaliar a prevalência da cárie dental em den tes permanentes de escolares de 7 a 13 anos de idade. Os re sultados podem ser analisados na Tabela 27 .

\footnotetext{
$* \mathrm{~N}=$ número de escolares examinados

$* \because \overrightarrow{\mathrm{E}}=$ número médio de dentes extraídos

$* *: \overline{E I}=$ nümero médio de dentes com extração indicada.
} 
TABELA 27 - CPO MEDIO E COMPONENTES, DE ESCOLARES DE 7 A 13 ANOS, SEGUNDO A IDADE, EM PORTO ALEGRE, 1974.

\begin{tabular}{ccccccc}
\hline Idades & $N$ & $\bar{C}$ & $\overline{0}$ & $\overline{\mathrm{E}}$ & $\overline{\mathrm{EI}}$ & $\overline{\mathrm{C} P \bar{O}}$ \\
\hline 7 & 675 & 1,30 & 0,70 & 0,02 & 0,08 & 2,10 \\
8 & 775 & 1,33 & 1,77 & 0,09 & 0,13 & 2,72 \\
10 & 792 & 1,63 & 1,29 & 0,15 & 0,25 & 3,32 \\
11 & 665 & 1,90 & 1,55 & 0,21 & 0,31 & 3,97 \\
12 & 610 & 2,46 & 1,74 & 0,28 & 0,38 & 4,86 \\
13 & 482 & 3,10 & 1,75 & 0,36 & 0,51 & 5,72 \\
\hline
\end{tabular}

Fonte: PINTO, V.G. (1974)

A SECRETARIA DA SAUUDE DO ESPIRITO SANTO (1975), através da Diretoria de Odontologia Sanisäria, realizou em Vitória (ES) um levantamento epidemiológico de cárie dental, ocasião em que foram examinados 5.431 escolares de 6 a 14 anos, cujos resultados estão assinalados na Tabela 28 . 
TABELA 28 - CPO MEDIO DO GRUPO ETÁRIO DE 7 A 14 ANOS, SEGUNDO A IDADE, EM VTTORIA, 1975.

\begin{tabular}{ccc} 
Idades & $\mathrm{N}$ & $\overline{\mathrm{CPO}}$ \\
\hline 7 & 633 & 2,16 \\
8 & 656 & 2,62 \\
9 & 614 & 3,81 \\
10 & 582 & 4,39 \\
11 & 601 & 5,92 \\
12 & 617 & 7,46 \\
13 & 590 & 9,10 \\
14 & 587 & 10,51 \\
\hline
\end{tabular}

Fonte: SECRETARIA DA SAÚDE DO ESPIRITO SANTO (1975)

ROCHA (1976) examinou 1.600 escolares do gru po etärio de 7 a 14 anos em Manaus (AM) cujos resultados estão dispostos na Tabela 29. 
TABELA 29 - CPO MEDIO DE ESCOLARES DE 7 A 14 ANOS, SEGUNDO A IDADE, EM MANAUS, 1976.

\begin{tabular}{|c|c|c|}
\hline Tdades & $N^{\top}$ & $\bar{C} \overline{P O}$ \\
\hline 7 & 200 & 3,17 \\
\hline 8 & 200 & 3,92 \\
\hline 9 & 200 & 5,18 \\
\hline 10 & 200 & 7,56 \\
\hline 11 & 200 & 9,28 \\
\hline 12 & 200 & 13,51 \\
\hline 13 & 200 & 14,17 \\
\hline 14 & 200 & 16,06 \\
\hline
\end{tabular}

Fonte: ROCHA, J.M.S. (1976)

ATALLAH e colaboradores (1976) avaliaram a prevalência da cárie dental em 4.068 escolares do grupo etā rio 7 a 14 anos em Rondōnia, apresentando os resultados que estão inseridos na Tabela 30 . 
TABELA 30 - CPO MEDIO DE 4.068 ESCOLARES DO GRUPO ETARTO DE 7 A 14 ANOS, SEGUNDO A IDADE EM PORTO VELHO (RON DÔNIA), 1976.

\begin{tabular}{ccc} 
Idades & $N$ & $\overline{C P O}$ \\
\hline 7 & 552 & 3,16 \\
8 & 532 & 3,82 \\
9 & 699 & 5,07 \\
10 & 627 & 7,35 \\
11 & 522 & 10,14 \\
12 & 509 & 11,40 \\
13 & 388 & 12,99 \\
14 & 239 & 13,75 \\
\hline
\end{tabular}

Fonte: ATTALAH, A.S.M. (1976)

DINIZ \& CARDOSO (1977) apresentaram uma compa ração entre a prevalência de cärie em Petrolina (PE) e Jua zeiro (BA) com resultados que podem ser observados na Tabe Ia 31.

A cidade de Juazeiro tem fluoretação na ärua de abastecimento público desde 1970. No levantamento ini 
cial a média de necessidades de tratamento para o grupo etá rio de 6 a 14 anos foi 5,09. Em 1977 a média foi 2,50 signi ficando uma redução de $50,9 \%$.

TABELA 31 - CPO MEDIO DO GRUPO ETARRIO DE 7 A 14 ANOS, SEGUNDO A IDADE, EM PETROLINA E JUAZEIRO, 1977.

\begin{tabular}{|c|c|c|}
\hline \multirow{2}{*}{ Idades } & \multicolumn{2}{|c|}{$\overline{\mathrm{CPO}}$} \\
\hline & Petrolina & Juazeiro \\
\hline 7 & 2,24 & 1,51 \\
\hline 8 & 3,08 & 2,19 \\
\hline 9 & 3,34 & 2,69 \\
\hline 10 & 4,46 & 3,94 \\
\hline 11 & 5,54 & 4,59 \\
\hline 12 & 6,59 & 5,85 \\
\hline 13 & 7,31 & 6,19 \\
\hline 14 & 8,59 & 7,39 \\
\hline
\end{tabular}

Fonte: DINIZ, J. \& CARDOSO, J.S. (19.78)

A EUNDAÇÃO EDUCACIONAL DO DISTRITO FEDERAL (1979) efetuou um levantamento epidemiológico da cárie den 
tal em Brasilia e cidades satélites, ocasião em que foram examinados 5.862 escolares de 6 a 12 anos de idade que rece biam assistência odontológica através do PISE (Projeto Inte grado de Saúde Escolarl, cujos resultados podem ser analisa dos na Tabela 32.

TABELA 32 - PREVALENCIA DA CARIE DENTAL EM ESCOLARES DE 7 A 12 ANOS, SEGUNDO A IDADE, EM BRASILIA, 1979.

\begin{tabular}{ccc}
\hline Idades & $N$ & $\overline{\mathrm{CPO}}$ \\
\hline 7 & 476 & 2,31 \\
8 & 1.060 & 3,42 \\
9 & 963 & 4,01 \\
11 & 1.010 & 5,07 \\
12 & 929 & 6,47 \\
\hline
\end{tabular}

Fonte: FUNDAÇÃO EDUCACIONAL DO DISTRITO FEDERAL (1979)

A UNIVERSIDADE FEDERAL DA BAHIA (1979) reali zou um levantamento epidemiológico de cárie dental em Salva dor (BA). Os resultados podem ser analisados na Tabela 33 . 
TABELA 33 - CPO MEDIO DO GRUPO ETARIO DE 7 A 14 ANOS, SEGUNDO A IDADE, EM SALYADOR, 1979.

\begin{tabular}{lcccccccc}
\hline Idades & 7 & 8 & 9 & 10 & 11 & 12 & 13 & 14 \\
\hline$\overline{\mathrm{CPO}}$ & 2,30 & 2,90 & 3,00 & 4,80 & 5,00 & 6,90 & 10,30 & 12,00 \\
\hline
\end{tabular}

Fonte: UNIVERSIDADE FEDERAL DA BAHIA (1979)

A prevalência de cárie da cidade de João Pes soa (PB) para o grupo etário de 7 a 14 anos foi estimada pe la SECRETARIA DA SAŨDE DO PARAIBA (1979), através de exames em 793 escolares, incluídos no Programa de saúde oral dos escolares do Estado da Paraíba. Os resultados estão apresen tados na Tabela 34 .

TABELA 34 - CPO MEDIO PARA ESCOLARES DE 7 A 14 ANOS, SEGUN DO A IDADE EM JOÃO PESSOA, 1979.

\begin{tabular}{ccc}
\hline Idades & $N$ & $\overline{\mathrm{CPO}}$ \\
\hline 7 & 125 & 2,08 \\
8 & 116 & 4,09 \\
9 & 111 & 4,87 \\
10 & 107 & 7,05 \\
11 & 100 & 7,93 \\
12 & 91 & 8,45 \\
13 & 80 & 7,55 \\
14 & 53 & 10,80 \\
\hline
\end{tabular}


ROCHA (1980) realizou um inquérito epidemioló gico em escolares de 7 a 14 anos de idade em Boa Vista (Ter ritôrio Federal de Roraimal, examinando 480 escolares com re sultados apresentados na Tabela 35 .

TABELA 35 - CPO MEDIO DO GRUPO ETARIO DE 7 A 14 ANOS, SEGUNDO A IDADE, EM BOA VISTA, 1980.

\begin{tabular}{|c|c|c|}
\hline Idades & $\mathrm{N}$ & $\overline{\mathrm{CPO}}$ \\
\hline 7 & 60 & 2,66 \\
\hline 8 & 60 & 2,98 \\
\hline 9 & 60 & 3,98 \\
\hline 10 & 60 & 4,16 \\
\hline 11 & 60 & 5,41 \\
\hline 12 & 60 & 6,56 \\
\hline 13 & 60 & 9,45 \\
\hline 14 & 60 & 10,60 \\
\hline
\end{tabular}

Fonte: ROCHA, J.M.S. (1980)

Em Pernambucio, a SECRETARIA DA SAUDE (1980), a través da Coordenação de Assistência Odontolōgica, executou uma avaliação da prevalência da cárie dental, ocasião em que 
foram examinados 441 escolares de 6 a 14 anos, apresentando os resultados que estão na Tabela 36 .

TABELA 36 - CPO MEDIO DE ESCOLARES DO GRUPO ETARIO DE 7 A 14 ANOS, SEGUNDO A IDADE, EM TRIUNFO (PE), 1980.

\begin{tabular}{ccc} 
Idades & $N$ & $\overline{C P O}$ \\
\hline 7 & 54 & 3,61 \\
8 & 49 & 5,28 \\
9 & 46 & 6,41 \\
10 & 53 & 8,62 \\
11 & 51 & 10,90 \\
12 & 58 & 13,91 \\
13 & 51 & 15,01 \\
14 & 47 & 13,85 \\
\hline
\end{tabular}

Fonte: SECRETARIA DA SAUDE DE PERNAMBUCO (1980).

Estudantes de Odontologia da UNIVERSIDADE FEDE RAL DO PIAUI (1980) realizaram um levantamento epidemiológico de cárie dental, abrangendo 53 unidades escolares do pri 
meiro grau em Teresina (PI). A Tabela 37 contém os resulta dos desse levantamento.

TABELA 37 - CPO MEDIO DE ESCOLARES DE 7 A 14 ANOS, SEGUNDO A IDADE EM TERESINA, 1981.

\begin{tabular}{ccc} 
Idades & $\mathrm{N}$ & $\overline{\mathrm{CPO}}$ \\
\hline 7 & 1.501 & 2,60 \\
8 & 1.459 & 3,60 \\
10 & 1.338 & 4,80 \\
11 & 1.390 & 5,20 \\
12 & 1.379 & 6,50 \\
13 & 1.510 & 11,00 \\
14 & 1.195 & 10,30 \\
\hline
\end{tabular}

Fonte: UNIVERSIDADE FEDERAL DO PIAUI (1981).

SANTOS (1981) apresentou resultados de um le vantamento epidemiológico de cárie dental realizado em ube raba (MG), que podem ser analisados na Tabela 38 . 
TABELA 38 - NUMERO MËDIO DE DENTES ATACADOS PELA CARIE NAS IDADES DE 7 A 14 ANOS, SEGUNDO A IDADE EM UBERA BA, EM 1981 .

\begin{tabular}{lcccccccc}
\hline Idades & 7 & 8 & 9 & 10 & 11 & 12 & 13 & 14 \\
\hline$\overline{\mathrm{CPO}}$ & 4,43 & 3,52 & 4,42 & 5,34 & 7,71 & 9,05 & 8,52 & 10,08
\end{tabular}

Fontes: SANTOS, C.P. (1981).

REZENDE e colaboradores ( 1981 ) coordenaram um levantamento epidemiológico de cärie dental em Uberlândia (MG), quando foram examinados 5.120 escolares, obtendo re sultados que podem ser vistos na Tabela 39. 
TABELA 39 - CPO MEDIO E COMPONENTES, NUMERO DE ESCOLARES EXA MINADOS, NUMERO MEDIO DE DENTES IRROMPIDOS DO GRUPO EIÁRIO DE 7 A 12 ANOS, SEGUNDO O SEXO E A IDA DE, EM UBERLÂNDIA, $198 .$. .

\begin{tabular}{|c|c|c|c|c|c|c|c|c|}
\hline SEXO & Idades & $N$ & $\bar{C}$ & $\overline{0}$ & $\bar{E}$ & $\overline{E I}$ & $\overline{\mathrm{CPO}}$ & $\overline{\mathrm{TI}} *$ \\
\hline & 7 & 376 & 1,73 & 0,29 & 0,02 & 0,11 & 2,15 & 8,60 \\
\hline M & 8 & 484 & 2,28 & 0,37 & 0,04 & 0,24 & 2,93 & 11,44 \\
\hline A & 9 & 518 & 2,78 & 0,69 & 0,09 & 0,37 & 3,94 & 14,29 \\
\hline$S$ & 10 & 439 & 3,82 & 0,77 & 0,14 & 0,50 & 5,22 & 18,10 \\
\hline C & 11 & 420 & 4,80 & 0,82 & 0,26 & 0,67 & 6,55 & 21,57 \\
\hline . & 12 & 274 & 6,17 & 0,90 & 0,26 & 0,82 & 8,15 & 23,96 \\
\hline F & 7 & 403 & 2,10 & 0,22 & 0,01 & 0,11 & 2,45 & 9,54 \\
\hline$E$ & 8 & 481 & 2,72 & 0,46 & 0,04 & 0,30 & 3,51 & 12,45 \\
\hline$M$ & 9 & 496 & 2,99 & 0,73 & 0,07 & 0,41 & 4,14 & 15,24 \\
\hline I & 10 & 512 & 3,92 & 0,72 & 0,09 & 0,59 & 5,32 & 19,36 \\
\hline $\mathrm{N}$ & 11 & 432 & 5,09 & 0,86 & 0,26 & 0,72 & 6,93 & 22,73 \\
\hline . & 12 & 283 & 6,47 & $.1,08$ & 0,29 & 0,84 & 8,68 & 25,04 \\
\hline $\mathrm{T}$ & 7 & 779 & 1,92 & 0,25 & 0,01 & 0,11 & 2,30 & 9,09 \\
\hline 0 & 8 & 965 & 2,50 & 0,41 & 0,04 & 0,27 & 3,22 & 11,95 \\
\hline $\mathrm{T}$ & 9 & 1.014 & 2,88 & 0,71 & 0,08 & 0,39 & 4,04 & 14,76 \\
\hline A & 10 & 951 & 3,87 & 0,74 & 0,11 & 0,55 & 5,27 & 18,78 \\
\hline \multirow[t]{2}{*}{$\mathrm{L}$} & 11 & 852 & 4,95 & 0,84 & 0,26 & 0,70 & 6,75 & 22,16 \\
\hline & 12 & 557 & 6,32 & 0,99 & 0,27 & 0,83 & 8,42 & $24,5 I$ \\
\hline
\end{tabular}

Fonte: REZENDE, A.B. et a1 (1981)

$* \overline{\mathrm{TI}}=$ nümero mëdio de dentes irrompidos 
A PREFEITURA MUNICIPAL DE PORTO ALEGRE (1982), como faz rotineiramente, realizou um levantamento epidemioló gico da cárie dental para avaliar os efeitos do programa de assistência odontológica e estimativa das necessidades de tratamento, com resultados que são apresentados na Tabela 40 .

TABELA 40 - CPO MEDIO E COMPONENTES DO GRUPO ETARIO DE 7 A 13 ANOS, SEGUNDO A IDADE, EM PORTO ALEGRE, 1982.

\begin{tabular}{cccccc}
\hline Idades & $\bar{C}$ & $\overline{0}$ & $\overline{\mathrm{E}}$ & $\overline{\bar{E}}$ & $\overline{\mathrm{CPO}}$ \\
\hline 7 & 1,23 & 0,38 & 0,03 & 0,12 & 1,73 \\
8 & 1,16 & 0,96 & 0,02 & 0,20 & 2,34 \\
10 & 1,42 & 1,41 & 0,07 & 0,25 & 3,15 \\
11 & 1,49 & 1,90 & 0,13 & 0,39 & 3,91 \\
12 & 1,60 & 2,44 & 0,23 & 0,40 & 4,67 \\
13 & 2,39 & 3,10 & 0,38 & 0,49 & 6,36 \\
\hline
\end{tabular}

Fonte: PREFEITURA MUNICIPAL DE PORTO ALEGRE (1982).

PINTO, (1983) publicou um trabalho sobre saūde bucal no Brasil incluindo dados epidemiológicos de cárie den 
tal, tendo como fontes principalmente dados de São Paulo, Bahia, Espirito Santo, Minas Gerais, Paraiba, Pernambu co, Rio Grande do Norte, Rio Grande do Sul e Distrito Fede ral. o nümero médio de dentes atacados pela cárie em sua es timativa para o Brasil pode ser analisado na Tabela 41.

TABEIA 41 - CPO MEDIO E COMPONENTES E NUMERO DE ESCOLARES EXAMINADOS, DO GRUPO ETARIO DE 7 A 14 ANOS, SEGUNN DO A IDADE NO BRASIL, EM 1983.

\begin{tabular}{ccccccc}
\hline Idades & $N$ & $\bar{C}$ & $\overline{0}$ & $\overline{\mathrm{E}}$ & $\overline{\mathrm{EI}}$ & $\overline{\mathrm{CPO}}$ \\
\hline 7 & 40.667 & 2,23 & 0,18 & 0,07 & 0,08 & 2,56 \\
8 & 37.852 & 2,29 & 0,85 & 0,09 & 0,16 & 3,39 \\
10 & 35.840 & 2,74 & 1,01 & 0,05 & 0,18 & 3,89 \\
11 & 35.091 & 2,86 & 1,16 & 0,34 & 0,38 & 4,74 \\
12 & 32.280 & 3,37 & 1,40 & 0,63 & 0,52 & 5,92 \\
13 & 28.923 & 4,22 & 1,78 & 0,78 & 0,47 & 7,25 \\
14 & 24.972 & 4,90 & 2,70 & 0,75 & 0,81 & 9,16 \\
\hline
\end{tabular}

Fonte: PINTO, V.G. (1983) 
2.3 Quadro Epidemiolögico do Grupo Etärio de 7 a 14 anos, no Estado de São Paulo.

Por ocasião da implantação do flúor na àgua de abastecimento da cidade de Campinas (SP), VIEGAS \& VIE GAS (1974), coordenaram o levantamento de Iinha de base do CPO em 1961 e também um novo levantamento do ataque de cá rie após dez anos de fluoretação em 1971.

Após 14 anos de fluoretação VIEGAS \& VIEGAS (1985) coordenaram uma nova avaliação da prevalência de cấ rie. Os resultados podem ser observados nas Tabelas 42,43 e 44 .

TABELA 42 - INDICE CPO E COMPONENTES, NUMERO MEDIO DE DEN TES IRROMPIDOS E NUMERO DE ESCOLARES DE 7 A 14 ANOS EXAMINADOS, SEGUNDO A IDADE, EM CAMPINAS, 1961.

\begin{tabular}{cccccccc}
\hline Idades & $\mathrm{N}$ & $\overline{\mathrm{C}}$ & $\overline{\mathrm{O}}$ & $\overline{\mathrm{E}}$ & $\overline{\mathrm{EI}}$ & $\overline{\mathrm{CPO}}$ & $\overline{\mathrm{TI}}$ \\
\hline 7 & 1.974 & 2,16 & 0,45 & 0,04 & 0,12 & 2,77 & 8,37 \\
8 & 2.032 & 1,90 & 0,98 & 0,12 & 0,17 & 3,17 & 11,47 \\
9 & 2.153 & 2,12 & 1,18 & 0,22 & 0,27 & 3,79 & 14,95 \\
10 & 1.921 & 3,00 & 1,41 & 0,33 & 0,35 & 5,09 & 18,73 \\
11 & 1.447 & 3,66 & 1,67 & 0,48 & 0,45 & 6,26 & 22,08 \\
12 & 1.121 & 3,71 & 2,70 & 0,55 & 0,40 & 7,36 & 24,87 \\
13 & 732 & 4,01 & 4,14 & 0,54 & 0,47 & 9,16 & 26,37 \\
14 & 451 & 3,42 & 6,19 & 0,60 & 0,27 & 10,48 & 26,86 \\
\hline
\end{tabular}


Após 10 anos de fluoretação ocorreram reduções de cärie dental que variaram de 70,76\% aos 7 anos e 48,37\% aos 14 anos de idade.

TABELA 43 - CPO MEDIO E COMPONENTES, NÜMERO MEDIO DE DENTES IRROMPIDOS E NUMERO DE ESCOLARES DE 7 A 14 ANOS EXAMINADOS, SEGUNDO A IDADE, EM CAMPINAS, 1972.

\begin{tabular}{cccccccc}
\hline Idades & $N$ & $\overline{\mathrm{C}}$ & $\overline{0}$ & $\overline{\mathrm{E}}$ & $\overline{\mathrm{EI}}$ & $\overline{\mathrm{CPO}}$ & $\overline{\mathrm{TI}}$ \\
\hline 7 & 1.346 & 0,35 & 0,44 & 0,01 & 0,01 & 0,81 & 9,02 \\
8 & 1.501 & 0,40 & 0,97 & 0,01 & 0,02 & 1,40 & 11,73 \\
9 & 1.599 & 0,47 & 1,31 & 0,04 & 0,04 & 1,86 & 14,15 \\
10 & 1.718 & 0,49 & 1,69 & 0,04 & 0,06 & 2,28 & 18,10 \\
11 & 1.090 & 0,51 & 2,18 & 0,07 & 0,07 & 2,83 & 22,52 \\
12 & 810 & 0,59 & 2,79 & 0,13 & 0,12 & 3,63 & 24,99 \\
13 & 524 & 0,71 & 3,20 & 0,21 & 0,12 & 4,24 & 25,53 \\
14 & 254 & 0,54 & 4,55 & 0,22 & 0,10 & 5,41 & 27,30 \\
\hline
\end{tabular}

Fonte: VIEGAS \& VIEGAS (1974) 
TABELA 44 - CPO MEDIO E COMPONENTES, NUMERO DE ESCOLARES DE 7 A 14 ANOS EXAMINADOS, SEGUNDO A IDADE, EM CAM PINAS, 1976 .

\begin{tabular}{ccccccc}
\hline Idades & $N$ & $\overline{\mathrm{C}}$ & $\overline{\mathrm{O}}$ & $\overline{\mathrm{E}}$ & $\overline{\mathrm{EI}}$ & $\overline{\mathrm{CPO}}$ \\
\hline 7 & 399 & 0,36 & 0,52 & 0,05 & 0,01 & 0,94 \\
8 & 610 & 0,46 & 0,89 & 0,02 & 0,04 & 1,41 \\
10 & 675 & 0,49 & 1,33 & 0,04 & 0,05 & 1,91 \\
11 & 570 & 0,56 & 1,72 & 0,02 & 0,04 & 2,34 \\
12 & 452 & 0,72 & 2,38 & 0,12 & 0,08 & 3,30 \\
13 & 415 & 0,89 & 2,89 & 0,13 & 0,12 & 4,01 \\
14 & 258 & 0,60 & 3,56 & 0,12 & 0,04 & 4,32 \\
\hline
\end{tabular}

Fonte: VIEGAS \& VIEGAS (1985)

EM Guaira (SP) CAMPANELLA \& CICIARELLI (1975), examinaram 1.710 escolares de 6 a 14 anos de idade com 0 objetivo de conhecer a prevalência de cárie no município, cu jo poder politico decidira implantar a fluoretação da água de abastecimento püblico. Os exames foram realizados nas es colas püblicas e os resultados podem ser analisados na Tabe la 45 . 
TABELA 45 - CPO MEDIO E COMPONENTES, NOMERO DE ESCOLARES DE $7 \AA 14$ ANOS EXAMINADOS E NUMERO MEDIO DE DENTES IRROMPIDOS, SEGUNDO A IDADE, EM GUAIRA, 1975.

\begin{tabular}{cccccccc}
\hline Idades & $N$ & $\bar{C}$ & $\overline{0}$ & $\overline{\mathrm{E}}$ & $\overline{\mathrm{EI}}$ & $\overline{\mathrm{CPO}}$ & $\overline{\mathrm{TI}}$ \\
\hline 7 & 201 & 2,03 & 0,20 & 0,03 & 0,08 & 2,34 & 9,65 \\
8 & 181 & 2,37 & 0,35 & 0,03 & 0,21 & 2,96 & 12,37 \\
9 & 202 & 2,55 & 0,66 & 0,07 & 0,24 & 3,52 & 15,27 \\
10 & 238 & 2,88 & 1,44 & 0,16 & 0,40 & 4,88 & 19,58 \\
11 & 160 & 4,24 & $=1,02$ & 0,27 & 0,44 & 5,97 & 22,72 \\
12 & 202 & 4,47 & 2,05 & 0,51 & 0,47 & 7,50 & 25,50 \\
13 & 185 & 5,14 & 2,77 & 0,49 & 0,49 & 8,89 & 26,84 \\
14 & 190 & 4,54 & 5,01 & 0,86 & 0,45 & 10,86 & 27,56 \\
\hline
\end{tabular}

Fonte: CAMPANELLA \& CICIARELLI (1975)

ALCAIDE \& VERONEZI (1977) ao analisarem a ocorrência de fluorose dental na cidade de Icém (SP), veri ficaram que a cidade era abastecida por dois poços artezia nos e ambos apresentavam alto teor de flūor natural: 4,0 ppm e 2,6 ppm. O CPO mëdio do grupo etário de 7 a 14 anos encontrado foi 2,60, exatamente a metade do CPO médio des se mesmo grupo etärio para o Brasil: 5,20, segundo estimativas feitas por PINTO (1983). 
miológico de cárie dental promovido pela PREFEITURA MUNICI PAL DE SANTA FE DQ SUL (1978), com o objetivo de obter da dos preliminares à fluoretação da água de abastecimento pū blico. Os resultados podem ser observados na Tabela 46.

TABELA 46 - CPO MEDIO DO GRUPO ETARIO DE 7 A 14 ANOS, SEGUNDO A IDADE, EM SANTA FE DO SUL (SP), em 1978.

\begin{tabular}{lcccccccc}
\hline Idades & 7 & 8 & 9 & 10 & 11 & 12 & 13 & 14 \\
\hline$\overline{\mathrm{CPO}}$ & 2,03 & 2,84 & 3,45 & 4,56 & 5,67 & 7,44 & 8,65 & 9,31 \\
\hline
\end{tabular}

Fonte: PREFEITURA MUNICIPAL DE SANTA FÉ DO SUL (1978)

FAGGIONI \& MARTINS (1978), analisando os re sultados de 5 anos de fluoretação da água de abastecimento pübIico de Garça (SP), observaram que no levantamento ini cial, apenas 4,6\% dos escolares de 7 a 12 anos estavam 1 i vres de cāries, enquanto após 5 anos de aplicação do método esse percentual aumentou para $26 \%$ Os autores utilizaram 0 Indice simplificado de Viegas para estimar o CPO médio e os resultados podem ser vistos na Tabela 47 . 
TABELA 47 - CPO MEDIO DOS ESCOLARES DE 7 A 12 ANOS, SEGUNDO A IDADE E A EPOCA DO LEVANTAMENTO, EM GARCG, $1973-78$.

\begin{tabular}{ccc}
\hline Idades & $\overline{\mathrm{CPO}}_{73}$ & $\overline{\mathrm{CPO}}_{78}$ \\
\hline 7 & 3,09 & 1,26 \\
8 & 3,69 & 1,95 \\
10 & 4,24 & 2,65 \\
11 & 6,48 & 4,30 \\
12 & 8,43 & 5,28 \\
\hline
\end{tabular}

Fonte: FAGGIONI \& MARTINS (1978)

Em 1979, apōs a criação da Divisão Odontológi ca no quadro da secretaria da saúde, a PREFEITURA MUNICIPAL DE SÃO JOSE DOS CAMPOS (1984) realizou um levantamento epi demiológico de cārie dental nas escolas municipais, cujos resultados podem ser vistos na Tabela 48 . 
TABELA 48 - CPO MEDIO E COMPONENTES, NUMERO MEDIO DE DENTES IRROMPIDOS, DO GRUPO ETARIO DE 7 A 14 ANOS, SEGUN DO A IDADE, EM SÃO JOSE DOS CAMPOS (SP), EM 1979 .

\begin{tabular}{ccccccc}
\hline Idades & $\bar{C}$ & $\overline{0}$ & $\bar{E}$ & $\overline{E I}$ & $\overline{C P O}$ & $\overline{T I}$ \\
\hline 7 & 1,71 & 0,21 & 0,07 & 0,07 & 2,06 & 9,29 \\
8 & 2,10 & 0,62 & 0,10 & 0,27 & 2,94 & 11,69 \\
10 & 2,47 & 0,74 & 0,25 & 0,40 & 3,86 & 16,92 \\
11 & 3,11 & 1,17 & 0,48 & 0,44 & 5,20 & 19,23 \\
12 & 3,41 & 1,63 & 0,58 & 0,48 & 6,10 & 22,80 \\
13 & 4,66 & 2,00 & 0,89 & 0,50 & 8,05 & 25,62 \\
14 & 5,59 & 2,49 & 1,03 & 0,79 & 9,00 & 27,24 \\
\hline & 4,88 & 3,84 & 1,45 & 0,70 & 10,88 & 27,70 \\
\hline
\end{tabular}

Fonte: PREFEITURA MUNICIPAL DE SÃO JOSE DOS CAMPOS (1984)

Foi estabelecido de inicio que seria aplicado - Sistema Incremental com o atendimento curativo priorizan do as menores idades e paralelamente foi implantado um pro grama preventivo com bochechos fluorados semanalmente (Na F $0,2 \%)$. Entretanto ocorreram mudanças na direção da Divisão de Odontologia e em 1983 e 84 uma parte dos recursos huma nos foi deslocada para o atendimento a adultos nas unidades 
bâsicas de saúde, em detrimento de assistência odontológica aos escolares. Após 4 anos e meio do início das atividades da Divisão de Odontologia foi realizado novo levantamento cujos resultados podem ser analisados na Tabela 49.

TABELA 49 - CPO MEDIO E COMPONENTES, NUMERO MEDIO DE DENTES IRROMPIDOS, DO GRUPO ETARRIO DE 7 A 14 ANOS, EM SÃO JOSE DOS CAMPOS (SP), em 1984.

\begin{tabular}{ccccccc}
\hline Idades & $\overline{\mathrm{C}}$ & $\overline{\mathrm{O}}$ & $\overline{\mathrm{E}}$ & $\overline{\mathrm{ET}}$ & $\overline{\mathrm{CPO}}$ & $\overline{\mathrm{TI}}$ \\
\hline 7 & 1,47 & 0,36 & 0,01 & 0,04 & 1,88 & 9,16 \\
8 & 1,32 & 1,23 & 0,04 & 0,05 & 2,64 & 11,85 \\
10 & 1,34 & 1,85 & 0,08 & 0,07 & 3,34 & 15,18 \\
11 & 1,40 & 2,71 & 0,17 & 0,12 & 4,40 & 19,41 \\
12 & 2,05 & 3,35 & 0,28 & 0,16 & 5,84 & 23,15 \\
13 & 2,70 & 4,28 & 0,44 & 0,11 & 7,53 & 25,51 \\
14 & 3,24 & 5,48 & 0,75 & 0,13 & 9,60 & 27,03 \\
1 & 4,30 & 6,47 & 0,95 & 0,30 & 12,02 & 27,61 \\
\hline
\end{tabular}

Fonte: PREFEITURA MUNICIPAL DE SÃO JOSE DOS CAMPOS (1984) 
3. MATERIAL E METODOS

\subsection{Amostra}

Nos levantamentos realizados em 1980 e 1982 , todos Cirurgiões Dentistas com atividades clínicas nas esco las estaduais do Estado de São Paulo, receberam instruções para examinarem 30 escolares de cada idade, do grupo etário de 7 a 14 anos, sendo 15 do sexo masculino e 15 do sexo femi nino. A amostra deveria ser obtida aleatoriamente, apenas com a preocupação de distribuir os indivíduos a serem exami nados no(s) período(s) de trabalho do Cirurgião Dentista. Deste modo um Cirurgião Dentista que trabalhasse 8 horas por dia em uma escola com três períodos de atividades, deveria distribuir sua amostra nos três períodos. Como não existem Cirurgiões Dentistas no Estado de São Paulo alocados em esco las rurais, o presente estudo refere-se a população urbana.

Nos dois levantamentos os exames foram executa dos no início do ano letivo, como rotina do planejamento a nivel de operações. Os procedimentos foram os mesmos nos dois levantamentos, entretanto em face do corte de verbas destinadas ao processamento eletrônico dos dados onorrido em 82, a DENPAO reduziu o nümero de registros enviados à PRODESP (Processamento de Dados de Estado de São Paulo), re sultando numa amostra menor do que em 1980. 
o critério para a redução dos registros foi a eliminação pon sorteio de um grande nümero de escolas situa das nos grandes municípios, porque mesmo assim o tamanho da amostra dos grandes municípios ainda seria significativo (mais de duzentos escolares por idade).

\subsection{Registro dos dados}

Os dados foram registrados em fichas padroni zadas, segundo o Manual de Normas e Instruçöes da DENPAO, Modelo 1 (Anexo 1), publicado pela SECRETARIA DA EDUCAÇÃo DO ESTADO DE SÃO PAULO (I980).

No cabeçalho da ficha Modelo 1 estão os dados de identificação da unidade escolar, municipio onde está lo calizada, idade e sexo dos escolares examinados além da identificação do(s) examinador(es) e a data da realização dos exames. No corpo da ficha são registrados em código pa dronizado a situação de cada dente em relação ao ataque de cárie, na horizontal para cada indivíduo seguindo-se a tota lização do CPO e componentes.

\section{Código}

C - dente cariado

o - dente obturado

$E$ - dente extraido

$E I$ - dente com extração indicada

$\mathrm{H}$ ou $\mathrm{N}$ - dente normal ou higido 


\section{A - dente ausente}

\subsection{Indice}

Foi utilizado o indice CPO proposto por KLEIN \& PALMER (1937), com a finalidade de se obter médias do ata que de cárie para as diferentes idades e sexo, cujo valor permite ter-se uma noção adequada do comportamento do indi ce, em relação aos dentes permanentes ou seja: cariados, perdidos e obturados, considerando-se os perdidos como ex traídos e extração indicada.

Face a impraticabilidade de calibrar mais de I.200 examinadores, as instruções e critérios clínicos para os exames foram fornecidos por escrito, assim como as re gras especiais para o preenchimento das fichas.

\section{Critërios}

- Espaço vazio

Registnar o espaço vazio como dente ausen te (A), quando a ausência é devida a:

a) dente permanente não inrompido

b) dente permanente impactado ou ausente congenitamente

c) dente permanente extraído por outros mo tivos que não a cárie dentária. 
- Dente cariado

Registrar o dente permanente com o código C quando existirem as seguintes evidências de cârie:

a) quando existir uma cavidade definida com descoloração ou opacidade ao longo das margens e nas quais o explorador possa ser inserido

b) nas cicatrículas e fissuras quando a ex tremidade do explonador prender e uma das condições abaixo for preenchida:

- presença evidente de tecido amolecido na base da cicatrícula ou fissura

- opaeidade ao longo das margens ou man cha indicando a presença de cárie sub jacente

c) em casos de superficies proximais, quan do o explorador ao se deslocar em movi mento na direção cérvico-oclusal pene trar e prender.

- Dente obturado

Registrar o dente permanente como obturado com o código 0 , quando houver restauração com material permanente, sem levar em conta - tipo de material restaurador. Se um dente estiver cariado e obturado ao mesmo tempo deve ser registrado como cariado. 
- Dente extraido

Registrar o dente Dermanente como extraído com o código E, quando a extração foi devida à cārie dentária.

- Dente permanente com extração indicada Registrar o cödigo EI sempre que houver evi dência que a câmara pulpar foi atingida.

- Dente permanente hígido ou normal

Registrar com os cöaigos $H$ ou $N$ quando não apresentar cārie ou restauração. Os dentes permanentes que se apresentarem restaurados por motivos que não a cárie dentária, como por exemplo por indicação protética ou fratu ras, serão considerados hígidos.

\section{Regras especiais}

- um dente é considerado irrompido quando hou ver qualquer porção de sua superfície expoṣ ta na cavidade bucal e puder ser tocada com a ponta do explorador

- um dente é considerado presente mesmo que apresente a coroa totalmente destruida, res tando apenas as raizes

- dentes supranumerários não são classificados

- na düvida entre cariado e hígido, classifi 
car como hígido

- na dúvida entre cariado e extração indica da, classificar como cariado

- na dúvida entre 19 ou 29 pré molar, classi ficar como 1! pré molar

- em caso de dúvida quanto aos motivos da ex tração perguntar ao paciente

3.4 Material

Os exames foram realizados nos consultórios odontológicos instalados nas escolas, sob luz natural ou artificial, utilizando-se espelhos bucais planos e explora dor comum, tipo no 5 da SS White.

\subsection{Processamento dos dados}

O processamento dos dados foi feito nos com putadores da PRODESP corn o objetivo de obter informações so bre os dentes permanentes explicitadas nos itens $3.5 .1,3$. 5.2 e 3.5 .3 .

3.5.I Prevalência da cārie dental no grupo etário 7 a 14 anos, segundo a idade e o sexo:

3.5.1.1 nümero médio de dentes irrompidos 3.5.1.2 número médio de dentes hígidos 
3.5.1.3 número médio de dentes cariados

3.5.1.4 nümero mëdio de dentes obturados

3,5,1,5 número médio de dentes extraidos

3.5.1.6 nümero médio de dentes com extração indicada

3.5.1.7 nümero médio das necessidades de trạ tamento $(C+E I)$

3:5.1.8 CPO médio ou seja: número médio de dentes atacados pela cárie

3.5.1.9 desvio padrão

3.5.1.10. média ponderada do grupo etärio 7 a 14 anos

3.5.2 Prevalência de cárie nos dentes anteriores, segundo a idade e o sexo

3.5.2.1 nümero médio de dentes irrompidos

3.5.2.2 número médio de dentes hígidos

3.5.2.3 nümero médio de dentes cariados

3.5.2.4 número médio de dentes obturados

3.5.2.5 nümero médio de dentes extraídos

3.5.2.6 número médio de dentes com extração indicada

3.5.2.7 número médio das necessidades de tra tamento $(C+E I)$ 
3.5.3 Prevalência de cárie nos dentes posteriores Foram processados os mesmos dados referentes aos dentes anteriores: dentes irrompidos, hi gidos, CPO e componentes e necessidades de tratamento, tratando-se sempre de médias em relação à idade e sexo.

3.5.4 Prevalência de cárie no quadrante superior direito

3.5.5 Prevalência de cárie no quadrante superior esquerdo

3.5.6 Prevalência de cárie no quadrante inferior direito

3.5.7 Prevalência de cárie no quadrante inferior esquerdo

3.5.8 Prevalência de cárie no lado direito

3.5.9 Prevalēncia de cärie no lado esquerdo

3.5.10 Prevalência de cärie na arcada superior

3.5.11 Prevalência de cárie na arcada inferior. 
Do sub İtem 3.5 .4 ao sub ítem 3,5,11 foram pro cessadas as mëdias referentes aos dentes irrompidos, hígi dos, cariados, obturados, extraídos, extração indicada e CPO, segundo a idade e o sexo.

3.5.12 Prevalência de cárie nos primeiros molares per manentes

Neste sub Item foram processadas apenas as mê dias referentes ao CPO e componentes, segundo a idade e o sexo.

Todos os dados foram consolidados a nível de Município, Delegacia de Ensino, Divisão Regional de Ensino, Interior, Região Metropolitana de São Paulo e Total do Estạ do. 
4, RESULTADOS E DISCUSSÃO

- levantamento de cárie realizado no Estado de São Paulo em 1980, envolveu 325 municípios $(56,8 \%)$ do to tal. Foram examinados 270.736 escolares de ambos os sexos com 7 a 14 anos de idade. Em 1982 o total de alunos examina dos foi de 144.480, distribuídos em 389 municípios ( $68 \%$ do total). A distribuição dos escolares examinados segundo a idade, sexo e época do levantamento pode ser observada na Tabela 50 .

TABELA 50 - NUMERO DE ESCOLARES EXAMINADOS, DO GRUPO ETARIO 7 A 14 ANOS, SEGUNDO A IDADE, SEXO E EPOCA DO LEVANTAMENTO, NO ESTADO DE SÃO PAULO, 1980-82.

\begin{tabular}{|c|c|c|c|c|c|c|}
\hline \multirow{2}{*}{ Idades } & \multicolumn{3}{|c|}{1980} & \multicolumn{3}{|c|}{1982} \\
\hline & Masc. & Fem. & Total & Masc. & Fem. & Total \\
\hline 7 & 18.071 & 17.947 & 36.018 & 9.887 & 9.849 & 19.736 \\
\hline 8 & 18.288 & 18.272 & 36.560 & 9.912 & 9.933 & 19.845 \\
\hline 9 & 18.549 & 18.347 & 36.896 & 9.891 & 9.931 & 19.822 \\
\hline 10 & 18.542 & 18.489 & 37.031 & 9.892 & 9.862 & 19.754 \\
\hline 11 & 17.875 & 17.843 & 35.718 & 9.677 & 9.552 & 19.229 \\
\hline 12 & 17.142 & 16.543 & 33.685 & 9.116 & 8.850 & 17.966 \\
\hline 13 & 15.525 & 14.975 & 30.500 & 8.028 & 7.544 & 15.572 \\
\hline 14 & 12.338 & 11.990 & 24.328 & 6.407 & 6.149 & 12.556 \\
\hline
\end{tabular}


Em 1.980, do total de escolares examinados, 68.781 residiam em 15 municípios da Região Metropolitana de São Paulo cuja participação em 1982 subiu para 44.900 esco lares distribuidos em 30 municipios.

Em relação ao Interior, no primeiro levanta mento foram examinados 201.955 escolares distribuidos em 310 municípios $(74,6 \%$ do total de escolares examinados). Em 1982 foram examinados 99.580 escolares que residiam em 359 municípios do Interior, significando 68,9\% do total de esco lares examinados. Podemos verificar ainda na Tabela 50 o ba Ianceamento da amostra em relação do sexo. Em 1980 o sexo masculino representou $51,36 \%$ da amostra e 51,39\% em 1982. A representação do sexo feminino foi $49,64 \%$ em 1980 e 49,61\% em 1982 .

Os resultados em relação ao ataque de cárie nos dois levantamentos pode ser observado nas Tabelas 51 e 52 . 
TABELA 51 - CPO MEDIO DE ESCOLARES DE 7 A 14 ANOS, SEGUNDO A IDADE E O SEXO, NO ESTADO DE SÃO PAULO EM 1980.

\begin{tabular}{cccc}
\hline & & $\overline{\mathrm{C}} \overline{\mathrm{PO}}$ \\
\cline { 2 - 4 } Idades & Masculino & Feminino & Masc. + Fem. \\
\hline 7 & 2,23 & 2,41 & 2,31 \\
8 & 3.07 & 3,25 & 3,16 \\
9 & 3,72 & 3,97 & 3,86 \\
10 & 4,54 & 5,02 & 4,78 \\
11 & 5,74 & 6,29 & 6,01 \\
12 & 6,90 & 7,58 & 7,24 \\
13 & 8,24 & 8,85 & 8,54 \\
14 & 9,44 & 10,02 & 9,72 \\
\hline
\end{tabular}

TABELA 52 - CPO MEDIO DE ESCOLARES DE 7 A 14 ANOS, SEGUNDO A IDADE E O SEXO, NO ESTADO DE SÃO PAULO EM 1982.

\begin{tabular}{cccc}
\hline & & \multicolumn{3}{c}{$\overline{\mathrm{PO}}$} \\
\cline { 2 - 4 } Idades & Masculino & Feminino & Masc. + Fem. \\
\hline 7 & 2,32 & 2,51 & 2,41 \\
8 & 3,13 & 3,26 & 3,19 \\
9 & 3,85 & 4,05 & 3,95 \\
10 & 4,66 & 5,00 & 4,83 \\
11 & 5,72 & 6,24 & 5,98 \\
12 & 6,85 & 7,42 & 7,13 \\
13 & 7,98 & 8,67 & 8,31 \\
14 & 9,29 & 9,73 & 9,51 \\
\hline
\end{tabular}


Analisando as Tabelas 51 e 52, podemos obser var que o sexo feminino apresenta um número maior de cáries do que o sexo masculino, na mesma idade cronológica. Este fato, também observado em todos os estudos epidemiológicos analisados se deve, segundo BRUCKNER e col. (1954), ao fato de que no sexo feminino os dentes erupcionam precocemente. Obser vação semelhante foi feita por FISCHMAN (1974), ao analisar a saüde bucal no Paraguai.

Os resultados obtidos no Estado de São Paulo em 1980 e 1982 são similares aos resultados de outros estü dos épidemiológicos realizados no Brasil, o que pode ser ve rificado na Tabela 53 . 
TABELA 53 - CPO MEDIO, SEGUNDO A IDADE, LOCAL E EPOCA DO LEVANTAMENTO, EM 8 CIDADES BRASILEIRAS, E NO BRASIL.

\begin{tabular}{|c|c|c|c|c|c|c|c|c|c|}
\hline \multirow{2}{*}{ Idades } & \multicolumn{8}{|c|}{ Local e Epoca do leyantamento } & \multirow[b]{2}{*}{$\begin{array}{l}\text { BRASIL } \\
\text { I983 }\end{array}$} \\
\hline & $\begin{array}{l}\text { CAMPINAS } \\
\text { SP-1961 }\end{array}$ & $\begin{array}{r}\text { GUAIRA } \\
\text { SP-1975 }\end{array}$ & $\begin{array}{l}\text { UBERLÂNDIA } \\
\text { MG - } 1975\end{array}$ & $\begin{array}{l}\text { VITORIA } \\
\text { ES-1975 }\end{array}$ & $\begin{array}{c}\text { S.FE DO SUL } \\
\text { SP-1978 }\end{array}$ & $\begin{array}{l}\text { S.J.CAMPOS } \\
\text { SP-1979 }\end{array}$ & $\begin{array}{l}\text { BOA VISTA } \\
\text { RO - } 1980\end{array}$ & $\begin{array}{c}\text { TERESINA } \\
1981\end{array}$ & \\
\hline 7 & 2,77 & 2,34 & 2,30 & 2,16 & 2,03 & 2,06 & 2,66 & 2,60 & 2,56 \\
\hline 8 & 3,17 & 2,96 & 3,22 & 2,62 & 2,84 & 2,94 & 2,98 & 3,60 & 3,39 \\
\hline 9 & 3,79 & 3,52 & 4,04 & 3,81 & 3,45 & 3,86 & 3,98 & 4,80 & 3,89 \\
\hline 10 & 5,09 & 4,88 & 5,27 & 4,39 & 4,56 & 5,20 & 4,16 & 5,20 & 4,74 \\
\hline 11 & 6,26 & 5,97 & 6,75 & 5,92 & 5,67 & 6,10 & 5,41 & 6,50 & 5,92 \\
\hline 12 & 7,36 & 7,50 & 8,42 & 7,46 & 7,44 & 8,05 & 6,56 & 8,40 & 7,25 \\
\hline 13 & 9,16 & $8,89$. & - & 9,10 & 8,65 & 9,90 & 9,45 & 10,30 & 9,16 \\
\hline 14 & 10,48 & 10,86 & - & 10,51 & 9,31 & 10,38 & 10,60 & 11,00 & 9,94 \\
\hline
\end{tabular}


Como jã assinalamos na revisão da literatura, alguns estudos apresentam uma prevalência de cárie ligeira mente maior, como por exemplo em Natal (Tabela 26), Manaus (Tabela 29), Porto Velho (Tabela 30) e Brasilia (Tabela 32 ).

Em alguns paises podemos verificar que a preva lência de cárie é bem menor, como por exemplo nos Estados U nidos (Tabela 14), Finlândia (Tabela 19), Bêlgica (Tabela 20) e Austrália (Tabela 18), o que se deve a adoção de métodos preventivos como fluoretação da água de abastecimento públi co ou métodos combinados utilizando flúor, controle da pla ca, educação em saúde da boca e programas de tratamento.

No Brasil também foi observada uma redução sig nificativa na quantidade de cáries em localidades que im plantaram a fluoretação da ägua de abastecimento püblico, como por exemplo em Baixo Guandu (Tabela 23), Campinas, após 10 anos de fluoretação (Tabela 43), Juazeiro, após 7 anos de fluoretação (Tabela 31) e Campinas, após 14 anos (Tubela 44).

Em 1980 a média ponderada dos componentes do CPO para o grupo etärio 7 a 14 anos foram:

$$
\begin{aligned}
& \bar{C}=2,84 \\
& \bar{O}=2,04 \\
& \bar{E}=0,26 \\
& \overline{E I}=0,30
\end{aligned}
$$

Isto significa que o componente cariado era $52,20 \%$ do total evidenciando falhas na assistência odontoló gica prestada aos escolares. Os dentes perdidos (E+EI) somam 
10,29 do total enquanto apenas $37,51 \%$ foi restaurado.

Em 1982 a situação encontrada foì praticamen te a mesma:

$$
\begin{aligned}
& \bar{C}=2,81 \\
& \bar{O}=1,93 \\
& \bar{E}=0,28 \\
& \overline{E I}=0,35
\end{aligned}
$$

O componente cariado representou $52,32 \%$ do to tal. Os dentes perdidos somaram $11,73 \%$ e apenas $35,95 \%$ dos dentes atacados pela cárie foi restaurado.

"Uma das caracteristicas da cārie dental è que ela se instala rapidamente após a erupção dentária, quan do existirem fatores que propiciem sua instalação, desde que não sejam adotados métodos de prevenção," segundo GRE ENE \& SUOMI (1978). Os primeiros molares permanentes são os primeiros dentes da segunda dentição que erupcionam ao re dor de seis anos de idade. Na Tabela 54 podemos observar a prevalência de cárie nos primeiros molares permanentes. 
TABELA 54 - PREVALENCIA DE CÁRIE DENTAL NOS PRIMEIROS MOLA RES PERMANENTES, SEGUNDO A IDADE E O SEXO, NO ESTADO DE SÃO PAULO, EM 1980 - 82.

\begin{tabular}{|c|c|c|c|c|c|c|}
\hline \multirow{2}{*}{ Idades } & \multicolumn{3}{|c|}{1980} & \multicolumn{3}{|c|}{1982} \\
\hline & $M$ & $F$ & MF & $M$ & $F$ & $M F$ \\
\hline 7 & 2,15 & 2,30 & 2,23 & 2,25 & 2,40 & 2,33 \\
\hline 8 & 2,84 & 2,95 & 2,90 & 2,91 & 3,00 & 2,95 \\
\hline 9 & 3,12 & 3,18 & 3,15 & 3,18 & 3,27 & 3,22 \\
\hline 10 & 3,21 & 3,29 & 3,24 & 3,30 & 3,34 & 3,32 \\
\hline 11 & 3,28 & 3,31 & 3,30 & 3,34 & 3,37 & 3,35 \\
\hline 12 & 3,30 & 3,34 & 3,32 & 3,36 & 3,37 & 3,36 \\
\hline 13 & 3,36 & 3,39 & 3,37 & 3,34 & 3,40 & 3,37 \\
\hline 14 & 3,41 & 3,44 & 3,43 & 3,42 & 3,43 & 3,42 \\
\hline
\end{tabular}

Os primeiros molares permanentes são muito importantes para a oclusão dental e sua perda precoce acar reta enormes prejuizos. Segundo VIEGAS (1949) "o primeiro molar permanente é fator essencial na oclusão dentäria, sen do mesmo tido como chave da oclusão desde Angle, que o es colheu por esse motivo para base da classificação das má-oclusões." Observando a Tabela 54 podemos verificar que 
no Estado de São Paulo, nos dois levantamentos, aos sete anos de idade mais da metade dos primeiros molares permanen tes jā está atacada pela cárie. Este fato evidencia falhas nos programas preventivos que estão sendo executados. Para evitar o ataque da cārie tão precoce nos primeiros molares, seria necessārio implantar métodos preventivos sistênicos ou tópicos antes do ingresso nas escolas de 1: grau. Na Ta bela 55 podemos analisar os componentes do CPO nos primei ros molares permanentes em 1980.

TABELA 55 - CPO MEDIO E COMPONENTES, DOS PRIMEIROS MOLARES PERMANENTES, SEGUNDO A IDADE NO ESTADO DE SÃO PAULO EM 1980 .

\begin{tabular}{ccccccc}
\hline Idades & $\overline{\mathrm{C}}$ & $\overline{\mathrm{O}}$ & $\overline{\mathrm{E}}$ & $\overline{\mathrm{EI}}$ & $\overline{\mathrm{E}+\overline{\mathrm{EI}}} *$ & $\overline{\mathrm{CPO}}$ \\
\hline 7 & 1,91 & 0,21 & 0,02 & 0,09 & 0,11 & 2,23 \\
8 & 1,73 & 0,95 & 0,06 & 0,16 & 0,22 & 2,90 \\
10 & 1,51 & 1,28 & 0,12 & 0,24 & 0,36 & 3,15 \\
11 & 1,35 & 1,40 & 0,19 & 0,30 & 0,49 & 3,24 \\
12 & 1,20 & 1,47 & 0,28 & 0,35 & 0,63 & 3,30 \\
13 & 1,06 & 1,56 & 0,35 & 0,35 & 0,70 & 3,32 \\
14 & 0,92 & 1,71 & 0,42 & 0,32 & 0,74 & 3,37 \\
& 0,79 & 1,85 & 0,48 & 0,31 & 0,79 & 3,43 \\
\hline
\end{tabular}

$\overline{* \overline{E+E I}}=$ número médio de dentes perdidos. 
Aos 9 anos de idade os escolares apresentam 3 primeiros molares atacados pela cárie e 15\% dos indivíduos já está com todos os primeiros molares atacados pela cárie. Aos 14 anos de idade $43 \%$ apresenta os 4 primeiros molares a tacados pela cárie. Quanto ao programa curativo, as falhas são visíveis, já que os primeiros molares não estão sendo restaurados com a devida prioridade. Nenhuma idade apresen ta pelo menos metade dos dentes atacados pela cárie como obturados. Podemos observar ainda que as extrações e extra ção indicada aumentam gradualmente, passando de 0,11 dentes perdidos aos 7 anos até atingir 0,79 dentes perdidos aos 14 anos de idade, o que permite concluir que o diagnöstico tão cedo quanto possivel e o atendimento imediato - 3 o nível de prevenção de LEAVELL \& CLARK (1958), não têm sido aplicados com eficiência no programa de assistência odontológica pres tada aos escolares do Estado de são Paulo.

FOSTER (1942), examinando um grupo de jovens de 6 a 16 anos no Winsconsin (EUA), verificou que de todos os dentes atacados pela cārie, 69,54\% eram primeiros mola res permanentes. O percentual encontrado no Estado de São Paulo, em 1980- foi de 54,69\% para o grupo etário de 7 a 14 anos de idade.

Em 1982 a situação encontrada foi praticamen te a mesma como pode ser observado na Tabela 56. 
TARELA 56 - CPO MEDIO E COMPONENTES, DOS PRIMEIROS MOLARES PERMANENTES, SEGUNDO A IDADE, NO ESTADO DE SÃO PAULO EM 1982.

\begin{tabular}{ccccccc}
\hline Idades & $\overline{\mathrm{C}}$ & $\overline{0}$ & $\overline{\mathrm{E}}$ & $\overline{\mathrm{EI}}$ & $\overline{\mathrm{E}+\overline{E I}}$ & $\overline{\mathrm{CPO}}$ \\
\hline 7 & 2,01 & 0,21 & 0,02 & 0,09 & 0,11 & 2,33 \\
8 & 1,61 & 1,13 & 0,06 & 0,15 & 0,21 & 2,95 \\
9 & 1,47 & 1,40 & 0,12 & 0,23 & 0,35 & 3,22 \\
10 & 1,35 & 1,46 & 0,21 & 0,30 & 0,51 & 3,32 \\
11 & 1,26 & 1,42 & 0,30 & 0,37 & 0,67 & 3,35 \\
12 & 1,14 & 1,46 & 0,40 & 0,36 & 0,76 & 3,36 \\
13 & 1,00 & 1,54 & 0,46 & 0,37 & 0,83 & 3,37 \\
14 & 0,87 & 1,67 & 0,54 & 0,34 & 0,87 & 3,42 \\
\hline
\end{tabular}

Como pôde ser verificado na Tabela 56, aos 9 anos de idade três primeiros molares estão atacados pela cá rie, sendo que $22 \%$ dos indivíduos estava com todos os pri meiros molares atacados pela cārie, percentual que aumenta gradualmente até atingir $42 \%$ aos 14 anos de idade. " Nessa mesma idade, $25 \%$ dos dentes atacados pela cárie estava pen dido, evidenciando as mesmas falhas observadas em 1980, a despeito do esforço realizado pelo óngão prestador de servi ço com treinamento de pessoal em todos os níveis em 1981. 
miológicos são de suma importância para a gerência de pro gramas de assistência odontológica, permitindo um planeja mento adequado e um acompanhamento eficaz dos programas. E necessārio salientar que a maioria dos serviços prestadores de assistência odontológica não realiza periodicamente le vantamentos epidemiológicos, tidos como necessärios para a organização e avaliaçãão dos programas. No Estado de São Pau lo, por exemplo, desde a criação do Serviço Dentärio Esco lar em 1938 até 1986 , foram realizados apenas os levantamen tos de 1980 e 1982 .

Na Tabela 57 podemos analisar o nümero médio de: dentes inrompidos e hígidos nos dois levantamentos.

TABELA 57 - NOMERO MEDIO DE DENTES IRROMPIDOS, SEGUNDO A IDADE, O SEXO E A EPOCA DO LEVANTAMENTO, NO ES TADO DE SÃO PAULO, 1980 - 82.

\begin{tabular}{|c|c|c|c|c|c|c|}
\hline \multirow{3}{*}{ Idades } & \multicolumn{6}{|c|}{ Epoca do Ievantamento } \\
\hline & \multicolumn{3}{|c|}{1980} & \multicolumn{3}{|c|}{1982} \\
\hline & M & $\mathrm{F}$ & MF & M & $\mathrm{F}$ & $M F$ \\
\hline 7 & 9,01 & 9,65 & 9,33 & 9,45 & 10,03 & 9,74 \\
\hline 8 & 11,83 & 12,45 & 12,15 & 12,06 & 12,51 & 12,29 \\
\hline 9 & 14,55 & 15,56 & 15,06 & 14,69 & 15,61 & 15,15 \\
\hline 10 & 18,27 & 19,81 & 19,03 & 18,64 & 19,91 & 19,27 \\
\hline 11 & 22,50 & 23,83 & 23,16 & 22,71 & 23,87 & 23,29 \\
\hline 12 & 25,40 & 26,25 & 25,81 & 25,64 & 26,33 & 25,98 \\
\hline 13 & 26,93 & 27,26 & 27,09 & 27,09 & 27,41 & 27,24 \\
\hline 14 & 27,55 & 27,62 & 27,58 & 27,65 & 27,67 & 27,66 \\
\hline
\end{tabular}


E fäcil notar que o nümero médio de dentes in rompidos é sempre maion no sexo feminino, o que vem corroborar observações feitas anteriormente e que, como diz VIEGAS (1961), "não se trata de maior suscetibilidade do sexo femi nino à cárie e sim maior tempo de exposição dos dentes ao ataque de cárie, face à precocidade na erupção dentária apre sentada pelo sexo feminino".

Analisando os resultados obtidos por VIEGAS \& VIEgAS (Tabela 43), observamos que dos 7 aos 11 anos de ida de, aproximadamente $88 \%$ dos dentes examinados estava livre de cáries, enquanto que dos 12 aos 14 anos $83 \%$ do total de dentes irrompidos estava livre de cáries, após 10 anos de fluoretação da água de abastecimento pūblico em Campinas.

Em 1980 dos 7 aos 11 anos de idade aproximada mente $75 \%$ dos dentes examinados estava hígido, percentual que dos 12 anos em diante vai sofrendo uma redução gradativa, pas sando de $72 \%$ aos $12,69 \%$ aos 13 e $65 \%$ de dentes livres de cá rie aos 14 anos de idade. Possivelmente este fato pode ser explicado pela erupção dos segundos molares permanentes, co. mo foi constatado por KOLEHMAINEN (1983), estudando a inci dência de cāries em escolares. Segundo esse autor, tal fato sucede em virtude da rápida ocorrência de cárie na superfí. cie oclusal dos segundos molares permanentes, possivelmente porque nessa idade os adolescentes consomem mais açúcar.

AINAMO \& HOLMBERG (1973) demonstraram em um es tudo longitudinal retrospectivo, que a situação bucal dos re crutas prestando serviço militar ( 19 anos de idade) na Fin 
lândia apresentaya níyel inadequado, embora esses individuos tivessem seus dentes tratados no serviço odontológico esco lar. Concluiram que näo houye sucesso no tratamento curati vo porque ocorreram câries em outras superficies dentais, em dentes vizinhos aos que haviam sido restaurados ou ocorreu doença periodontal.

Consequentemente, apenas o programa curativo, não é suficiente para alcançar bons resultados; é necessá rio, em paralelo, aplicação de métodos preventivos combina dos e ênfase em educação. em saúde da boca, finalizaram os autores do estudo.

Nas Tabelas 58 e 59 pode ser analisada $\circ \mathrm{com}$ portamento do CPO e componentes nos dois levantamentos.

TABELA 58 - CPO MEDIO E COMPONENTES, SEGUNDO A IDADE NO ESTA DO DE SÃO PAULO, EM 1980.

\begin{tabular}{cccccccc}
\hline Idades & $\overline{\mathrm{C}}$ & $\overline{0}$ & $\overline{\mathrm{E}}$ & $\overline{\mathrm{EI}}$ & $\overline{\mathrm{C}+\mathrm{EI}}$ & $\overline{\mathrm{E}+\mathrm{EI}}$ & $\overline{\mathrm{CP}} \overline{0}$ \\
\hline 7 & 1,98 & 0,22 & 0,02 & 0,09 & 2,07 & 0,11 & 2,31 \\
8 & 1,96 & 0,98 & 0,06 & 0,16 & 2,12 & 0,22 & 3,16 \\
9 & 2,09 & 1,40 & 0,13 & 0,25 & 2,34 & 0,38 & 3,87 \\
10 & 2,54 & 1,72 & 0,21 & 0,31 & 2,85 & 0,52 & 4,78 \\
11 & 3,16 & 2,15 & 0,31 & 0,39 & 3,55 & 0,70 & 6,01 \\
12 & 3,69 & 2,72 & 0,41 & 0,41 & 4,10 & 0,82 & 7,23 \\
13 & 3,94 & 3,64 & 0,54 & 0,43 & 4,42 & 1,00 & 8,55 \\
14 & 4,00 & 4,63 & 0,65 & 0,47 & 4,47 & 1,12 & 9,75 \\
& & $\ldots$ & & & & & \\
\hline
\end{tabular}


TABELA 59 - CPO MEDIO E COMPONENTES, SEGUNDO A TDADE NO ES TADO DE SÃO PAULO, EM 1982.

\begin{tabular}{cccccccc}
\hline Idades & $\overline{\mathrm{C}}$ & $\overline{\mathrm{O}}$ & $\overline{\mathrm{E}}$ & $\overline{\mathrm{EI}}$ & $\overline{\mathrm{C}+\overline{\mathrm{E}} \bar{I}}$ & $\overline{\mathrm{E}+\overline{\mathrm{EI}}}$ & $\overline{\bar{C} \bar{O}}$ \\
\hline 7 & 2,05 & 0,22 & 0,02 & 0,12 & 2,17 & 0,14 & 2,41 \\
8 & 1,79 & 1,16 & 0,06 & 0,18 & 1,97 & 0,24 & 3,19 \\
9 & 2,02 & 1,52 & 0,13 & 0,27 & 2,29 & 0,40 & 3,94 \\
10 & 2,46 & 1,78 & 0,22 & 0,36 & 2,82 & 0,58 & 4,82 \\
11 & 3,16 & 2,04 & 0,34 & 0,44 & 3,60 & 0,78 & 5,98 \\
12 & 3,68 & 2,52 & 0,46 & 0,48 & 4,16 & 0,94 & 7,14 \\
13 & 4,04 & 3,20 & 0,56 & 0,51 & 4,55 & 1,07 & 8,31 \\
14 & 4,10 & 4,13 & 0,70 & 0,57 & 4,67 & 1,27 & 9,50 \\
\hline
\end{tabular}

Analisando as Tabelas 58 e 59 podemos verifi car que a situação em 1980 e 1982 è praticamente equivalente. O número de dentes cariados é sempre maior que o número de dentes obturados, exceto aos 14 anos.

o número médio de dentes perdidos (E+EI) au menta gradualmente chegando a um dente perdido aos 13 anos de idade. Nos estudos de VIEGAS \& VIEGAS, após 10 anos de fluoretação em Campinas-SP, ${ }^{(96)}$ a média de dentes perdidos aos 14 anos foi 0,32. Os mesmos autores, após 14 anos de fluoretação encontraram uma mêdia de 0,16 dentes perdidos aos 14 anos de idade.

Analisando as necessidades de tratamento(C+EI) verificamos nos dois levantamentos que elas aumentam de ida 
de para idade. Isto significa que não vem sendo executado o programa incremental, no qual o atendimento às menores ida des e posterior tratamento de manutenção possibilita um au mento gradual da cobertura.

Nos países escandinavos, o governo propicia atendimento odontológico gratuito de 0 a 18 anos de idade, porém, cumpre ressaltar que isto só se tornou possível após grande investimento na aplicação de mëtodos preventivos com binados, utilizando pessoal auxiliar. No serviço público es tadual de são Paulo, no que tange à assistência odontológi. ca não existe nenhum tipo de pessoal auxiliar, ocorrendo um sistema de trabalho totalmente obsoleto, no qual o Cirur gião Dentịsta trabalha sozinho e no programa preventivo, quando existe, são executados apenas bochechos fluorados.

Esses fatos levam a uma situação muito sêria pois a média ponderada das necessidades de tratamento (C+EI) em 1982 foi 3,16 dentes permanentes a serem restaurados e ou extraídos. Considerando o total de alunos matriculados somen te na rede estadual de ensino de 1o grau no início de 1983 $3.537 .323 \%$, teríamos $3,16 \times 3.537 .323=11.177 .940$ dentes permanentes a serem restaurados e ou extraídos, como sendo

* Fonte: Estatisticas Educacionais - Secretaria de Educação - Assessoria Técnica de Planejamento e Controle E ducacional - Centro de Informações Educacionais 1983 . 
as necessidades de tratamento dos escolares de 7 a 14 anos, matriculados no primeiro grau em São Paulo. Se um Cirurgião Dentista da DENPAO, contratado por 20 horas semanais traba lhasse efetivamente durante os 180 dias letivos previstos em lei e com um rendimento operacional de 1,5 dentes perma nentes tratados por hora, a capacidade produtiva seria 180 dias $X 4$ horas $X$ rendimento $1,5=1080$ unidades de traba Iho ou sejam: 1.080 dentes permanentes restaurados e extrai. dos, no período de um ano. Isto significa que seriam neces sārios 10.350 Cirurgiões Dentistas para a cobertura comple ta das necessidades de tratamento dos escolares de 7 a 14 anos no Estado de São Paulo, número esse muito além dos atuais 1.109 Cirurgiões Dentistas com atividades clínicas na DENPAO.*

E evidente que uma reformulação na política de atendimento odontológico se faz necessāria para a solu ção do problema, utilizando pessoal auxiliar e investindo seriamente na prevenção.

Para que tais fatos ocorram efetivamente, pa rece ser indicada a municipalização da assistência odontoló gica, com repasse de verbas estaduais e federais aos municí pios, para que estes possam administrar com mais eficiència os programas atrayés de uma supervisão efetiva e um acompa nhamento e controle das atividades.

Informação verbal prestada por Nelson Francisco Fiuza-Ci rurgião Dentista Sanitarista da DENPAO, em 4 de novembrö de 1986 . 
Na Tabela 60 podemos analisan o CPO médio e componentes obtidos após 14 anos de fluoretação da água de abastecimento público de Campinas.

TABELA 60 - CPO MEDIO E COMPONENTES DO GRUPO ETARIO DE 7 A 14 ANOS, APÓS 14 ANOS DE ELUORETACÃA, SEGUNDO A IDADE, EM CAMPINAS, 1976.

\begin{tabular}{ccccccc}
\hline Idades & $\mathrm{N}$ & $\overline{\mathrm{C}}$ & $\overline{\mathrm{O}}$ & $\overline{\mathrm{E}}$ & $\overline{\mathrm{E}} \overline{\mathrm{I}}$ & $\overline{\mathrm{CP}} \overline{\mathrm{O}}$ \\
\hline 7 & 397 & 0,36 & 0,56 & 0,05 & 0,17 & 0,94 \\
8 & 610 & 0,46 & 0,89 & 0,02 & 0,04 & 1,41 \\
9 & 675 & 0,49 & 1,33 & 0,04 & 0,05 & 1,91 \\
10 & 670 & 0,56 & 1,72 & 0,02 & 0,04 & 2,34 \\
11 & 557 & 0,43 & 2,03 & 0,05 & 0,07 & 2,58 \\
12 & 452 & 0,72 & 2,38 & 0,12 & 0,08 & 3,30 \\
13 & 415 & 0,89 & 2,89 & 0,13 & 0,12 & 4,01 \\
14 & 258 & 0,60 & 3,56 & 0,12 & 0,04 & 4,32 \\
\hline
\end{tabular}

Fonte: VIEGAS, A.R. \& VIEGAS, Y. (1985)

A mêdia ponderada das necessidades de trata mento $(C+E I)$ nesse estudo é 0,62 . Aplicando o raciocínio anterior para estimar as necessidades de tratamento totais, considerando a população de 7 a 14 anos matriculada em 1983, teríamos:

$3.537 .323 \times 0,62=2.193 .140$ dentes permanen 
tes a serem tratados. Considerando os mesmos padrões de pro dutividade anteriormente descritos, necessitaríamos de 2.030 Cirurgiões Dentistas para cobertura total das necessidades de tratamento, se a fluoretação da ägua de abastecimento pū. blico fosse adotada em todos os municipios do Estado de são Paulo, o que significa uma redução de $80 \%$ na mão de obra ne cessária para o tratamento de todos os escolares de 7 a 14 anos. Elícito afirmar que para o desenvolvimento eficiente de um programa odontolögico, seria importantissimo que o mé todo de prevenção de cärie adotado fosse o de maior força nos resultados que è a fluoretação das águas de abastecimento público.

Em 1984 no Estado de São Paulo, segundo BATA LHA (1984), 204 municípios estavam com suas águas de abaste cimento público fluoretadas. Atualmente a SABESP (Saneamen to Bäsico do Estado de São Paulo) está fluoretando as águas de 294 municípios, inclusive a Capital do Estado.*

Somando-se a esses os serviços autônomos e os municipios com flüor natural nas äguas de abastecimento pú blico, verificamos que dos 572 municípios paulistas, 392 es tão com águas fluoretadas ou seja 68,53\% do total. A popula ção beneficiada pode ser estimada em 19.300 .971 pessoas.**

* Informação verbal do Engenheiro Sanitarista Luiz Henrique H. Macedo, Coordenador da SDI da SABESP.

** Fontes: SABESP (1986)

IBGE (I985) 
Na Figura 2 podemos observar a situação de uma população sem ảgua fluoretada e totalmente desassistida em relação a tratamento odontológico, atravês da composição percentual do Indice CPO.

FIGURA 2 - COMPOSIÇÃO PERCENTUAL DO INDICE CPO EM CRIANÇAS BRASILEIRAS DE 7 A 14 ANOS, EM 1955.

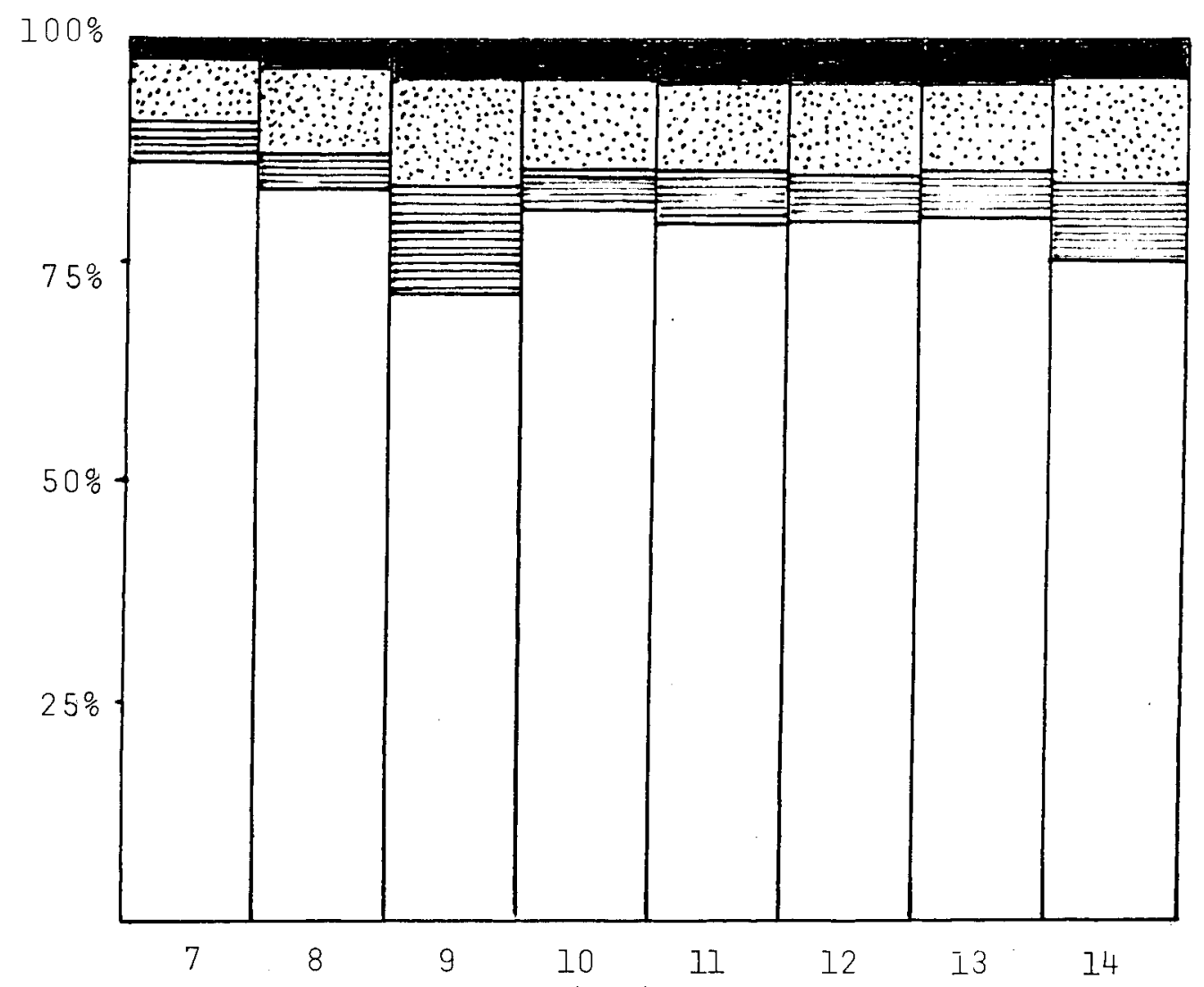

Fonte: FRANKEL, J.M. \& CHAVES, M.M. (1955)

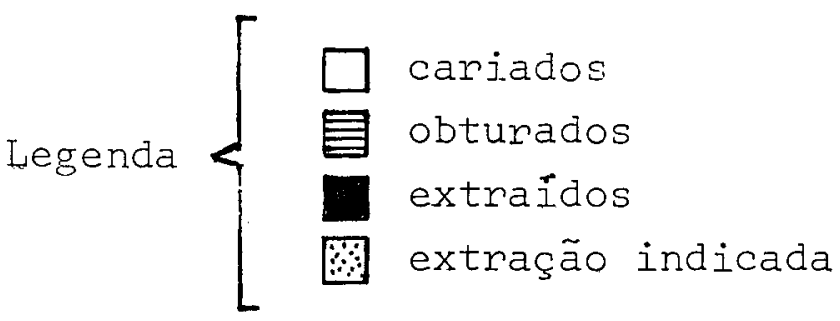

Como podemos observar, o percentual de dentes cariados é de 70 a $85 \%$, enquanto as extrações indicadas es 
tão ao redor de $10 \%$ em todas as idades, o que significa que essa população é totalmente desassistida quanto ao tratamen to odontológico.

Nas Figuras 3 e 4 podemos observar a composi ção percentual do Indice CPO no Estado de São Paulo, nos dois levantamentos.

FIGURA 3 - COMPOSIÇÃO PERCENTUAL DO INDICE CPO PARA O GRUPO ETÅRIO 7 A 14 ANOS, NO ESTADO DE SÃO PAULO EM 1980.

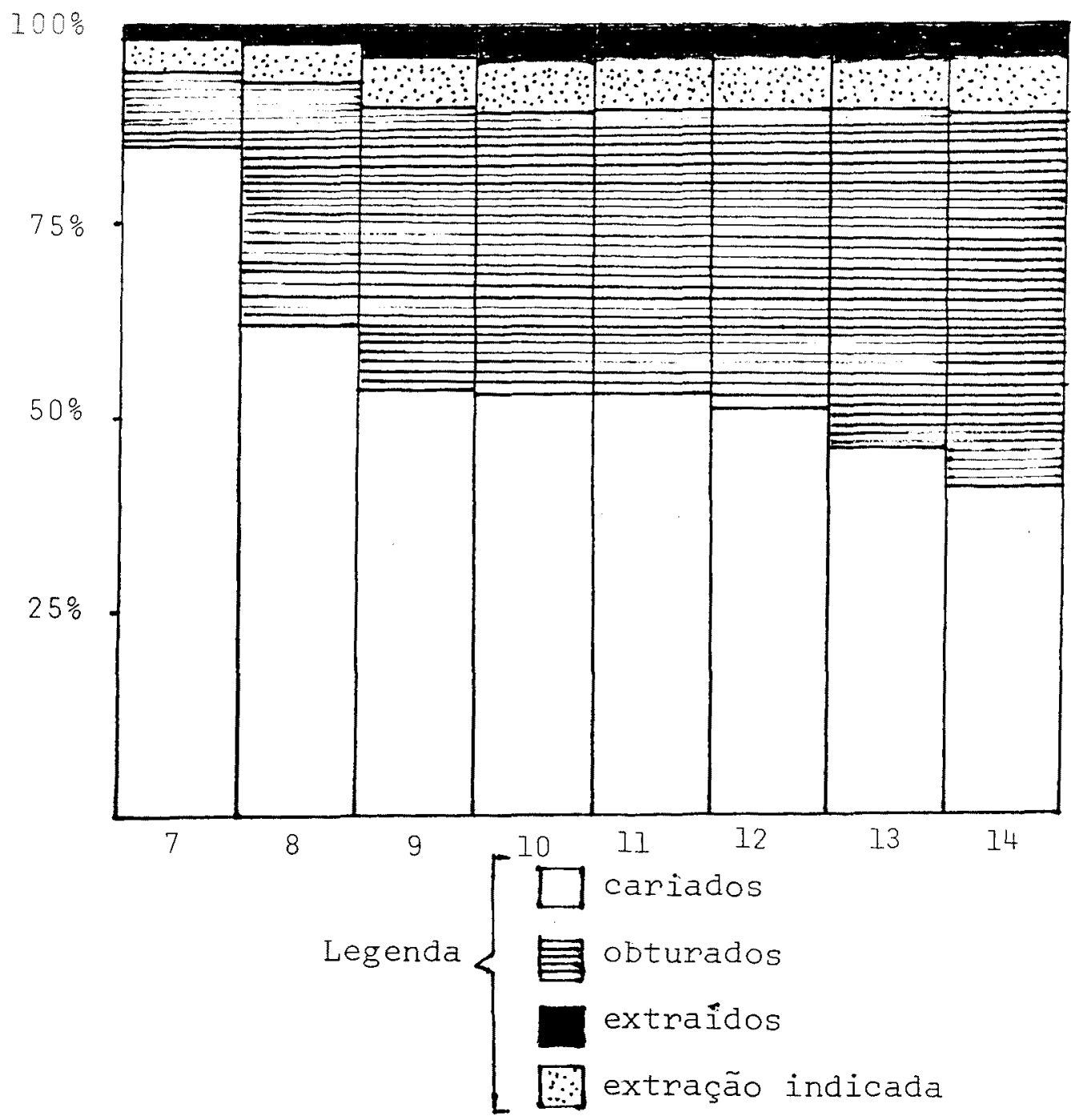


FIGURA 4 - COMPOSIÇÃO FERCENTUAL DO INDICE CPQ PARA O GRUPO ETARIO 7 A 14 ANOS, NO ESTADO DE SÃO PAULO EM 1982.

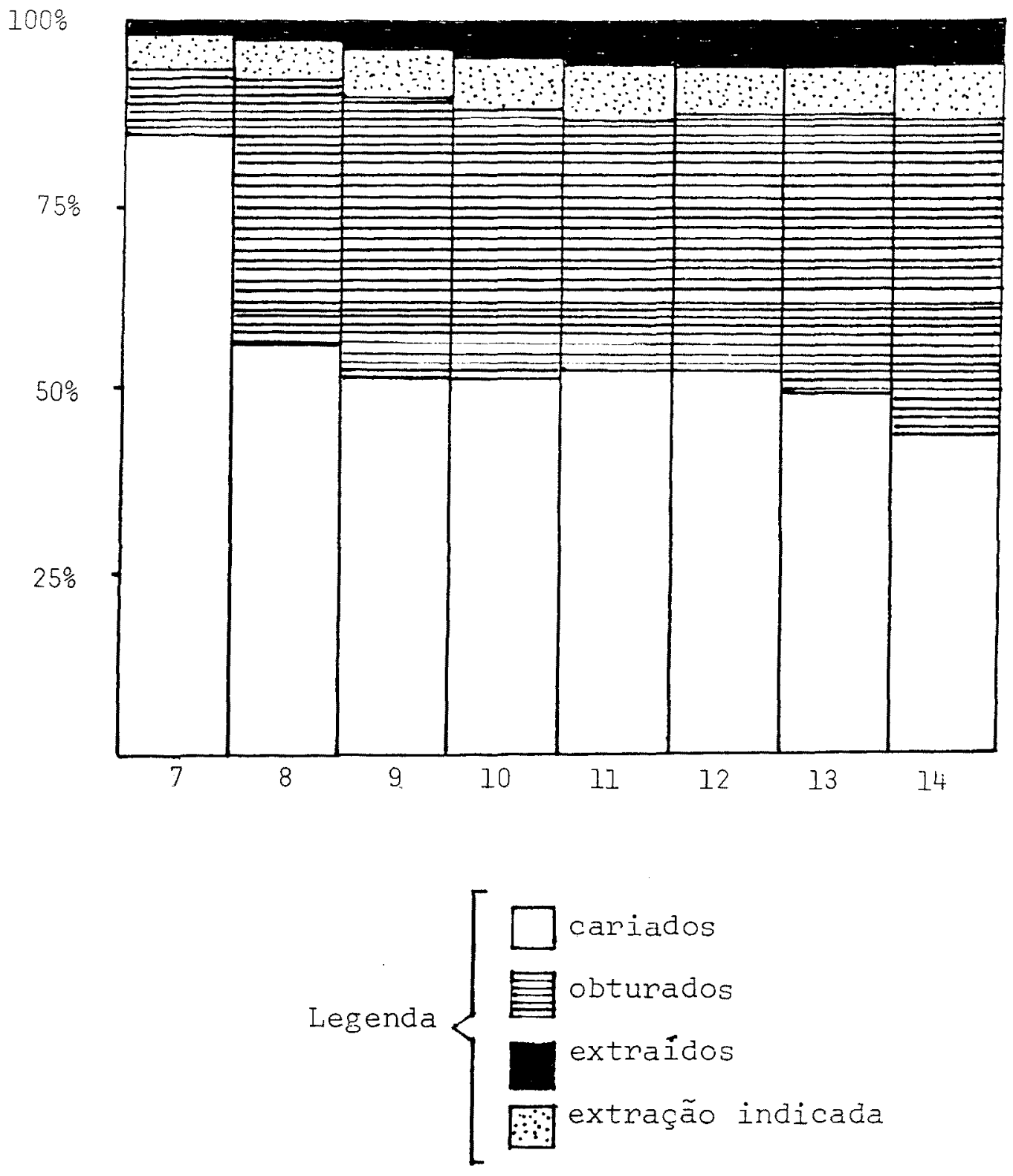

Podemos observar que a situação nos dois le vantamentos é similar, a cobertura vai aumentando gradual mente apenas até 9 anos de idade, permanecendo praticamente nos mesmos patamares nas idades subsequentes. 
Nas Figunas 5 e 6 pode ser analisada a situa ção da assistência odontolögica prestada pela PREFEITURA DE SÃO JOSE DOS CAMPOS (I984).

FIGURA 5 - COMPOSIÇÃO PERCENTUAL DO INDICE CPO EM ESCOLA RES DE 7 A 14 ANOS, EM SÃO JOSE DOS CAMPOS EM 1979.

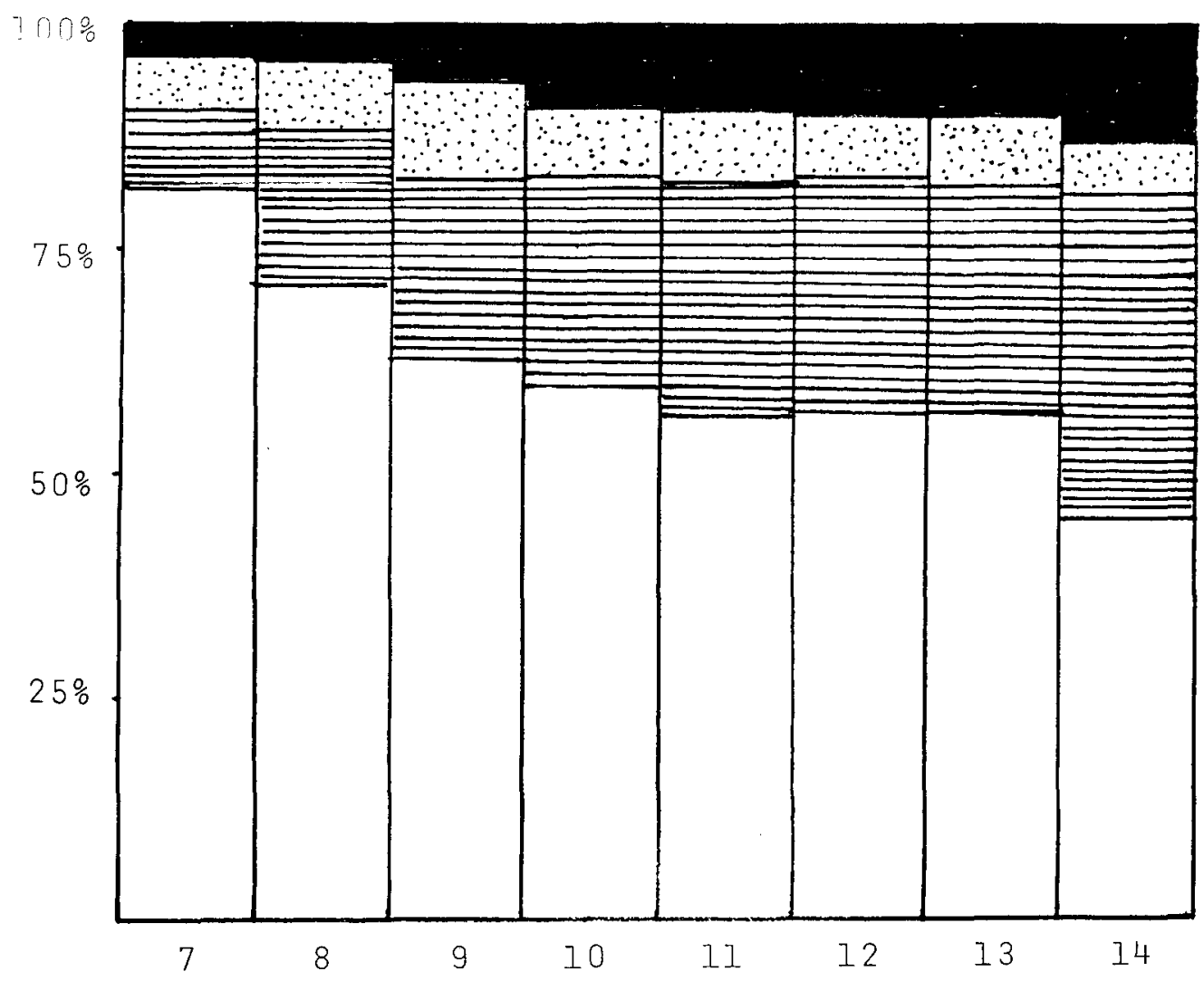

Legenda $\left\{\begin{array}{l}\square \text { cariados } \\ \text { obturados } \\ \text { extraídos } \\ \text { Jextração indicada }\end{array}\right.$ 
FIGURA 6 - COMPOSIÇÃO PERCENTUAL DO INDICE CPO EM ESCOLARES DE 7 A 14 ANOS, EM SÃO JOSE DOS CAMPOS, EM 1983.

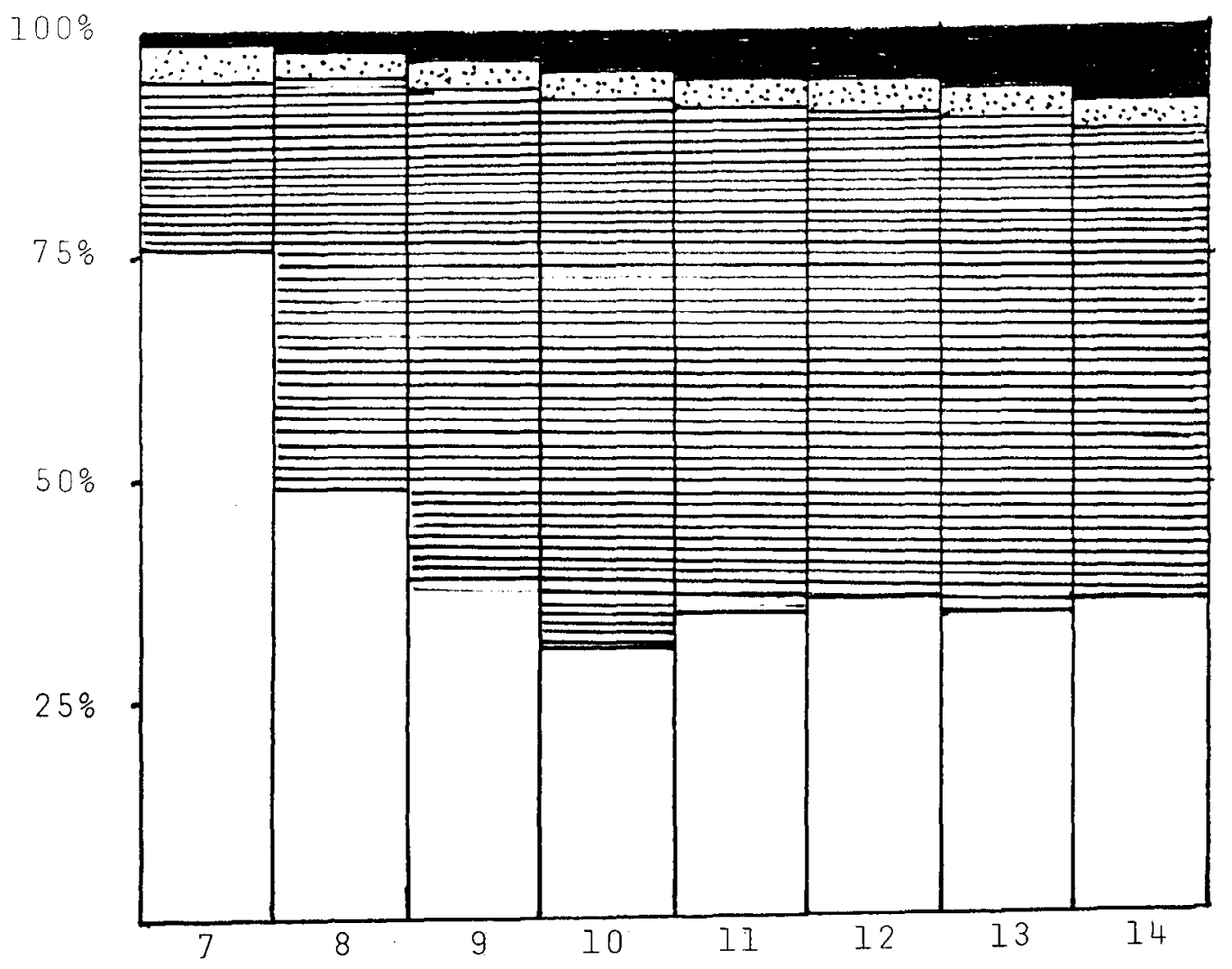

Legenda $\begin{cases}\square & \text { cariados } \\ \text { obturados } & \text { extraidos } \\ \text { extração indicada }\end{cases}$

Podemos observar que após 3 anos de implanta ção do programa ocorreu uma inversão dos componentes do CPO. - pencentual de dentes obturados que era menor que dos den tes cariados, passou a ser maior. A perda de dentes foi pra ticamente reduzida em 50\%. Entretanto, a partir dos 10 anos de idade, a situação fica estabilizada, fazendo supor que a 
capacidade operacional dos recursos humanos existentes alcan çou seu limite máximo e que somente com a introdução de ou tras medidas preventivas poder-se-ä reduzir as necessidades de tratamento e aumentar a cobertura sem injetar recursos hu manos adicionais. Cumpre ressaltar que nesse período ocorre ram mudanças polîticas em São Josê dos Campos e a nova dire ção da Divisão de odontologia desviou recursos humanos para - atendimento de adultos, em detrimento da assistência prio ritária aos escolares de 7 a 14 anos.

Segundo PINTO (1979), "a prioridade classica mente aceita para o escolar de 1o grau tem uma profunda ra zão epidemiológica que não pode ser desconhecida, estando justificada pela constatação de que a cārie é uma doença que apresenta uma curva de ataque durante a vida humana com um äpice nesse período. E ineludivel por outro lado, que diante de recursos escassos e competitivos, quando um adulto, um dente temporário ou um problema endodôntico é resolvido, au tomaticamente uma criança, um dente permanente e vários pro blemas iniciais deixam de ser equacionados. Em Odontologia, quando um problema não é solucionado em sua etapa inicial de evolução, agrava-se em geral rapidamente e passa a pressio nar o sistema prestador de serviços que, então, terá que de dicar-lhe tempo adicional e pessoal qualitativamente supe rior."

\section{A "FEDERATION DENTAIRE INTERNATIONALE" (1982)}

publicou as metas da Organização Mundial de Säude para o ano 2.000, que entre elas estabeleceu um CPO igual ou menor que 
3, a para a idade de 12 anos, a todos paises membros indus trializados ou em desenvolvimento entre os quais se inclui o Brasil, tendo em vista que existem métodos preventivos que permitem uma drảstica redução na prevalência da cārie dental. Essas metas já foram praticamente alcançą das nos Estados Unidos (Tabela 8), Suécia (KOCH - 1982), Austrália (Tabela 18) e algumas regiões da Inglaterra (Tabe la 15 ).

STOOKEY (1985) encontrou um CPO médio aos 12 anos em escolares do Estado de Indiana (EUA) igual a 1,48, tendo observado uma redução de $70 \%$ em relação a exames fei tos 23. anos antes.

Na Nova Zelândia, HUNTER (1982) verificou um CPO médio aos 12 e 13 anos de idade de 2,70 para ambos os sexos.

FREIRE (1970) publicou a prevalência de cárie dental em 14 Estados do Brasil para o grupo etário de 6 a 14 anos e o menor indice encontrado aos 12 anos de idade foi no Rio Grande do Norte - 6,59, enquanto os demais apresentaram Indices variando de 7,32 a 10,30, como pode ser observado na Tabela 25.

No Estado de São Paulo em 1980 o CPO médio aos 12 anos foi de 7,24 em 1980 e 7,13 em 1982, o que significa mais do que o dobro da meta estabelecida pela OMS. Podemos ainda ob servar pelas Tabelas 55 e 56 que somente o CPO médio dos pri meiros molares permanentes já supera a meta de 3,0 dentes 
atacados pela cärie.

Levantamentos epidemiolögicos realizados pela FSESP* mais necentemente, envolveram 69.291 escolares de 6 a 14 anos de idade em 15 Estados brasileiros, registrando um CPO médio aos 12 anos igual a 7,51. Segundo INFIRRI \& BARNES (1979) um CPO médio aos 12 anos maior que 6,60 é muito alto segundo a classificação da Organização Mundial de Saủde.

Apōs 14 anos de fluoretação da água de abaste cimento público em Campinas o CPo médio aos 12 anos foi 3,30 e em Baixo Guandu no mesmo prazo 2,66. Isto significa que apenas com a adoção da fluoretação da água de abastecimento público, a meta é praticamente alcançada.

Segundo o Prof. Newbrum** ideal seria a fluo retação da água de abastecimento público, mais a utilização de dentifrícios fluorados e outros métodos de ação local do flúor. Com esse conjunto de métodos preventivos à luz dos co nhecimentos científicos atuais, a cárie pode ser controlada. Em virtude dessa filosofia que é mundjal, a cārie tem sido reduzida em diversos países, principalmente nos países indus trializados, com exceção do Japão.

* Comunicação Pessoal - aula proferida na Faculdade de Saú de Pública da USP em 1986 por Renato Cordeiro - Cirurgião Dentista Sanitarista da FSESP.

* Palestra proferida durante o III Encontro da ABOPREV (As sociação Brasileira de Odontologia. Preventiva) pelo ProfE. Newbrun da Universidade da Califónia, em novembro de 1986. 
A bilateralidade da cárie dental. foi demons trada entre outros autores por BERTRAM (1943) e DE JONG \& DUNNING (1971). Em São Paulo este fato pode ser observado na Tabela 61 e Figura 7 .

TABELA $6 I$ - CPO MEDIO DOS LADOS DIREITO E ESQUERDO, SEGUNDO A IDADE E O SEXO NO ESTADO DE SÃO PAULO EM 1980.

\begin{tabular}{ccccccc}
\hline & \multicolumn{3}{c}{ Lado Direito } & \multicolumn{2}{c}{ Lado Esquerdo } \\
\cline { 2 - 7 } Idades & M & F & MF & $M$ & $F$ & MF \\
\hline 7 & 1,11 & 1,20 & 1,16 & 1,11 & 1,20 & 1,16 \\
8 & 1,53 & 1,63 & 1,58 & 1,53 & 1,62 & 1,58 \\
9 & 1,88 & 1,99 & 1,93 & 1,88 & 1,98 & 1,93 \\
10 & 2,28 & 2,51 & 2,40 & 2,27 & 2,50 & 2,38 \\
11 & 2,89 & 3,15 & 3,02 & 2,85 & 3,14 & 3,00 \\
13 & 3,47 & 3,80 & 3,64 & 3,43 & 3,78 & 3,60 \\
14 & 4,15 & 4,45 & 4,30 & 4,09 & 4,39 & 4,24 \\
& 4,76 & 5,06 & 4,91 & 4,66 & 4,97 & 4,82 \\
\hline
\end{tabular}

o Indice é coincidente em três idades e as variações que ocorreram nas demais são iguais ou inferiores a 10 centésimos.

Em 1982 o mesmo fenômeno foi observado e po de ser analisado na Figura 7. 
VIEGAS (1968) citou outros la autores que de monstraram que a cârie dental ocorre bilateralmente em estu dos de grupos populacionais. Portanto, a bilateralidade da cârie observada no Estado de São Paulo era esperada e assim sendo permite que se admita que os dados obtidos são preci sos.

FIGURA 7 - CPO MEDIO DOS LADOS DIREITO E ESQUERDO, SEGUNDO A IDADE NO ESTADO DE SÃO PAULO EM 1982.

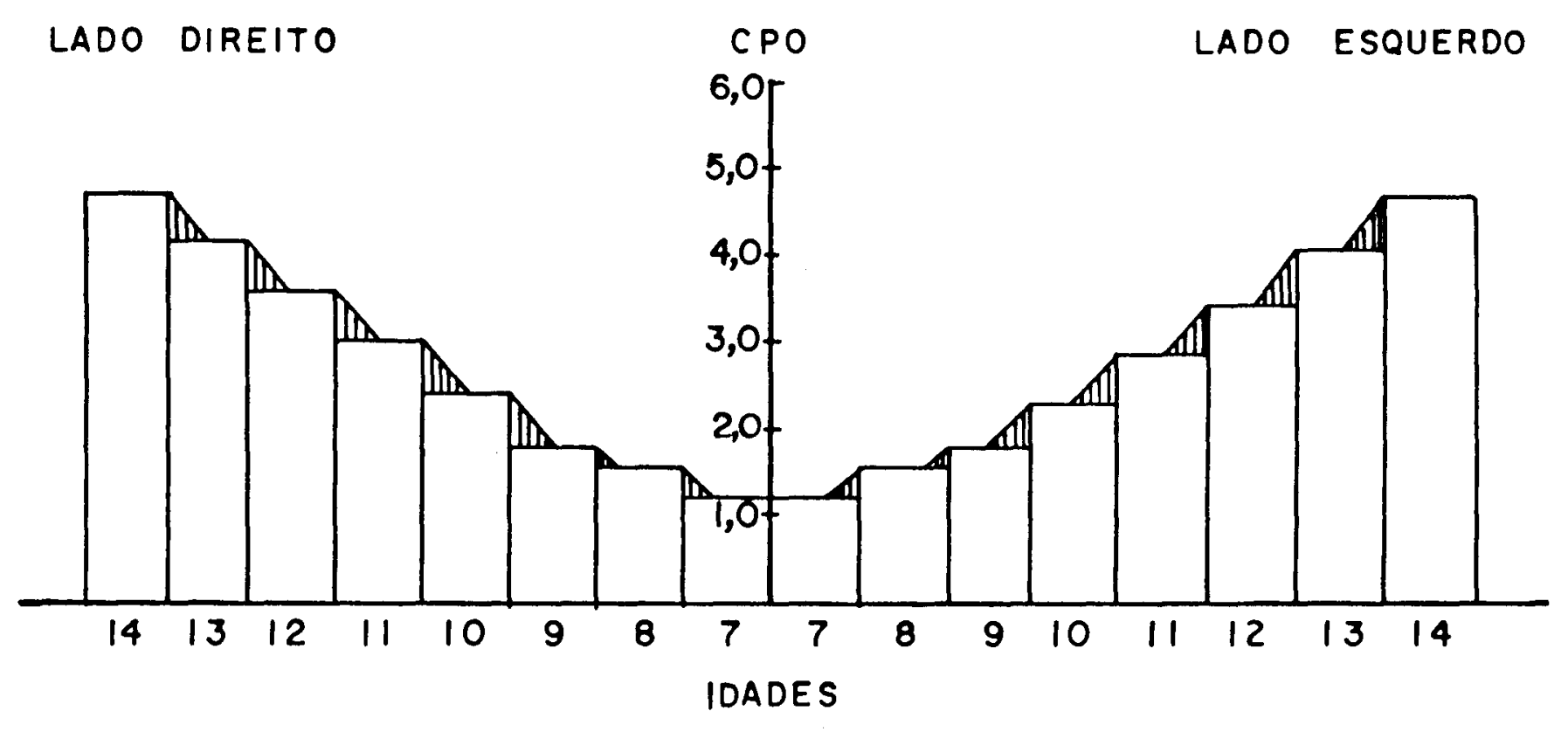

Nas Tabelas 62 podemos observar a ocorrência de cárie nos arcos superior e inferior, nos anos de 1980 e 1982. 
TABELA 62 - CPO MEDIO DAS ARCADAS SUPERIOR E INFERIOR EM ES COLARES DE 7 A 14 ANOS, SEGUNDO A IDADE, NO ES TADO DE SÄO PAULO EM 1980 e 19.82.

\begin{tabular}{ccccc}
\hline \multirow{2}{*}{ Idades } & \multicolumn{2}{c}{$\overline{\mathrm{CPO}}_{1980} \overline{\mathrm{CPO}}_{1982}$} \\
\cline { 2 - 5 } & $\begin{array}{c}\text { ARCADA } \\
\text { SUPERIOR }\end{array}$ & $\begin{array}{c}\text { ARCADA } \\
\text { INFERIOR }\end{array}$ & $\begin{array}{c}\text { ARCADA } \\
\text { SUPERIOR }\end{array}$ & $\begin{array}{c}\text { ARCADA } \\
\text { INFERIOR }\end{array}$ \\
\hline 7 & 0,95 & 1,37 & 0,98 & 1,43 \\
9 & 1,46 & 1,70 & 1,47 & 1,72 \\
10 & 1,94 & 1,92 & 1,99 & 1,95 \\
11 & 2,52 & 2,25 & 2,56 & 2,26 \\
13 & 3,23 & 2,78 & 3,23 & 2,75 \\
14 & 3,93 & 3,31 & 3,87 & 3,26 \\
& 4,68 & 3,85 & 4,55 & 3,76 \\
\hline
\end{tabular}

Nas idades de 7 e 8 anos o CPO mëdio é maion nos dentes inferiores, certamente porque o nümero médio de dentes irrompidos também è maior na arcada inferior. No le vantamento de 1980, por exemplo, o número médio de dentes irrompidos ê 4,35 e 5,91 para os dentes superiores nas ida des de 7 e 8 anos respectivamente, enquanto para os inferio res é 5,39 aos 7 anos e 6,38 aos 8 anos de idade. Dos 9 anos em diante, quase não hâ diferença entre o número médio de dentes irrompidos nos arcos superior e inferior, entre 
tanto o número médio de dentes atacados pela cárie é menor nos dentes inferiores. Isto ocorre em virtude da ação mais efetiva da saliva na proteçäo dos dentes inferiores, os re sultados obtidos nos levantamentos de 1980 e 1982 são simi lares no que se diz respeito a dentes superiores e inferio res.

Na Tabela 63 podemos analisar os resultados do ataque de cárie nos dentes anteriores. Podemos observar que a partir de 11 anos mais de um dente anterior está ata cado pela cárie alcançando um valor próximo de dois aos 14 anos de idade.

TABELA 63 - NÚMERO MEDIO DE DENTES ANTERIORES ATACADOS PELA CARIE, SEGUNDO A IDADE E A EPOCA DO LEVANTAMEN TO, NO ESTADO DE SÃO PAULO, $1980-82$.

\begin{tabular}{ccc}
\hline & & $\overline{\mathrm{CPO}}$ \\
\cline { 2 - 3 } Idades & 1980 & 1982 \\
\hline 7 & 0,07 & 0,08 \\
9 & 0,19 & 0,18 \\
10 & 0,44 & 0,44 \\
11 & 0,75 & 0,73 \\
12 & 1,07 & 1,04 \\
13 & 1,32 & 1,27 \\
14 & 1,57 & 1,48 \\
\hline
\end{tabular}


Analisando O CPO mëdio e componentes dos den tes anteriones nas Tabelas 64 e 65, yerificamos que as ex trações sô oconrem a pantin dos Il anos de idade.

TABELA 64 - CPO MEDIO E COMPONENTES DOS DENTES ANTERIORES, SEgUndo A IDADE, NO ESTAdO DE SÃO PAULO EM 1980.

\begin{tabular}{cccccc}
\hline Idades & $\overline{\mathrm{C}}$ & $\overline{\mathrm{O}}$ & $\overline{\mathrm{E}}$ & $\overline{\mathrm{EI}}$ & $\overline{\overline{\mathrm{C}} \overline{0}}$ \\
\hline 7 & 0,06 & 0,01 & 0,00 & 0,00 & 0,07 \\
8 & 0,17 & 0,02 & 0,00 & 0,00 & 0,19 \\
10 & 0,38 & 0,06 & 0,00 & 0,00 & 0,44 \\
11 & 0,61 & 0,13 & 0,00 & 0,01 & 0,75 \\
12 & 0,82 & 0,23 & 0,01 & 0,01 & 1,07 \\
13 & 0,93 & 0,35 & 0,02 & 0,02 & 1,32 \\
14 & 0,96 & 0,55 & 0,03 & 0,03 & 1,57 \\
\hline
\end{tabular}


TABELLA 65 - CRO MEDIO E COMPONENTES DOS DENTES ANTERIORES, SEGUNDO A IDADE, NO ESTADO DE SÃO PAULO EM 1982.

\begin{tabular}{cccccc}
\hline Idades & $\bar{C}$ & $\overline{0}$ & $\overline{\mathrm{E}}$ & $\overline{\mathrm{EI}}$ & $\overline{\mathrm{CPO}}$ \\
\hline 7 & 0,04 & 0,01 & 0,00 & 0,03 & 0,08 \\
9 & 0,14 & 0,02 & 0,00 & 0,02 & 0,18 \\
10 & 0,35 & 0,06 & 0,00 & 0,03 & 0,44 \\
11 & 0,56 & 0,14 & 0,00 & 0,03 & 0,73 \\
12 & 0,77 & 0,22 & 0,01 & 0,04 & 1,04 \\
13 & 0,88 & 0,33 & 0,02 & 0,04 & 1,27 \\
14 & 0,92 & 0,48 & 0,03 & 0,05 & 1,48 \\
& 0,94 & 0,67 & 0,05 & 0,08 & 1,74 \\
\hline
\end{tabular}

Sabe-se que as cáries que ocorrem nos dentes anteriores são, na quase totalidade, cāries de superficies lisas. Pela prevenção pode-se obter uma significativa redu ção do ataque de cárie nesses dentes; fato concreto dessa possibilidade encontra apoio na fluoretação da água de abas tecimento público, como pode ser verificado no estudo de Brantford-Sarnia, BROWJ e col. (1956), no qual após 15 anos de fluoretação foi observada uma redução de $92,69 \%$ na ocorrên 
cia de cäries em incisivos superiones, nas crianças com 9 a 11 anos de idade, enquanto de 12 a 14 anos ocorneu nos mes mos dentes uma redução de $84,70 \%$. Resultados significativos foram também obtidos por AXELSSON e LINDHE (1975) através de programas de controle da placa bacteriana dental e uso lo cal de flúor.

Nas Tabelas 64 e 65 podemos ainda notar que 0 componente $\mathrm{C}$ (cariado) è sempre maior do que o componente 0 (obturado), o que demonstra falhas no atendimento odontoló gico, pois essas cāries ocorrem quando a criança já está na escola e, portanto, sob os cuidados do óngão prestador do serviço.

A participação dos dentes anteriores em rela ção ao total do Indice CPO pode ser observada na Tabela 66. TABELA 66 - PERCENTUAL DE PARTICIPAÇÃO DOS DENTES ANTERIO RES EM RELAÇÃO AO CPO MEDIO, SEGUNDO A IDADE E A EPOCA DO LEVANTAMENTO, NO ESTADO DE SÃO PAU LO, $1980-82$.

\begin{tabular}{ccc}
\hline & \multicolumn{2}{c}{ Epoca do Levantamento } \\
\cline { 2 - 3 } Idades & 1980 & 1982 \\
\hline 7 & $3,03 \%$ & $3,32 \%$ \\
8 & $6,01 \%$ & $5,64 \%$ \\
9 & $11,39 \%$ & $11,17 \%$ \\
10 & $15,69 \%$ & $15,11 \%$ \\
11 & $17,80 \%$ & $17,39 \%$ \\
12 & $18,23 \%$ & $17,79 \%$ \\
13 & $18,36 \%$ & $17,81 \%$ \\
\hline
\end{tabular}


A mêdia ponderada do grupo etảrio de 7 a 14 anos é de 13,28\% do total do indice em 1980 e 12,87\% em 1982, - que permite estimar em $13 \%$ as necessidades de mate rial de restauração para dentes anteriores e $87 \%$ dos recur sos, tratando-se de gerência de serviços odontolögicos, des tinar-se-á a materiais de restauração para dentes posterio res e material para tratamento emergencial.

Resultados semelhantes foram apresentados pe la regional de Minas Gerais da FSESP em 1985.* Foram res taurados 16,253 dentes permanentes com amálgama e 2.496 com cimento de silicato, totalizando 18.749 dentes restaurados, - que demonstra e confirma que a participação dos dentes an teriores no total das restaurações está em tomo de $13 \%$.

Na Tabela 67 podemos analisar a ocorrência de cárie nos dentes posteriores.

* Relatónio anual de atividades da regional de Minas Gerais, ESESP, 1985. 
TABELA 67 - CPO MEDIO E COMPONENTES DOS DENTES POSTERIORES, SEGUNDO A IDADE E A EPOCA DO LEVAN TAMENTO, NO ESTADO DE SÃO PAULO.

\begin{tabular}{|c|c|c|c|c|c|c|c|c|c|c|}
\hline \multirow{3}{*}{ Idades } & \multicolumn{5}{|c|}{$\begin{array}{llll}1 & 9 & 8 & 0\end{array}$} & \multicolumn{3}{|c|}{$\begin{array}{llll}1 & 9 & 8 & 2\end{array}$} & & \multirow{3}{*}{$\overline{\mathrm{CPO}}$} \\
\hline & \multirow[b]{2}{*}{$\bar{C}$} & Componentes & do & $\mathrm{CPO}$ & \multirow{2}{*}{$\overline{\mathrm{CPO}}$} & \multicolumn{4}{|c|}{ Comporientes do CPO } & \\
\hline & & $\overline{0}$ & $\bar{E}$ & $\overline{E I}$ & & $\bar{c}$ & $\overline{0}$ & $\bar{E}$ & $\overline{E I}$ & \\
\hline 7 & 1,93 & 0,22 & 0,01 & 0,09 & 2,25 & 2,01 & 0,22 & 0,02 & 0,09 & 2,34 \\
\hline 8 & 1,79 & 0,96 & 0,06 & 0,16 & 2,97 & 1,65 & 1,14 & 0,06 & 0,15 & 3,00 \\
\hline 9 & 1,71 & 1,34 & 0,13 & 0,24 & 3,42 & 1,67 & 1,46 & 0,13 & 0,24 & 3,50 \\
\hline 10 & 1,93 & 1,59 & 0,21 & 0,30 & 4,03 & 1,90 & 1,64 & 0,22 & 0,33 & 4,09 \\
\hline 11 & 2,34 & 1,92 & 0,30 & 0,37 & 4,93 & 2,39 & 1,82 & 0,33 & 0,40 & 4,94 \\
\hline 12 & 2,77 & 2,37 & 0,39 & 0,39 & 5,92 & 2,80 & 2,19 & 0,44 & 0,43 & 5,86 \\
\hline 13 & 2,98 & 3,09 & 0,50 & 0,39 & 6,96 & 3,12 & 2,72 & 0,53 & 0,46 & 6,83 \\
\hline 14 & 3,00 & 3,87 & 0,60 & 0,41 & 7,88 & 3,17 & 3,47 & 0,64 & 0,49 & 7,77 \\
\hline
\end{tabular}


Cumpre salientar que os componentes C+EI que representam as necessidades de tratamento, são sempre maio. res do que $50 \%$ do total do Índice evidenciando ineficiência no atendimento.

Nas Figuras 8 e 9 podemos observar o CPO mé dio dos quadrantes:

$$
\begin{aligned}
& \text { superion direito } \\
& \text { superior esquerdo } \\
& \text { inferior direito } \\
& \text { inferior esquerdo }
\end{aligned}
$$

FIGURA 8 - CPO MEDIO SEGUNDO A IDADE E O QUADRANTE NO ESTADO DE SÃO PAULO, EM 1980

QUADRANTE

QUADRANTE

SUPERIOR

SUPERIOR

DIREITO

ESQUERDO

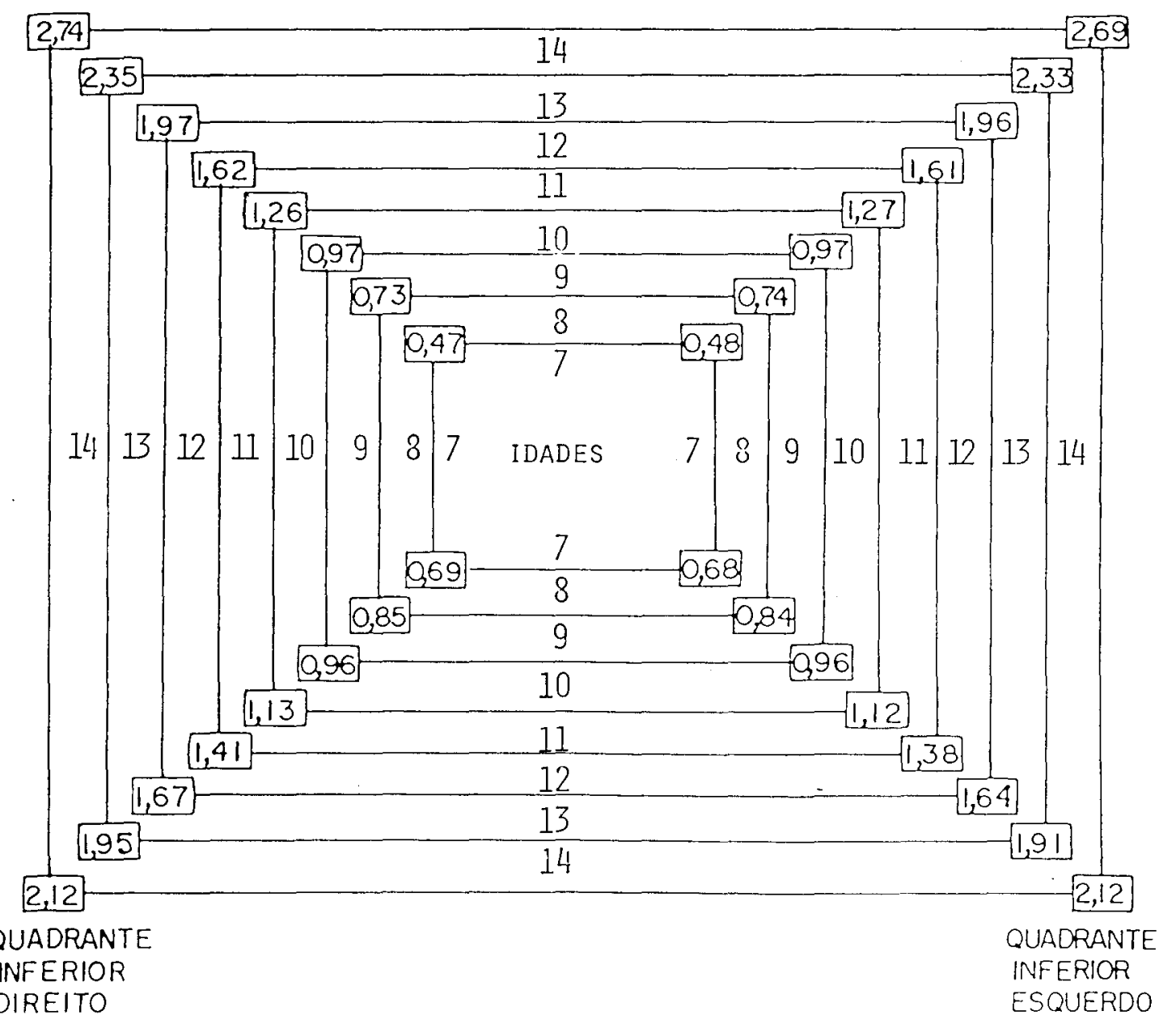


FIGURA 9 - CPO MEDIO SEGUNDO A IDADE E O QUADRANTE NO ESTA DO DE SÃO PAULO EM 1982.

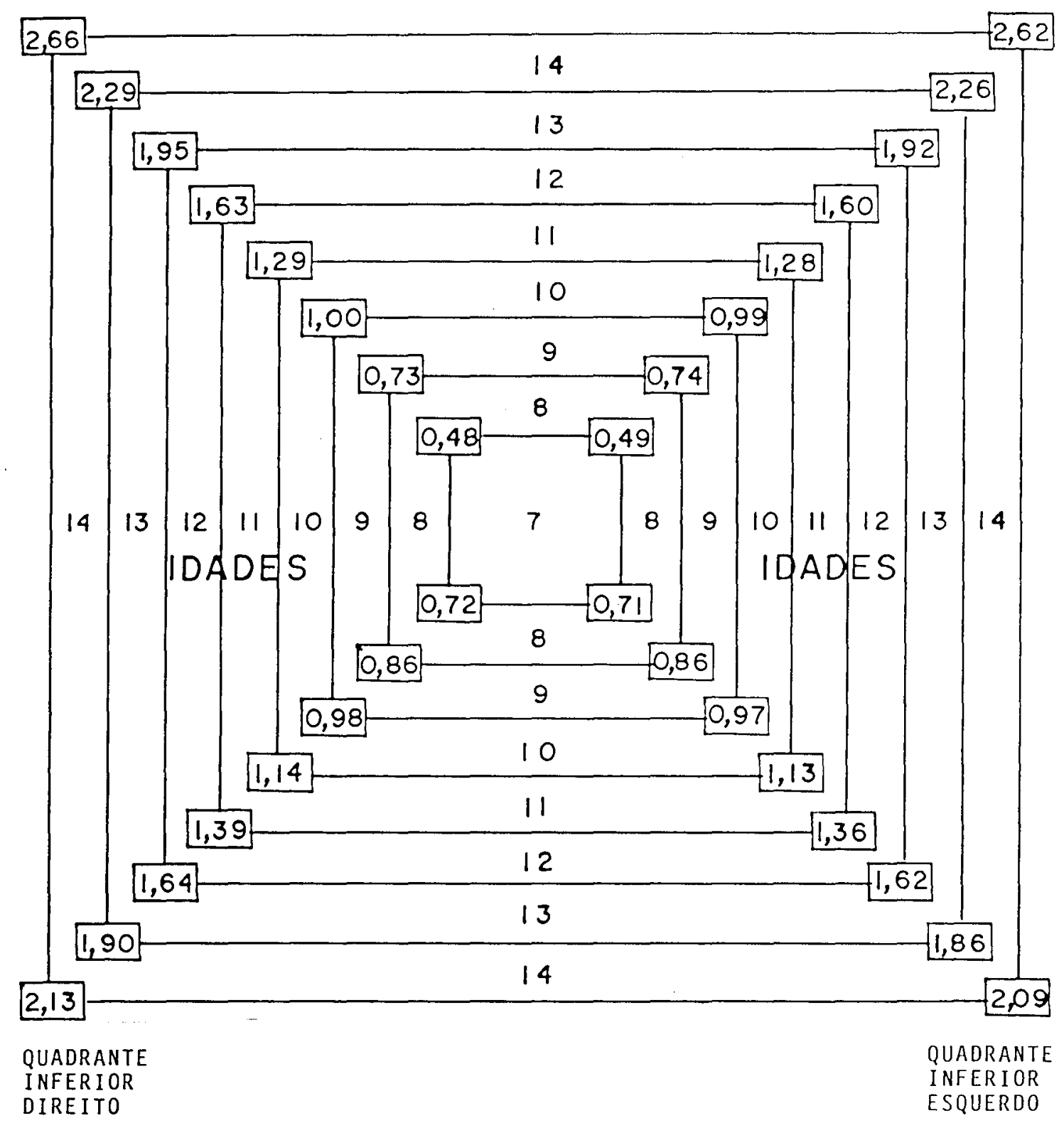


Podemos observar nas Figuras 8 e 9 que a ocor rência de cárie nos quadrantes direito e esquerdo é similar, tanto nos superiores como nos inferiores, confirmando o que jā foi assinalado anteriormente de que a ocorrência de cá rie $\vec{e}$ bilateral.

Para fins administrativos a Secretaria da Edu cação em 1980 e 1982 estava dividida em duas grandes áreas: Região Metropolitana de São Paulo e Interior. A primeina era composta de 3 Regionais no município de São Paulo e mais 4 a saber: Norte, Sul, Leste e Oeste, com sedes respec tivamente em: Guarulhos, Santo André, Mogi das Cruzes e Osasco. No Interion existiam 11 Regionais de Ensino: Lito ral, Vale do Paraíba, Sorocaba, Campinas, Ribeirão Preto, Bauru, São José do Rio Preto, Araçatuba, Presidente Pruden te, Marília e Vale do Ribeira.

Os resultados dos 2 levantamentos em relação à Região Metropolitana de São Paulo e Interior podem ser analisados nas Tabelas 68, 69, 70 e 71 .

Os resultados dos 2 levantamentos em relação às Regionais de Educação da Região Metropolitana de São Pau lo e do Interior podem ser analisados nos quadros constan tes dos Anexos 2 a 33. 
TABELA 68 - NUMERO DE ESCOLARES EXAMINADOS, CPO MEDIO, COMPONENTES, NECESSIDADES DE TRATAMEN TO, SERVIÇOS EXECUTADOS E DESVIO PADRÃO, SEGUNDO A IDADE, NA REGIÃO METROPOLITANA DE SÃo PAULO, EM 1980.

\begin{tabular}{|c|c|c|c|c|c|c|c|c|c|}
\hline Idades & $\begin{array}{l}\text { Nümero de } \\
\text { Escolares } \\
\text { Examinados }\end{array}$ & $\bar{c}$ & $\overline{0}$ & $\bar{E}$ & $\overline{E I}$ & $\overline{\mathrm{C}+E \bar{I}}$ & $\overline{O+E}$ & $\overline{C P O}$ & $\begin{array}{l}\text { Desvio } \\
\text { Padrão }\end{array}$ \\
\hline 7 & 9.135 & 1,87 & 0,21 & 0,02 & 0,09 & 1,96 & 0,23 & 2,19 & 1,64 \\
\hline 8 & 9.561 & 2,01 & 0,81 & 0,06 & 0,17 & 2,18 & 0,87 & 3,05 & 1,72 \\
\hline 9 & 9.577 & 2,20 & 1,17 & 0,14 & 0,26 & 2,46 & 1,31 & 3,77 & 2,20 \\
\hline 10 & 9.659 & 2,58 & 1,42 & 0,20 & 0,32 & 2,90 & 1,62 & 4,52 & 2,81 \\
\hline 11 & 9.224 & 3,27 & 1,69 & 0,29 & 0,40 & 3,67 & 1,98 & 5,65 & 3,67 \\
\hline 12 & 8.433 & 3,88 & 2,09 & 0,39 & 0,45 & 4,33 & 2,48 & 6,81 & 4,17 \\
\hline 13 & 7.413 & 4,29 & 2,77 & 0,49 & 0,51 & 4,80 & 3,26 & 8.06 & 4,55 \\
\hline 14 & 5.779 & 4,31 & 3,68 & 0,62 & 0,52 & 4,83 & 4,30 & 9,13 & 4,82 \\
\hline
\end{tabular}


TABELA 69 - NUMERO DE ESCOLARES EXAMINADOS, CPO MEDIO, COMPONENTES, NECESSIDADES DE TRATAMEN TO; SERVIÇOS EXECUTADOS E DESVIO PADRÃO, SEGUNDO A IDADE, NA. REGIAO METROPOLITANA DE SAO PAULO, EM 1982 .

\begin{tabular}{|c|c|c|c|c|c|c|c|c|c|}
\hline Idades & $\begin{array}{l}\text { Nümero de } \\
\text { Escolares } \\
\text { Exa minados }\end{array}$ & $\overline{\mathrm{C}}$ & $\overline{0}$ & $\overline{\mathrm{E}}$ & $\overline{E I}$ & $\overline{C+E I}$ & $\overline{O+E}$ & $\overline{\mathrm{CPO}}$ & $\begin{array}{l}\text { Desvio } \\
\text { Padrão }\end{array}$ \\
\hline 7 & 6.073 & 1,86 & 0,17 & 0,02 & 0,10 & 1,96 & 0,19 & 2,15 & 1,57 \\
\hline 8 & 6.379 & 1,67 & 1,05 & 0,07 & 0,15 & 1,82 & 1,12 & 2,94 & 1,56 \\
\hline 9 & 6.330 & 1,80 & 1,37 & 0,13 & 0,23 & 2,03 & 1,50 & 3,53 & 1,88 \\
\hline 10 & 6.278 & 2,21 & 1,57 & 0,22 & 0,32 & 2,53 & 1,79 & 4,32 & 2,49 \\
\hline 11 & 6.039 & 2,90 & 1,69 & 0,30 & 0,44 & 3,34 & 1,99 & 5,33 & 3,33 \\
\hline 12 & 5.489 & 3,52 & 1,97 & 0,44 & 0,48 & 4,00 & 2,41 & 6,41 & 3,89 \\
\hline 13 & 4.665 & 3,93 & 2,42 & 0,53 & 0,51 & 4,44 & 2,95 & 7,39 & 4,41 \\
\hline 14 & 3.647 & 4,02 & 3,32 & 0,65 & 0,55 & 4,57 & 3,97 & 8,54 & 4,79 \\
\hline
\end{tabular}


TABELA 70 - NUMERO DE ESCOLARES EXAMINADOS, CPO MEDIO, COMPONENTES, NECESSIDADES DE TRATAMEN TO, SERVIÇOS EXECUTADOS E DESVIO PADRAO, SEGUNDO A IDADE, NO INTERIOR, EM 1980.

\begin{tabular}{|c|c|c|c|c|c|c|c|c|c|}
\hline Idades & $\begin{array}{l}\text { Nümero de } \\
\text { Escolares } \\
\text { Examinados }\end{array}$ & $\bar{c}$ & $\overline{0}$ & $\bar{\Sigma}$ & $\overline{\mathrm{EI}}$ & $\overline{C+E I}$ & $\overline{O+E}$ & $\overline{\mathrm{CPO}}$ & $\begin{array}{l}\text { Desvio } \\
\text { Padrão }\end{array}$ \\
\hline 7 & 26.883 & 2,02 & 0,23 & 0,02 & 0,09 & 2,11 & 0,25 & 2,36 & 1,68 \\
\hline 8 & 26.999 & 1,94 & 1,04 & 0,06 & 0,16 & 2,10 & 1,10 & 3,20 & 1,73 \\
\hline 9 & 27.319 & 2,05 & 1,48 & 0,12 & 0,24 & 2,29 & 1,60 & 3,89 & 2,17 \\
\hline 10 & 27.372 & 2,53 & 1,82 & 0,22 & 0,30 & 2,83 & 2,04 & 4,87 & 2,99 \\
\hline 11 & 26.494 & 3,12 & $2,3 I$ & 0,32 & 0,38 & 3,50 & 2,63 & 6,13 & 3,81 \\
\hline 12 & 25.252 & 3,63 & 2,93 & 0,42 & 0,40 & 4,03 & 3,35 & 7,38 & 4,38 \\
\hline 13 & $23 \quad 087$ & 3,83 & 3,92 & 0,55 & 0,40 & 4,23 & 4,47 & 8,70 & 4,76 \\
\hline 14 & 18.549 & 3,90 & 4,92 & 0,66 & 0,43 & 4,33 & 5,58 & 9,91 & 5,03 \\
\hline
\end{tabular}


TABELA 71 - NOMERO DE ESCOLARES EXAMINADOS, CPO MEDIO, COMPONENTES, NECESSIDADES DE TRATAMEN TO, SERVIÇOS EXECUTADOS E DESVIO PADRÃO, SEGUNDO A IDADE, NO INTERIOR, EM 1982.

\begin{tabular}{|c|c|c|c|c|c|c|c|c|c|}
\hline Idades & $\begin{array}{l}\text { Número de } \\
\text { Escolares } \\
\text { Examinados }\end{array}$ & $\overline{\mathrm{C}}$ & $\sigma$ & $\bar{E}$ & $\overline{E I}$ & $\overline{C+E I}$ & $\overline{\mathrm{O}+\mathrm{E}}$ & $\overline{\mathrm{CPO}}$ & $\begin{array}{l}\text { Desvio } \\
\text { Padrão }\end{array}$ \\
\hline 7 & 13.663 & 2.13 & 0,24 & 0,02 & 0,13 & 2,26 & 0,26 & 2,52 & 1,77 \\
\hline 8 & 13.466 & 1,85 & 1,21 & 0,06 & 0,19 & 2,04 & 1,27 & 3,31 & 1,74 \\
\hline 9 & 13.492 & 2,13 & 1,59 & 0,13 & 0,29 & 2,42 & 1,72 & 4,14 & 2,36 \\
\hline 10 & 13.476 & 2,57 & 1,88 & 0,23 & 0,38 & 2,95 & 2,11 & 5,06 & 3,14 \\
\hline 11 & 13.190 & 3,28 & 2,20 & 0,35 & 0,44 & 3,72 & 2,55 & 6,27 & 3,86 \\
\hline 12 & 12.477 & 3,76 & 2,76 & 0,46 & 0,48 & 4,24 & 3,16 & 7,46 & 4,48 \\
\hline 13 & 10.907 & 4,09 & 3,54 & 0,57 & 0,51 & 4,60 & 4,11 & 8,71 & 4,94 \\
\hline 14 & 8.909 & 4,14 & 4,47 & 0,72 & 0,58 & 4,72 & 5,19 & 9,91 & 5,24 \\
\hline
\end{tabular}


Analisando os resultados dos leyantamentos epi demiológicos de cárie dental realizados em 1980 e 1982, pode mos notar que as necessidades de tratamento são maiores na Região Metropolitana de São Paulo do que no Interior, embora a prevalência de cârie seja maion no Interion. Isto indica que o tratamento odontológico de um modo geral apresenta maior rendimento no Interior. Tal fato a nosso ver pode ser explicado pela maior exigência que os Diretores de escola do Interior fazem, quanto ao cumprimento do horário de trabalho dos Cirurgiões Dentistas, Quanto ao programa preventivo que vem sendo executado atravês de bochechos fluorados, os resul tados de 1980 e 1982 apresentam apenas uma diferença de 7 centêsimos. Im 1980 ○ CPO mëdio ponderado do grupo etärio de 7 a 14 anos foi 5,44 e em 1982 foi 5,37 .

Não ê demais insistir que para o controle efe tivo da situação, o programa curativo isolado sem o suporte de programas preventivos é ineficaz, como comprova entre ou tros estudos o que foi realizado no sri lanka após a implan tação de um sistema püblico de atendimento a escolares, uti lizando pessoal auxiliar, tipo enfermeira da Nova Zelândia. AMARATUNGE e colaboradores (1980) constataram após 16 anos da implantação do programa, que as necessidades de tratamen to aumentavam sempre, principalmente após os 12 anos de ida de, tornando os recursos disponiveis sempre insuficientes pa ra $\circ$ atendimento total da demanda. 
Nas figuras 10 e 11 podemos obsenvar o CPO e componentes cujo comportamento é similar em 1980 e 1982.

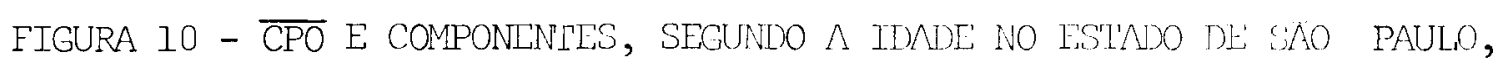
EM 1980 .

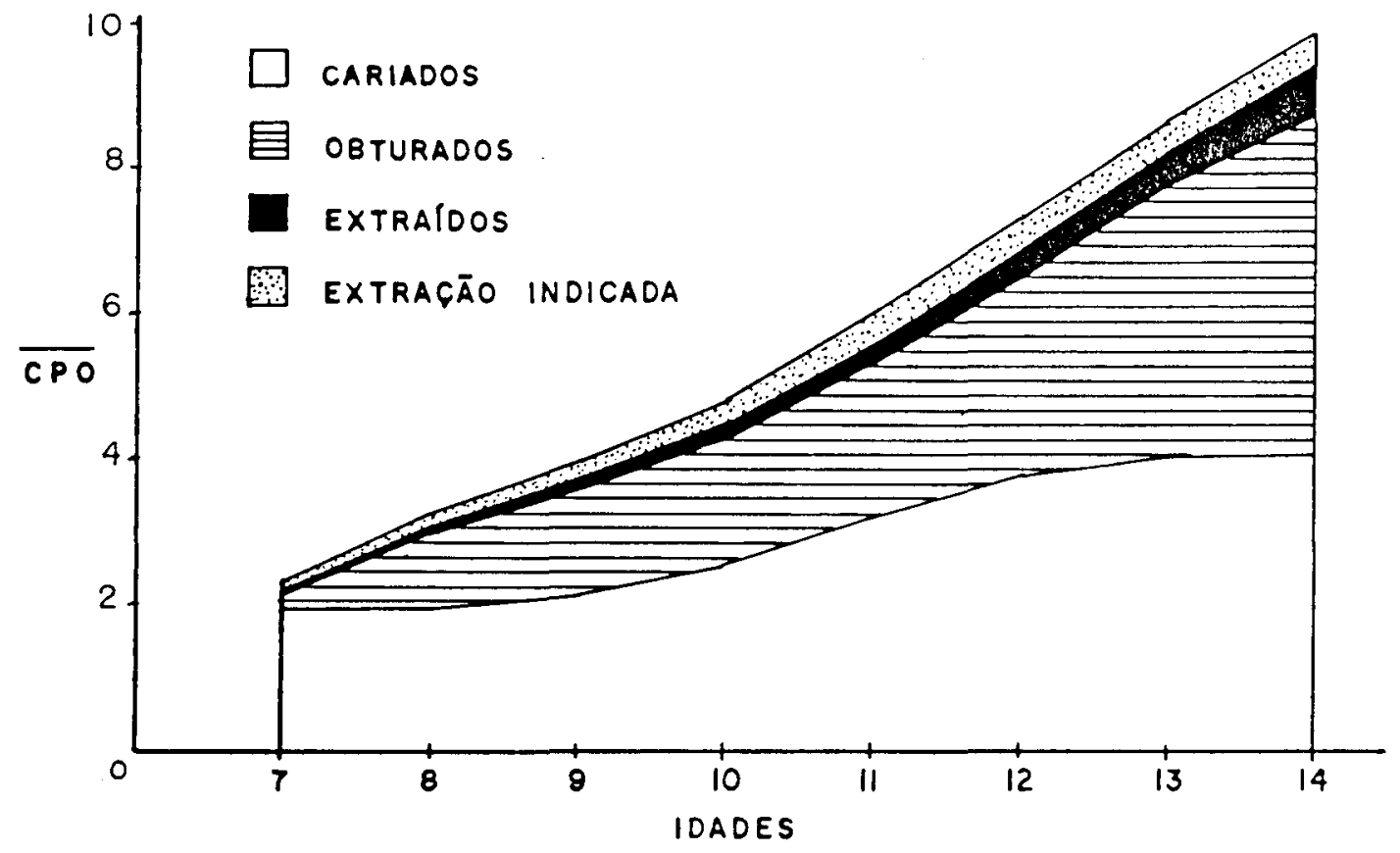

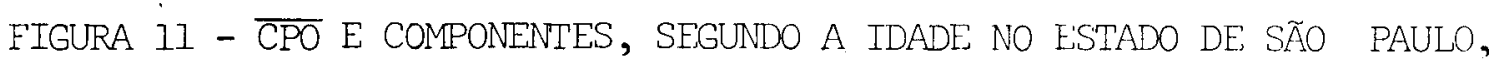

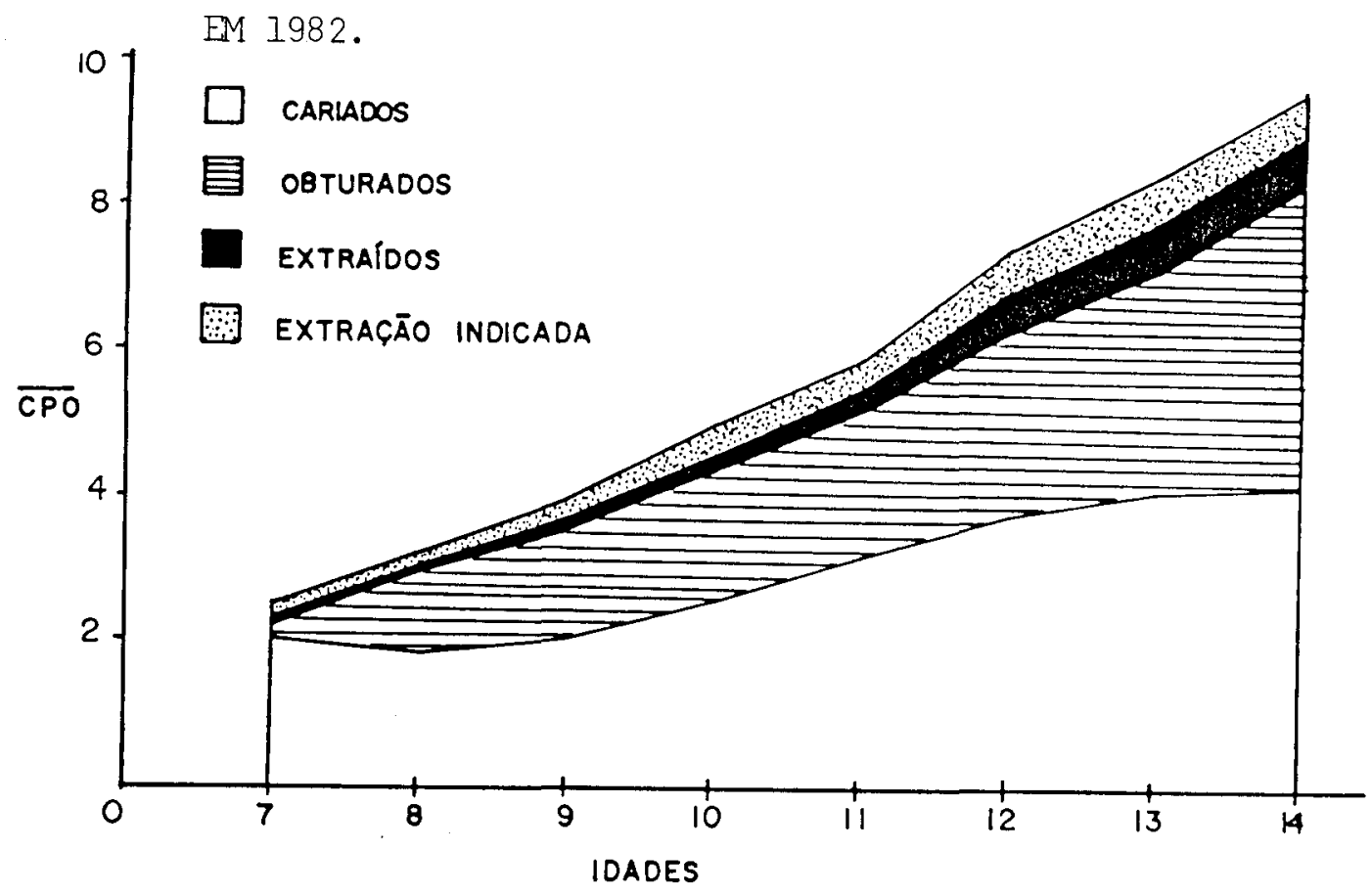


Na Tabela 72 podemos obseryar o CPO mëdio pon derado do grupo etärio de 7 a 14 anos segundo as Divisões Regionais de Ensino (DRE).

TABELA 72 - CPO MEDIO DO GRUPO ETARIO DE 7 A 14 ANOS DA RE GIÃO METROPOLITANA DE SÃO PAULO E DO INTERIOR, SEGUNDO AS DIVISOES REGIONAIS DE ENSINO, NO ES TADO DE SÃO PAULO EM 1980 E 1982.

\begin{tabular}{|c|c|c|c|}
\hline \multirow{2}{*}{\multicolumn{2}{|c|}{ Regionais de Ensino }} & \multicolumn{2}{|c|}{$\overline{\mathrm{CPO}}$} \\
\hline & & 1980 & 1982 \\
\hline \multicolumn{2}{|c|}{ São Paulo (DRE Cap* I, II, III) } & 5,17 & 4,90 \\
\hline \multicolumn{2}{|c|}{ DRE Osasco } & 5,08 & 4,50 \\
\hline DRE & Guarulhos & 4,48 & 4,70 \\
\hline DRE & Santo André & 4,81 & 4,60 \\
\hline DRE & Mogi das Cruzes & 5,78 & 4,43 \\
\hline \multicolumn{2}{|c|}{ Reg.Metropolitana de São Paulo } & 5,09 & 4,77 \\
\hline DRE & Litoral & 4,60 & 4,65 \\
\hline DRE & Vale do Paraíba & 5,71 & 5,75 \\
\hline DRE & Sorocaba & 5,57 & 6,06 \\
\hline DRE & Campinas & 5,16 & 5,17 \\
\hline DRE & Ribeirão Preto & 5,74 & 6,04 \\
\hline DRE & Bauru & 5,85 & 4,91 \\
\hline DRE & São José do Rio Preto & 5,42 & 5,33 \\
\hline DRE & Araçatuba & 6,30 & 6,81 \\
\hline DRE & Presidente Prudente & 5,42 & 5,82 \\
\hline DRE & Marilia & 6,13 & 5,82 \\
\hline DRE & Vale do Ribeira & 6,39 & 5,81 \\
\hline Inter & rion & 5,55 & 5,64 \\
\hline
\end{tabular}

* DRE - Cap = Divisão Regional de Ensino da Capital. 
Ao finalizar este capitulo onde assinalamos as observaçōes relacionadas às caracteristicas epidemiológi cas da cârie dental, na dentição permanente de escolares de 7 a 14 anos no Estado de São Paulo e também algumas conside rações do ponto de vista da administração de serviços de as sistência odontolögica, cumpre ressaltar a necessidade de levantamentos periódicos da prevalência da cárie dental, a fim de que possa ser avaliado o impacto dos programas im plantados, preventivos e curativos. Por outro lado os levan tamentos epidemiológicos mesmo que sejam feitos apenas para estimar as necessidades de tratamento (C+EI), constituem 0 meio mais correto para um planejamento eficiente e obtenção de padrões para avaliação de desempenho individual. Sob o ponto de vista administrativo, por exemplo, os levantamen tos de massa realizados em 1980 e 1982 revelaram que as ne cessidades de tratamento para o grupo etário de 7 a 14 anos,

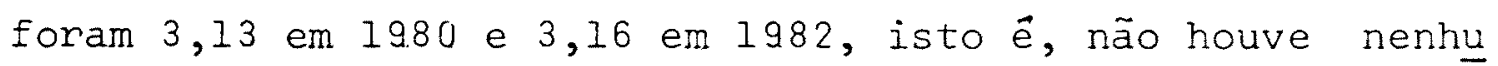
ma melhora na execução dos programas, embora tenham sido realizados esforços nesse sentido. 


\section{CQNCLUSÕES}

5.1. Os valores do CPO médio para o grupo etário de 7 a 14 anos foram $5,44 \mathrm{em} 1980 \mathrm{e} 5,37 \mathrm{em} \mathrm{1982,} \mathrm{sig}$ nificando uma diferença de apenas 0,07 .

5.2. O componente cariado do grupo etärio de 7 a 14 anos foi $52,20 \%$ do total do indice em $1980 \mathrm{e}$ $52,32 \%$ do total do indice em 1982 .

5.3. O nümero mẻdio dentes perdidos (extraídos + ex tração indicada) foi $0,53 \mathrm{em} 1980$ e 0,63 em 1982, significando respectivamente $10,29 \%$ e $11,37 \%$ do total de dentes atacados pela cárie.

5.4. O CPO médio aos doze anos de idade foi 7,24 em 1980 e 7,13 em 1982, sendo, portanto, mais do que o dobro da meta prevista pela organização Mundial de Saúde para o ano 2.000 - não mais do que $3 \mathrm{CPO}_{12}$.

5.5. O sexo feminino apresentou valores de CPO sempre maiones do que o sexo masculino, na mesma idade cronológica.

5.6. Nos dois levantamentos, aos 7 anos de idade mais da metade dos primeiros molares permanentes já 
está atacada pela cârie.

5.7. Aos 14 anos, 43\% dos individuos apresentam os 4 primeiros molanes atacados pela cärie e os $57 \%$ restantes está com 75\% dos primeiros molares ata cados pela cảrie.

5.8. O ataque de cârie é bilateral pois os valores CPO para os lados direito e esquerdo são semelhantes nos dois levantamentos.

5.9. Os valores do CPO são menores nos dentes inferio res, excetuando as idades de 7 e 8 anos, nos dois levantamentos,

5.10. A análise dos valores do CPO nos quadrantes em 1980 e 1982 evidencia a bilateralidade da ocor rência de cárie.

5.11. Os valores do Indice CPO são menores na Região Metropolitana de são Paulo nos dois levantamen tos.

5.12. As necessidades de tratamento são maiores na Re gião Metropolitana de são Paulo do que no Interior, em 1980 e 1982. 
6. REFERENCIAS BIBLIOGRĀFICAS

ADENUBI, J.O. Caries experience of 8-year old Nigerian schoolchildren. Community Dent. oral Epidem., 12: 343 $-8,1984$.

AINAMIO, J. \& HOLMBERG, S. A retrospective longitudinal study of caries prevalence during and 7 years after free dental care at school in Finland. Community Dent.oral Epidem., 1: $30-6,1973$.

ALCAIDE, A.L. \& VERONEZI, O. Prevalência de fluorose denta]. na cidade de Icem, SP, Icem, Prefeitura Municipal, 1977.

AMARATUNGE, A. et al. Dental caries in a group of school children in Kandy, Sri Lanka. Acta odont. scand., 38: $263-8,1980$.

ANDERSON, R.J. et al. The reduction of dental caries pre valence in english schoolchildren. J.dent. Res., 6I: $1311-6,1982$.

ATALLAH, A.S.M. Inquérito epidemiológico da cárie dentā ria em escolares da cidade de Porto Velho, Território Feảeral de Rondōnia; relatónio final. Porto Velho, s. d. Mimeograiado] 
AXELSSON, P. \& LINDHE, J. Effect of fluoride on gingivitis and dental caries in a preventive program based on pla que control. Community Dent. oral Epidem., 3: 156-60, 1975.

BAGRAMIAN, R.A. \& RUSSELL, A.L. An epidemiologic study of dental caries in race and geographic area. J.dent. Res., 50: $1553-6,1971$.

BATALHA, B.L. Binomio fluoretação da āgua e cárie dentā ria. Engenharia, 448: 26-40, 1984.

BENTZ, R.A. Oral pathology in the Dominican Republic: a brief account of the commonest diseases. Int. dent.J., 15: $326-30,1965$.

BERTRAM, F.P. Phenomenon of bilateral dental caries: a statistical analysis. J.Amer.dent.Ass., 30: 1392 - 5, 1943 .

BESTEN, (1894). Sitzungsberichte der physical - medecin Gessellschaft. apud FINN, S.B. Prevalence of dental caries. In: TOVERUD, G. et al. A survey of the literature of dental caries. Washington, DC., National Academy of Sciences/National Research Council, 1952. p. $117-73$. 
BILLITER, C. (1901). Berichte uber Untersuchungen an Schulkindern Schaffhausens. apud FINN, S.B. Pre valence of dental caries. In: TOVERUD, G. et al. $\underline{A}$ survey of the literature of dental caries. Washington, DC, National Academy of Sciences/National Research Council, 1952. p. $117-73$.

BOHANNAN, H.M. Caries distribution and the case for sealants. J. publ.HIth Dent., 43: 200-4, 1983.

BRITSH DENTAL ASSOCIATION. Reports of the school communi ties of the British Dental Association on the condition of the teeth of schoolchildren. apud FINN, S.B. Pre valence of dental caries. In: TOVERUD, G. et al. A survey of the literature of dental caries. Washington, DC, National Academy of Sciences/National Research Council, 1952. P.117-73.

BROWN, H.K. et al. The Brantford--Sarnia-Stratford fluoridatiom caries study. Canad. dent. Ass. J., 22: 207-16, 1956.

BROWN, R.H. Evidence of decrease in the prevalence of dental caries in New Zealand. J.dent. Res., 61: 1327 $-30,1982$.

BRUCKNER, R.J. et al. A study of dental caries prevalence in schoolchildren. J. dent. Res., 30: 464, 1954. 
BUTTNER, M. \& KOHL, L. Epidémiologie de la carie dentaire parmi les écoliens liégeois ages de 7 a 12 ans. Rev. helg. Méd. Dent., 39: 119-23, 1984 .

CAMPANELLA, S. \& CICIARELLI, J.R.R. Análise dos dados de prevalência da cárie dental na cidade de Guaíra, SP, Bra sil, em 1710 escolares de ambos os sexos, segundo a ida de. Guaira, Prefeitura Municipal, 1975.

CAMPATELLI, V. La carie dentaria nell'infonzia. apud FINN, S.B. Prevalence of dental caries. In:TOVERUD, G. et al. A survey of the literature of dental caries. Washington, DC, National Academy of Sciences/ National Research Council, 1952. P. 117-73.

CARR, L.M. Dental health of children in Australia 1977-1982. Aust dent. J., 28: 269-76, 1983.

CASTRO, O. L. \& ALBUQUERQUE, A.J. Levantamento epidemioIógico de cárie dentária em bairro da cidade de Natal, RN. Natal, Editora Universitária, 1974.

CHUNG, C.S. et al. Genetic and epidmiologic studies of oral chanacteristics in Hawai's schoolchildren. I.. Caries and periodontal disease. J. dent. Res., 49: $1374-85,1970$. 
CONSELHO CONSULTIVO DA ADMINISTRAÇÃO DE SAUDE PREVIDENCIĀ RIA (CONASP). Assistência odontológica no âmbito da previdência social: anālise e proposta de reorienta ção. Brasilita, 1983. [Mimeografado]

CUNNINGHAM, G. Experience of a school dental clinic: Cambridge dental institute. apud FINN, S.B. Preva lence of dental caries. In: TOVERUD, G. et al. A survey of the literature of dental caries. Washington, DC, National Academy of Sciences/National Research Council, 1952. P. 117-73.

DE JONG, N. \& DUNNING, J.M. Bilateral symetry of dental restorations in a dental care program. J.pubi. Hith Dent., 3I: 251-5, 1971.

DINIZ, J. \& CARDOSO, J.S. Estudo comparativo dos efei tos da fluoretação artificial da ägua de abastecimento público entre as cidades de Juazeiro (BA) e Petrolina (PE). Rev. Fund. SESP, 23: 71-6, 1978 .

FAGIONI, P. \& MARTINS, I.Z. Resultados de 5 anos de fluo retação das águas de abastecimento püblico na cidade de Garça, SP. Garça, Prefeitura Municipal, 1978.

FEDERATION DENTAIRE INTERNATIONALE. GIObal goals for oral health in the year 2.000. Int. dent. J., 32:74$-7,1982$. 
FEJERSKOV, 0 . et al. Decrease in caries experience in danish children and young adults in the 1970's. J. dent. Res., 61: 1305-16, 1982.

FENCHEL, A. (1893). Die karies frequenz der Zahne Hamburgischer kinder. apud FINN, S.B. Prevalence of dental caries. In: TOVERUD, G. et al. A survey of the literature of dental caries. Washington, DC, National Academy of Sciences/National Research Council, 1952. p. 117-73.

FINN, S.B. Prevalence of dental caries. In: TOVERUD, G. et al. A survey of the literature of dental caries. Washington, DC, National Academy of Sciences / National Research Council, 1952. P. 117-73.

FISCHMAN, S.L. Oral health in the Republic of Paraguay. Community Dent. oral Epidem., 2: 176-81, 1974.

FORATTINI, O.P. Epidemiologia geral. São Paulo, Ed. Edgard Blucher/Ed. USP, 1976.

FOSTER, L.W. Dental conditions in white and indian children in northern Winsconsin. J.Amer. dent. Ass., 29: $2251-6,1942$. 
FRANCI, G.B. Profilassi della carie dentaria. apud FINN, S.B. Prevalence of dental caries. In: TOVERUD, G. et al. A survey of the literature of dental caries. Washington, DC, National Academy of Sciences / National Research Council, 1952. p. 117-73.

FRANKEL, J.M. \& CHAVES, M.M. A utilização de um método sim ples de inquérito para avaliação da prevalência da cárie dentäria em 3.009 crianças brasileiras. Rev.bras.odont., 13: $84-105,1955$.

FREIRE, P.S. Primeiros resultados com a fluoretação de äguas no Brasil. Rev. Fund. SESP, 9: 327-40, 1957.

FREIRE, P.S. O problema da cârie dental no Brasil. Rev. Fund. SESP, 15: 89-97, 1970 .

FRICKE, (1900). Die Zahne der schulkinder in Schleswig -Holstein. apud FINN, S.B. Prevalence of dental caries. In: TOVERUD, G. et al. A survey of the literature of dental caries. Washington, DC, National Academy of Sciences/National Research Council, 1952. p. 117-73.

FUNDAÇÃO EDUCACIONAL DO DISTRITO FEDERAL. Prevalência da cárie dental em escolares de 6 a 12 anos, Projeto Saủde Bucal - PISE. Brasịlia, 1979. [Mimeografado] 
FUNDAÇÃO DE SAUDE AMAURY DE MEDEIROS. Coondenação de As sistência Odontológiaa - Inquêrito epidemiológico de cá rie dental em 826 escolares de 6 a 14 anos, na zona urba na e rural da cidade de Triunfo (PE). Recife, 1980. [Mimeografado]

GONZALEZ, F.O. et al. Estudio de la preválencia de la caries dental en escolares de Granada. Rev. San. Hig. publ., 58: 269-89, 1984 .

GREENE, J.C. \& SUOMI, J.D. Cárie e doença periodontal: as pectos epidemiológicos e de saúde públicá. Rev. bras. Odont., 35: 31-6, 1978 .

GUILHERMIN, V. (1895). Untersuchungen ... der Zahne von schulkinder. Schweiz. apud FINN, S.B. Prevalence of dental caries. In: TOVERUD, G. et al. A survey of the literature of dental caries. Washington, DC, $\mathrm{Na}$ tional Academy of Sciences/National Research Council, 1952. P. $117-73$.

HARVEY, C. \& KELLY, J.E. Decayed, missing, and filled teeth among persons $1-74$ years. Vital Hlth Stat. Ser. II, (223), 1981 . 
HAUSEN, $H$, et al, Caries frequency among 6-17 years-old participants of the finnish public dental care during 1975-79. Community Dent. oral Epidem., 11: 74 - 80, 1983.

HESSELGREN, K. \& THYSTRUP, A. Development in dental caries among children in 1961-79 in a danish community with school dental service. Community Dent. oral Epidem., 10: $276-81,1982$.

HOLST, D. Dental caries in schoolchildren in some danish communities with and without school dental service. Community Dent. oral Epidem., 3: 237-43, 1975.

HOUPT, M. et al. An epidemiologic study of tooth decay in Newark school children. J. New Jersey dent. Ass., 54: $64-9,1983$.

HUNTER, P.B.V. \& HENDERSON, M.B.N. The oral health of 8-and 9-year old children in Timaru e Oamaru. N.Z. dent. J., 38: 94,1982 .

HUNTER, P.B.Y. The preyalence of dental caries in 12-and 13 year old New Zealand children in 1977 and 1982. N. Z. dent. I., 80: 16-8, 1984 . 
INFIRRI, J,S, \& BARNES, D,E, Epidemiology of oral diseases: differences in national problems, Int. dent. J., 29: 183 $-90,1979$.

JARVINEN, S. Epidemiologic characteristics of dental caries: relation of DMFS to DMFT. Community Dent, oral Epidem. , 11: $363-6,1983$.

JONHSON, H. Estatística aplicada à odontologia. Ann arbor, University of Michigan, 1950. [Mimeografado]

KAALSBEEK, H. Evidence of decrease in prevalence of dental caries in the Netherlands: an evaluation of epidemiological caries surveys on $4-6$ and $11-15$ year-old children, performed between 1965 and 1980. J. dent. Res., 61: 1321-6, 1982.

KLEIN, H. \& PALMER, C.E. Dental caries in american indian clildren. Publ. Hlth Bull., (239): 1-53, 1937.

KNUTSON, J.W. Simplified procedure for the collection of basic data for planning appraisal. J.Amer. publ. Hlth Ass., $37: 1439,1947$.

KOCH, G. Evidence for declining caries prevalence in Sweden. J. dent. Res., 61: 1340-5, 1982. 
KOLEHMAINEN, L, Dental caries on different toot surfaces among 13-15 year old Helsinki schoolchildren. Porc. Finn. dent. Soc., 79: 107-14, 1983.

KROHN, C. Kinderzahnpflege. apud FINN, S.B. Prevalen ce of dental caries, In: TOVERUD, G. et al. A survey of the literature of dental caries. Washington, DC, National Academy of Sciences/National Research Council, 1952. p.117-73.

LEAVELL, H.R. \& CLARK, F.G. Preventive medicine for the doctor in his community: an epidemiologic approach. 2. ed., New York, Mc Graw-Hill, 1958.

LIND, P.O. \& LARSEN, M.J. apud THYSTRUP, A. et al. Ca ries prevalence in danish children living in areas with low and optimal levels of natural water fluoride. Caries Res., 16: 413-20, 1982.

MARTIN, B.V.M. Programa incremento de la atención estomatológica a escolares de primaria 1970-71 a 1979-80. Rev. cuba. Estomatol., 19: 237-46, 1982.

MORBIDITY AND MORTALITY WEEKLY REPORT. Atlanta, Ga., 34 : (6) 1985 . 
MOSHA, H.J. \& LANGEBAEK, J. Dental caries, oral hygiene, periodontal disease and dental fluorosis among school children in Northern Tanzania. Odontostmat. trop., 6 : $149-56,1983$.

ODENTHAL (1887) Kariose zahne als eingangspforte infectiosen materials und ursache chronischer lymphdrusen schwellungen am halse. apud FINN, S.B. Prevalence of dental caries. In: TOVERUD, G. et al. A survey of the literature of dental caries. Washington, DC, National Academy of Sciences/National Research Council,1952. P. 117-73.

O'MULLANE, D.M. The changing pattern's of dental caries in irish schoolchildren between 1961 and 1981 . I. dent. Res., 61: 1317-20, 1982 .

ORGANIZAÇÃO MUNDIAL DA SAŨDE. Expert Committee on Organization of Dental Public Health Services, Geneva, 1964. Report. Geneva, 1965. (Techn. Rep. Ser., 298)

PINTO, V.G. Setor de Odontologia Sanitäria: análise crí tica. Porto Alegre, Prefeitura Municipal, 1974. [Mimeografado] 
PINTO, V.G. Estado atual e perspectivas da odontologia ins titucional nos paises latinoamericanos. In: Congresso Lationoamericaro, 1.7Nacional de odontologia Institucio. nal, 2., México, DF, 1979. [Mimeografado]

PINTo, V.G. Saúde bucal no Brasil. Rev. Saúde públ., S. Paulo, 17: $316-27,1983$.

PREFEITURA MUNICIPAL DE PORTO ALEGRE. Setor de Odontologia Sanitária - Levantamento de cárie em escolares de 6 a 13 anos, da rede municipal de ensino. Porto Alegre, 1982. [Mimeografado]

PREFEITURA MUNICIPAL DE SÃO JOSE DOS CAMPOS. Divisão Odontológica - Relatório comparativo das atividades da Divi são Odontológica da Secretaria da Saũde: 1979-1984. São José dos Campos, 1984. [Mimeografado]

REZENDE, A.B. et al. Prevalência da cārie dentária em esco lares de Uberlândia-MG. Rev. bras. Odont., 38: 20-9, 1981 .

ROCHA, J.M.S. Determinação da prevalência da cárie dental em escolares de 7 a 14 anos em Manaus, Estado do Amazo nas: relatörio final. Manaus, Serviço de Odontologia Sa nitāria da Secretaria da Saúde, 1976. [Mimeografado] 
ROCHA, J.M.S, Inquérito epidemiológico de cárie dental em escolares de 7 a 14 anos de Boa Vista - Território Fede ral de Roraima: relatónio final. Boa Vista, Serviço de Odontologia Sanitäria da Secretaria da Saủde e Ação So cial, 1980. [Mimeografado]

SANTOS, C.P. Levantamento epidemiológico de cárie dentá ria em escolas de Uberaba, Minas Gerais. Uberaba, Fa culdades Integradas de Uberaba, 1981. [Mimeografad]

SCHEININ, A. et al. Prevalence of dental caries and dental health in relation to variable concentration of fluoride in drinking water: a clinical study on finnish school children. Acta odont. scand., 22: 22954, 1964.

SCHNARZ, E. Inaug. Dissertation. Tubigen. apud FINN, S.B. Prevalence of dental caries. In: TOVERUD, G. et a1. A survey of the literature of dental caries. Was hington, DC, National Academy of Sciences/National Research Council, 1952. p. 117-73.

SCHWARZ, E. \& HANSEN, E.R. Caries experience of danish children evaluated by the child dental health recording system. Community Dent. oral Epidem., 7: 107-14, 1979. 
SECRETARIA DE EDUCAÇÃO DE SÃo PAULO, Divisão de Estudos, Normas e Programas em Assistência Odontolögica. Normas e Instruções. São Paulo, 1980.

SECRETARIA DE SAUDE DO ESPIRITO SANTO. Diretoria de Odon tologia Sanitāria. Levantamento epidemiológico de cá rie dental em Vitória, ES: resumo geral. Vitónia, 1973. [Mimeografado]

SECRETARIA DE SAŨDE DA PARAIBA. Programa de saúde oral dos escolares do Estado da Paraíba. João Pessoa, 1979. [Mimeografado]

SERVIÇO AUTONOMO DE AgUA E ESGOTO DE SANTA FE dO SUL. As pectos sobre fluoretação das águas de abastecimento pu blico e sua ação na prevenção da cárie dental. Santa Fé do Sul, SP, Prefeitura Municipal, 1978.

STOOKEY, G.K. Prevalence of dental caries in Indiana schoolchiluren: results of 1982 survey. Ped. Dent., 7: $8-13,1985$.

TAMARI, J.W. An assesment of oral disease among primary schoolchildren in Lebanon. 1. Assesment of dental caries. Int. dent. J.., 24: 407-I5, 1974. 
TORO-FREIRE, C. Dental caries in schoolchildren. apud FINN, S.B. Prevalence of dental caries. In: TOVERUD, G. et al. A survey of the literature of dental caries. Washington, DC, National Academy of Sciences / National Research Council, 1952. p-117-73.

TRUIN, G.J. et al. Dental caries in 5-7-9 and 11 year old schoolchildren during a 9-year dental health campaign in the Hague. Community Dent. oral Epidem., 9 : 55-60, 1981.

UNIVERSIDADE FEDERAL DA BAHIA. Faculdade de Odontologia. Prevalência da cárie dental no bairro de Alagados. Sal vador, BA, 1979. [Mimeografado]

UNIVERSIDADE FEDERAL DO PIAUI. Epidemiolgia da cárie den tária: situação na saúde bucal de escolares da rede of cial de ensino da cidade de Teresina, PI. :Teresina, 1981. [Mimeografado]

VIEGAS, A.R. Porque devemos dar especial atenção aos den tes na idade pré-escolar. Rev. bras. Odont., 37: 30-6, 1949.

VIEGAS, A.R. Aspectos preventivos da cárie dentäria. São Paulo, Paculdade de Higiene e Saūde Püblica/USP, 1961. (Manual de odontologia Sanitäria v. 3). 
VIEGAS, A.R. Indice Simplificado para estimar a prevalència de cârie dental em crianças de 7 a 12 anos de idade. São Paulo, 1968. [Tese de Cátedra - Faculdade de Higie ne e Saủde Püblica da USP]

VIEGAS, A.R. \& VIEGAS, Y. Análise dos dados de prevalên cia de cárie dental na cidade de Campinas, SP, Brasil, depois de dez anos de fluoretação da água de abastecimen to püblico. Rev. Saúde pübl., S. Paulo, 8: 399 - 409 , 1974 .

VIEGAS, A.R. \& VIEGAS, Y. Prevalência de cárie dental na cidade de Campinas, SP, Brasil, depois de 14 anos de fluoretação da água de abastecimento público. Rev.Ass. paul. cirurg. Dent., 39: 272-82, 1985.

VON DER FEHR, F.R. Evidence of decreasing caries prevalen ce in Norway. J.dent. Res., 61: 1331-5, 1982.

YASSIN, I \& LOW, T. Caries prevalence in different racial groups of schoolchildren in West Malaysia. Community Dent. oral Epidem., 3: 179-83, 1975.

WALDMAN, H.B. Dental care needs and services for children: England, Wales and United States compared. U. Dent. Child., 50: 48-54, 1984 . 
WISAN, J.M. \& CHILTON, N.W, Studies in dental public health administration IV. Dental caries experience of New Jersey school children. J.Amer. dent. Ass., 37: 519 $-25,1948$. 
$A N E X O S$ 
LEVANTAMENTO EPIDEMIOLÓGICO DA CÁRIE DENTÁRIA = C.P.O

N. Municipio.

Classe

Periodo............................ Inferior Direito

EXAMINADOR

Inferior Esquerdo $\quad$ Inferior Direito

SUMÁRIO

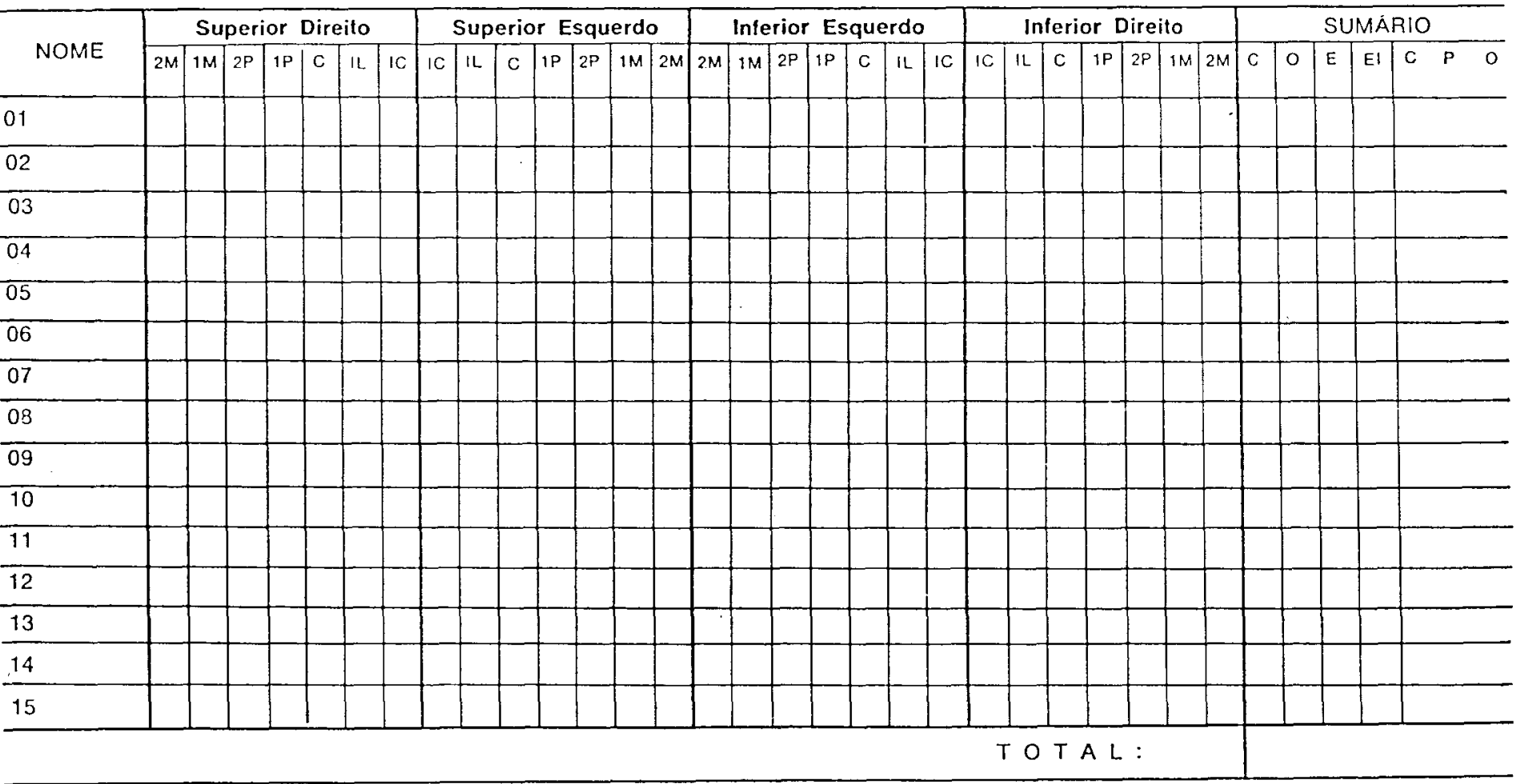


QUADRO 1 - NUMERO DE ESCOLARES EXAMINADOS, CPO MEDIO E COMPONENTES, NECESSIDADES DE TRATAMEN TO, SERVIÇOS EXECUTADOS E DESVIO PADRÃO, SEGUNDO A IDADE, NAS REGIONAIS DA CIDADE DE SÃO PAULO, EM 1980 .

\begin{tabular}{cccccccccc}
\hline Idades & $\begin{array}{l}\text { ivumerode } \\
\text { Escolares } \\
\text { Examinados }\end{array}$ & $\overline{\mathrm{C}}$ & $\overline{0}$ & $\overline{\mathrm{E}}$ & $\overline{\mathrm{EI}}$ & $\overline{\mathrm{C}+\overline{E I}}$ & $\overline{0+\bar{E}}$ & $\overline{\text { CPO }}$ & $\begin{array}{c}\text { Desvio } \\
\text { Padrão }\end{array}$ \\
\hline 7 & 6.360 & 1,88 & 0,20 & 0,02 & 0,08 & 1,96 & 0,22 & 2,18 & 1,63 \\
8 & 6.541 & 2,03 & 0,86 & 0,06 & 0,16 & 2,19 & 0,94 & 3,11 & 1,69 \\
9 & 6.478 & 2,20 & 1,25 & 0,15 & 0,26 & 2,46 & 1,40 & 3,86 & 2,15 \\
10 & 6.562 & 2,52 & 1,55 & 0,20 & 0,32 & 2,84 & 1,75 & 4,59 & 2,77 \\
11 & 6.252 & 3,28 & 1,81 & 0,30 & 0,43 & 3,71 & 2,11 & 5,82 & 3,70 \\
12 & 5.772 & 3,93 & 2,23 & 0,40 & 0,47 & 4,40 & 2,63 & 7,03 & 4,12 \\
13 & 5.059 & 4,27 & 2,90 & 0,51 & 0,53 & 4,80 & 3,41 & 8,21 & 4,56 \\
14 & 4.007 & 4,39 & 3,62 & 0,67 & 0,57 & 4,96 & 4,29 & 9,25 & 4,78 \\
\hline
\end{tabular}


QUADRO 2 - NUMERO DE ESCOLARES EXAMINADOS, CPO MEDIO, COMPONENTES, NECESSIDADES DE TRATAMENTO, SERVIÇOS EXECUTADOS E DESVIO PADRÃO, SEGUNDO A IDADE, NAS REGIONAIS DA CIDADE DE SÃO PAULO, EM 1982 .

\begin{tabular}{|c|c|c|c|c|c|c|c|c|c|}
\hline Idades & $\begin{array}{l}\text { Número de } \\
\text { Escolares } \\
\text { Examinados }\end{array}$ & $\overline{\mathrm{C}}$ & $\overline{0}$ & $\bar{E}$ & $\overline{\mathrm{EI}}$ & $\overline{C+E I}$ & $\overline{O+E}$ & $\overline{\mathrm{CPO}}$ & $\begin{array}{l}\text { Desvio } \\
\text { Padrão }\end{array}$ \\
\hline 7 & 3.762 & 1,85 & 0,18 & 0,02 & 0,07 & 1,92 & 0,20 & 2,12 & 1,52 \\
\hline 8 & 3.9 .03 & 1,71 & 1,06 & 0,06 & 0,16 & 1,87 & 1,12 & 2,99 & 1,54 \\
\hline 9 & 3.881 & 1,85 & 1,40 & 0,12 & 0,22 & 2,07 & 1,52 & 3,59 & 1,86 \\
\hline 10 & 3.856 & 2,25 & 1,70 & 0,19 & 0,29 & 2,54 & 1,89 & 4,43 & 2,49 \\
\hline 11 & 3.764 & 2,82 & 1,93 & 0,30 & 0,39 & 3,21 & 2,23 & 5,44 & 3,27 \\
\hline 12 & 3.456 & 3,28 & 2,33 & 0,41 & 0,42 & 3,70 & 2,74 & 6,44 & 3,80 \\
\hline 13 & 3.095 & 3,69 & 2,80 & 0,50 & 0,46 & 4,15 & 3,30 & 7,45 & 4,30 \\
\hline 14 & 2.515 & 3,83 & 3,78 & 0,64 & 0,50 & 4,33 & 4,42 & 8,75 & 4,76 \\
\hline
\end{tabular}


QUADRO 3 - NOMERO DE ESCOLARES EXAMINADOS, CPO MEDIO, COMPONENTES, NECESSIDADE DE TRATAMENTO E DESVIO PADRÃO, SEGUNDO A IDADE, NA REGIÃO DE GUARULHOS, EM 1980.

\begin{tabular}{|c|c|c|c|c|c|c|c|c|c|}
\hline Idades & $\begin{array}{l}\text { Nümero de } \\
\text { Escolares } \\
\text { Examinados }\end{array}$ & $\overline{\mathrm{C}}$ & $\overline{0}$ & $\bar{E}$ & $\overline{\mathrm{EI}}$ & $\overline{C+E I}$ & $\overline{O+E}$ & $\overline{\mathrm{CPO}}$ & $\begin{array}{l}\text { Desvio } \\
\text { Padrão }\end{array}$ \\
\hline 7 & 270 & 2,07 & 0,23 & 0,03 & 0,02 & 2,09 & 0,27 & 2,35 & 1,63 \\
\hline 8 & 270 & 1,87 & 0,79 & 0,06 & 0,14 & 2,01 & 0,85 & 2,86 & 1,83 \\
\hline q & 254 & 2,25 & 1,17 & 0,17 & 0,28 & 2,53 & 1,34 & 3,87 & 2,26 \\
\hline 10 & 239 & 3,40 & 1,04 & 0,29 & 0,46 & 3,86 & 1,33 & 5,19 & 3,49 \\
\hline II & 210 & 3,63 & 1,44 & 0,32 & 0,42 & 4,78 & 1,76 & 5,81 & 3,93 \\
\hline 12 & 89 & 4,45 & 1,89 & 0,47 & 0,33 & 4,78 & 2,36 & 7,14 & 4,91 \\
\hline 13 & 48 & 5,48 & 2,85 & 0,52 & 1,06 & 6,54 & 3,37 & 9,91 & 4,74 \\
\hline 14 & 32 & 6,78 & 2,38 & 1,19 & 1,34 & 8,12 & 3,57 & 11,69 & 4,54 \\
\hline
\end{tabular}


QUADRO 4 - NUMERO DE ESCOLARES EXAMINADOS, CPO MEDIO, COMPONENTES, NECESSIDADES DE TRATAMENTO E DESVIO PADRÃO, SEGUNDO A IDADE, NA REGIÃO DE GUARULHOS, EM 1982.

\begin{tabular}{|c|c|c|c|c|c|c|c|c|c|}
\hline Idades & $\begin{array}{l}\text { iNúmero de } \\
\text { Escolares } \\
\text { Examinados }\end{array}$ & $\vec{c}$ & $\overline{0}$ & $\bar{E}$ & $\overline{E I}$ & $\overline{C+E I}$ & $\overline{O+E}$ & $\overline{\mathrm{CPO}}$ & $\begin{array}{l}\text { Nümero } \\
\text { Padrão }\end{array}$ \\
\hline 7 & 246 & 2,38 & 0,16 & 0,02 & 0,09 & 2,47 & 0,18 & 2,65 & 1,47 \\
\hline 8 & 279 & 1,82 & 0,97 & 0,06 & $a, 23$ & 2,05 & 1,03 & 3,08 & 1,70 \\
\hline 9 & 257 & 1,70 & 1,58 & 0,16 & 0,23 & 1,93 & 1,74 & 3,67 & 2,29 \\
\hline 10 & 251 & 2,33 & 1,74 & 0,25 & 0,43 & 2,76 & 1,99 & 4,75 & 2,85 \\
\hline 11 & 205 & 3,48 & 1,58 & 0,22 & 0,69 & 4,17 & 1,80 & 5,97 & 4,04 \\
\hline 12 & 197 & 4,57 & 1,69 & 0,42 & 0,77 & 5,34 & 2,11 & 7,45 & 4,71 \\
\hline 13 & 99 & 3,78 & 1,82 & 0,62 & 0,56 & 4,34 & 2,44 & 6,78 & 4,11 \\
\hline 14 & 49 & 4,51 & 2,33 & 0,92 & 1,14 & 5,65 & 3,25 & 8,90 & 5,27 \\
\hline
\end{tabular}


QUADRO 5 - NUMERO DE ESCOLARES EXAMINADOS, CPO MEDIO, COMPONENTES, NECESSIDADES DE TRATAMENTO E DESVIO PADRÃO, SEGUNDO A IDADE, NA REGIÃO DE MOGI DAS CRUZES, EM 1980.

\begin{tabular}{|c|c|c|c|c|c|c|c|c|c|}
\hline Idades & $\begin{array}{l}\text { Número de } \\
\text { Escolares } \\
\text { Examinados. }\end{array}$ & $\overline{\mathrm{C}}$ & $\overline{0}$ & $\bar{E}$ & $\overline{E I}$ & $\overline{\mathrm{C}+\overline{E I}}$ & $\overline{O+E}$ & $\overline{\mathrm{CPO}}$ & $\begin{array}{l}\text { Desvio } \\
\text { Padrão }\end{array}$ \\
\hline 7 & 275 & 2,28 & 0,13 & 0,05 & 0,18 & 2,46 & 0,18 & 2,64 & 1,79 \\
\hline 8 & 300 & 2,10 & 0,77 & 0,09 & 0,30 & 2,40 & 0,86 & 3,26 & 1,72 \\
\hline 9 & 300 & 2,27 & 0,97 & 0,15 & $a, 39$ & 2,66 & 1,12 & 3,78 & 2,00 \\
\hline 10 & 292 & 2,90 & 1,00 & 0,29 & 0,54 & 3,44 & 1,29 & 4,73 & 2,83 \\
\hline 11 & 270 & 4,36 & 1,22 & 0,59 & 0,66 & 5,02 & 1,81 & 6,83 & 3,59 \\
\hline 12 & 262 & 5,48 & 1,21 & 0,65 & 0,77 & 6,25 & 1,86 & 8,17 & 4,82 \\
\hline 13 & 216 & 6,48 & 1,56 & 0,90 & 0,77 & 7,25 & 2,46 & 9,71 & 5,07 \\
\hline 14 & 139 & 6,96 & 2,37 & 1,14 & 1,02 & 7,98 & 3,51 & $11,49$. & 6,31 \\
\hline
\end{tabular}


QUADRO 6 - NUMERO DE ESCOLARES EXAMINADOS, CPO MEDIO, COMPONENTES, NECESSIDADES DE TRATAMENTO E DESVIO PADRÃO, SEGUNDO A IDADE, NA REGIÃO DE MOGI DAS CRUZES, EM I982.

\begin{tabular}{|c|c|c|c|c|c|c|c|c|c|}
\hline Idades & $\begin{array}{l}\text { Nümero de } \\
\text { Escolares } \\
\text { Examinados }\end{array}$ & $\overline{\mathrm{C}}$ & $\overline{0}$ & $\overline{\mathrm{E}}$ & $\overline{\mathrm{EI}}$ & $\overline{\mathrm{C}+\mathrm{EI}}$ & $\overline{O+E}$ & $\overline{\mathrm{CPO}}$ & $\begin{array}{l}\text { Desvio } \\
\text { Padrão }\end{array}$ \\
\hline 7 & 359 & 1,72 & 0,16 & 0,00 & 0,40 & 2,12 & 0,16 & 2,28 & 2,19 \\
\hline 8 & 360 & 1,56 & 0,92 & 0,09 & 0,26 & 1,82 & 1,01 & 2,83 & 1,67 \\
\hline 9 & 360 & 1,68 & 1,36 & 0,15 & 0,32 & 2,00 & 1,51 & 3,51 & 1,87 \\
\hline 10 & 358 & 2,32 & 1,19 & $a, 29$ & 0,44 & 2,76 & 1,48 & 4,24 & 2,37 \\
\hline 11 & 347 & 3,21 & 0,84 & 0,30 & 0,74 & 3,95 & 1,14 & 5,09 & 3,25 \\
\hline 12 & 291 & 4,10 & 0,82 & 0,56 & 0,64 & 4,74 & 1,38 & 6,12 & 3,90 \\
\hline 13 & 227 & 4,95 & 0,84 & 0,69 & 0,72 & 5,67 & 1,53 & 7,20 & 5,04 \\
\hline 14 & 145 & 4,87 & 0,64 & 0,74 & 0,88 & 5,75 & 1,38 & 7,13 & 4,71 \\
\hline
\end{tabular}


QUADRO 7 - NOMERO DE ESCOLARES EXAMINADOS, CPO MEDIO, COMPONENTES, NECESSIDADES DE TRATAMENTO E DESVIO PADRÃO, SEGUNDO A IDADE, NA REGIÃO DE SANTO ANDRE, EM 1980.

\begin{tabular}{|c|c|c|c|c|c|c|c|c|c|}
\hline Idades & $\begin{array}{l}\text { Número de } \\
\text { Escolares } \\
\text { Examinados }\end{array}$ & $\overline{\mathrm{C}}$ & $\overline{0}$ & $\overline{\mathrm{E}}$ & $\overline{E I}$ & $\overline{\mathrm{C}+\overline{\mathrm{EI}}}$ & $\overline{\mathrm{O}+\mathrm{E}}$ & $\overline{\mathrm{CPO}}$ & $\begin{array}{l}\text { Desvio } \\
\text { Padrão }\end{array}$ \\
\hline 7 & 1.630 & 1,66 & 0,21 & 0,01 & 0,08 & 1,74 & 0,23 & 1,96 & 1,60 \\
\hline 8 & $1.857^{\circ}$ & 1,89 & 0,77 & 0,05 & 0,14 & 2,03 & 0,82 & 2,85 & 1,74 \\
\hline 9 & 1.963 & 1,94 & 1,12 & 0,13 & 0,20 & 2,14 & 1,25 & 3,39 & 1,93 \\
\hline 10 & 1.980 & 2,38 & 1,31 & 0,18 & 0,28 & 2,66 & 1,49 & 4,15 & 2,71 \\
\hline 11 & 1.917 & 2,68 & 1,61 & 0,25 & 0,30 & 2,98 & 1,86 & 4,84 & 3,19 \\
\hline 12 & 1.830 & 3,36 & 2,05 & 0,37 & 0,37 & 3,73 & 2,42 & 6,15 & 3,91 \\
\hline 13 & 1.673 & 3,91 & 2,92 & 0,44 & 0,42 & 4,33 & 3,36 & 7,69 & 4,42 \\
\hline 14 & 1.303 & 3,68 & 4,14 & 0,51 & 0,40 & 4,08 & 4,65 & 8,73 & 4,68 \\
\hline
\end{tabular}


QUADRO 8 - NOMERO DE ESCOLARES EXAMINADOS, CPO MEDIO, COMPONENTES, NECESSIDADES DE TRATAMENTO E DESVIO PADRÃO, SEGUNDO A IDADE, NA REGIÃO DE SANTO ANDRE, EM 1982.

\begin{tabular}{|c|c|c|c|c|c|c|c|c|c|}
\hline Idades & $\begin{array}{l}\text { Número de } \\
\text { Escolares } \\
\text { Examinados }\end{array}$ & $\overline{\mathrm{C}}$ & $\overline{0}$ & $\bar{E}$ & $\overline{E I}$ & $\overline{C+E I}$ & $\overline{O+E}$ & $\overline{\mathrm{CPO}}$ & $\begin{array}{l}\text { Desvio } \\
\text { Parnão }\end{array}$ \\
\hline 7 & 957 & 1,94 & 0,20 & 0,01 & $a, 08$ & 2,02 & 0,21 & 2,23 & 1,56 \\
\hline 8 & 1.020 & 1,50 & 1,18 & 0,07 & $a, 12$ & 1,72 & 1,25 & 2,87 & 1,59 \\
\hline 9 & 1.016 & 1,76 & 1,30 & 0,13 & 0,21 & 1,97 & 1,43 & 3,40 & 1,85 \\
\hline 10 & 1.016 & 2,00 & 1,49 & 0,23 & 0,29 & 2,29 & 1,72 & 4,01 & 2,55 \\
\hline 11 & 991 & 2,80 & 1,53 & 0,30 & 0,38 & 3,18 & 1,83 & 5,01 & 3,28 \\
\hline 12 & 853 & 3,68 & 1,74 & 0,44 & 0,43 & 4,11 & 2,18 & 6,29 & 3,97 \\
\hline 13 & 721 & 4,32 & 2,15 & 0,50 & 0,43 & 4,75 & 2,65 & 7,40 & 4,67 \\
\hline 14 & 537 & 4,31 & 3,08 & 0,56 & 0,43 & 4,74 & 3,64 & 8,38 & 4,84 \\
\hline
\end{tabular}


QUADRO 9 - NUMERO DE ESCOLARES EXAMINADOS, CPO MEDIO, COMPONENTES, NECESSIDADES DE TRATAMENTO E DESVIO PADRÃO, SEGUNDO A IDADE, NA REGIÃO DE OSASCO, EM 1980.

\begin{tabular}{|c|c|c|c|c|c|c|c|c|c|}
\hline Idades & $\begin{array}{l}\text { Número de } \\
\text { Escolares } \\
\text { Examinados }\end{array}$ & $\overline{\mathrm{C}}$ & $\overrightarrow{0}$ & $\bar{E}$ & $\overline{\mathrm{EI}}$ & $\overline{\mathrm{C}+\overline{\mathrm{EI}}}$ & $\overline{\mathrm{O}+\mathrm{E}}$ & $\overline{\mathrm{CPO}}$ & $\begin{array}{l}\text { Desvio } \\
\text { Padrão }\end{array}$ \\
\hline 7 & 600 & 2,00 & 0,17 & 0,04 & 0,16 & 2,16 & 0,21 & 2,37 & 1,68 \\
\hline 8 & 593 & 2,15 & 0,51 & 0,06 & 0,37 & 2,52 & 0,57 & $3,0.9$ & 1,77 \\
\hline 9 & 582 & 2,89 & 0,86 & 0,17 & 0,37 & 3,26 & 1,03 & 4,29 & 2,98 \\
\hline 10 & 586 & 3,28 & 0,99 & 0,26 & 0,53 & 3,81 & 1,25 & 5,06 & 3,27 \\
\hline 11 & 575 & 4,01 & 0,91 & 0,35 & 0,58 & 4,59 & 1,25 & 5,85 & 4,04 \\
\hline 12 & 480 & 4,67 & 1,00 & 0,46 & 0,63 & 5,30 & 1,46 & 6,76 & 4,50 \\
\hline 13 & 417 & 5,06 & 1,03 & 0,57 & 0,72 & 5,78 & 1,60 & 7,38 & 4,57 \\
\hline 14 & 298 & 5,96 & 1,52 & 0,82 & 0,57 & 6,53 & 2,34 & 8,87 & 4,74 \\
\hline
\end{tabular}




\section{ANEXO 11}

QUADRO 10 -NOMERO DE ESCOLARES EXAMINADOS, CPO MEDIO, COMPONENTES, NECESSIDADES DE TRATAMENTO E DESVIO PADRÃO, SEGUNDO A IDADE, NA REGIÃO DE OSASCO, EM 1982.

\begin{tabular}{|c|c|c|c|c|c|c|c|c|c|}
\hline Idades & $\begin{array}{l}\text { Nümero de } \\
\text { Escolares } \\
\text { Examinados }\end{array}$ & $\overline{\mathrm{C}}$ & $\ddot{0}$ & $\overline{\mathrm{E}}$ & $\overline{\mathrm{EI}}$ & $\overline{\mathrm{C}}+\overline{\mathrm{E}} \overline{\mathrm{I}}$ & $\overline{O+E}$ & $\overline{\mathrm{CPO}}$ & $\begin{array}{l}\text { Desvio } \\
\text { Padrão }\end{array}$ \\
\hline 7 & 749 & 1,76 & 0,13 & 0,05 & 0,13 & 1,89 & 0,18 & 2,07 & 1,49 \\
\hline 8 & 817 & 1,68 & 0,91 & 0,10 & 0,19 & 1,87 & 1,01 & 2,88 & 1,54 \\
\hline 9 & 816 & 1,72 & 1,23 & 0,15 & 0,28 & 2,00 & 1,38 & 3,38 & 1,85 \\
\hline 10 & 797 & 2,20 & 1,19 & 0,31 & 0,44 & 2,64 & 1,50 & 4,14 & 2,28 \\
\hline 11 & 732 & 3,12 & 1,16 & 0,33 & 0,59 & 3,71 & 1,49 & 5,20 & 3,18 \\
\hline 12 & 692 & 3,97 & 1,03 & 0,48 & 0,65 & 4,62 & 1,51 & 6,13 & 3,89 \\
\hline 13 & 523 & 4,42 & 1,30 & 0,68 & 0,79 & 5,21 & 1,98 & 7,19 & 4,44 \\
\hline 14 & 401 & 4,56 & 1,66 & 0,78 & 0,89 & 5,45 & 2,44 & 7,89 & 4,68 \\
\hline
\end{tabular}




\section{ANEXO 12}

QUADRO $I I$ - NUMERO DE ESCOLARES EXAMINADOS, CPO MEDIO, COMPONENTES, NECESSIDADES DE TRATAMENTO E DESVIO PADRÃO, SEGUNDO A IDADE, NA REGIÃO DO .LITORAL, EM 1980.

\begin{tabular}{|c|c|c|c|c|c|c|c|c|c|c|}
\hline Idades & $\begin{array}{l}\text { Nümero de } \\
\text { Escolares } \\
\text { Examinados }\end{array}$ & $\bar{C}$ & $\overline{0}$ & $\bar{E}$ & $\overline{E I}$ & $\overline{C+\overline{E I}}$ & & $\overline{O+E}$ & $\overline{C P O}$ & $\begin{array}{l}\text { Desvio } \\
\text { Padrão }\end{array}$ \\
\hline 7 & 827 & 1,78 & 0,34 & 0,02 & 0,11 & 1,89 & & 0,36 & 2,25 & 2,51 \\
\hline 8 & 842 & 2,03 & 0,59 & 0,05 & 0,18 & 2,21 & & 0,64 & 2,85 & 1,87 \\
\hline 9 & 843 & 2,26 & 0,64 & 0,15 & 0,31 & 2,58 & $=$ & 0,79 & 3,36 & 1,92 \\
\hline 10 & 815 & 2,52 & 0,78 & 0,22 & 0,36 & 2,88 & & 1,00 & 3,88 & 2,80 \\
\hline 11 & 823 & 3,16 & 0,99 & 0,29 & 0,50 & 3,66 & & 1,28 & 4,94 & 3,48 \\
\hline 12 & 822 & 3,61 & 1,25 & 0,44 & 0,59 & 4,19 & & 1,69 & 5,89 & 4,02 \\
\hline 13 & 739 & 4,35 & 1,58 & 0,48 & 0,51 & 4,86 & & 2,06 & 6,92 & 4,47 \\
\hline 14 & 594 & 4,23 & 2,47 & 0,69 & 0,63 & 4,86 & & 3,16 & 8,02 & 4,60 \\
\hline
\end{tabular}


QUADRO 12 - NUMERO DE ESCOLARES EXAMINADOS, CPO MEDIO, COMPONENTES, NECESSIDADES DE TRATAMENTO E DESVIO PADRÃO, SEGUNDO A IDADE, NA REGIÃO DO LITORAL, EM 1982.

\begin{tabular}{|c|c|c|c|c|c|c|c|c|c|}
\hline Idades & $\begin{array}{l}\text { Nümero de } \\
\text { Escolares } \\
\text { Examinados }\end{array}$ & $\bar{C}$ & $\overline{0}$ & $\overline{\mathrm{E}}$ & $\overline{\mathrm{EI}}$ & $\overline{\mathrm{C}+\mathrm{EI}}$ & $\overline{O+E}$ & $\overline{\mathrm{C}} \overline{\mathrm{PO}}$ & $\begin{array}{l}\text { Desvio } \\
\text { Padrão }\end{array}$ \\
\hline 7 & 1.056 & 1,98 & 0,35 & 0,03 & 0,13 & 2,11 & 0,38 & 2,49 & 2,58 \\
\hline 8 & 1.103 & 1,96 & 0,77 & 0,07 & 0,18 & 2,14 & 0,84 & 2,98 & 1,62 \\
\hline 9 & I.090 & 2,14 & 0,95 & 0,16 & 0,30 & 2,44 & 1,11 & 3,55 & 1,92 \\
\hline 10 & 1.116 & 2,35 & 1,24 & 0,22 & 0,36 & 2,72 & 1,46 & 4,17 & 2,60 \\
\hline 11 & 1.066 & 3,21 & 1,31 & 0,34 & 0,47 & 3,68 & 1,65 & 5,38 & 3,26 \\
\hline 12 & 953 & 3,52 & 1,39 & 0,49 & 0,54 & 4,06 & 1,88 & 5,94 & 3,70 \\
\hline 13 & 807 & 3,97 & 1,72 & 0,56 & 0,56 & 4,52 & 2,28 & 6,81 & 4,06 \\
\hline 14 & 664 & 4,12 & 2,52 & 0,66 & 0,61 & 4,73 & 3,18 & 7,91 & 4,61 \\
\hline
\end{tabular}


QUADRO 13- NUMERO DE ESCOLARES EXAMINADOS, CPO MEDIO, COMPONENTES, NECESSIDADES DE TRATAMENTO E DESVIO PADRÃO, SEGUNDO A IDADE, NA REGIÃO DO VALE DO PARAÍBA, EM 1980.

\begin{tabular}{|c|c|c|c|c|c|c|c|c|c|}
\hline Idades & $\begin{array}{l}\text { Nümero de } \\
\text { Escolares } \\
\text { Examinados }\end{array}$ & $\overline{\mathrm{C}}$ & $\overline{0}$ & $E$ & $\overline{\mathrm{EI}}$ & $\bar{C}+\overline{E I}$ & $\overline{O+E}$ & CPO & $\begin{array}{l}\text { Desvio } \\
\text { Padrão }\end{array}$ \\
\hline 7 & 1.869 & 2,02 & 0,23 & 0,02 & 0,14 & 2,15 & 0,25 & 2,41 & 1,65 \\
\hline 8 & 1.858 & 2,09 & 0,89 & 0,10 & 0,26 & 2,35 & 0,99 & 3,34 & 1,78 \\
\hline 9 & 1.860 & 2,20 & 1,31 & 0,18 & 0,35 & 2,54 & 1,49 & 4,04 & 2,30 \\
\hline 10 & 1.843 & 2,81 & 1,65 & 0,34 & 0,44 & 3,25 & 1,99 & 5,24 & 3,23 \\
\hline 11 & 1.819 & 3,37 & $I, 88$ & 0,42 & 0,55 & 3,92 & 2,30 & 6,22 & 3,87 \\
\hline 12 & 1.682 & 3,99 & 2,49 & 0,59 & 0,58 & 4,58 & 3,08 & 7,65 & 4,42 \\
\hline 13 & 1.518 & 4,30 & 3,15 & 0,72 & 0,61 & 4,91 & 3,87 & 8,78 & 4,95 \\
\hline 14 & 1.313 & 4,56 & 4,00 & 0,86 & 0,70 & 5,27 & 4,86 & 10,12 & 5,36 \\
\hline
\end{tabular}




\section{ANEXO 15}

QUADRO 14 - NOMERO DE ESCOLARES EXAMINADOS, CPO MEDIO, COMPONENTES, NECESSIDADES DE TRATAMENTO E DESVIO PADRÃO, SEGUNDO A IDADE, NA REGIÃO DO VALE DO PARAIBA, EM 1982.

\begin{tabular}{|c|c|c|c|c|c|c|c|c|c|}
\hline Idades & $\begin{array}{l}\text { Nümero de } \\
\text { Escolares } \\
\text { Examinados }\end{array}$ & $\bar{C}$ & $\overline{0}$ & $\vec{E}$ & $\overline{\mathrm{EI}}$ & $\mathrm{C}+\mathrm{EI}$ & $\widehat{O+E}$ & $\overline{\mathrm{CPO}}$ & $\begin{array}{l}\text { Desvio } \\
\text { Padrão }\end{array}$ \\
\hline 7 & 1.148 & 1,89 & 0,28 & 0,02 & 0,08 & 1,97 & 0,30 & 2,27 & 1,62 \\
\hline 8 & 1.100 & 1,77 & 1,15 & 0,07 & 0,15 & 1,92 & $I, 22$ & 3,14 & 1,65 \\
\hline 9 & 1.125 & 2,13 & 1,61 & 0,14 & 0,30 & 2,43 & 1,75 & 4,18 & 2,37 \\
\hline 10 & 1.094 & 2,69 & 1,83 & 0,27 & 0,40 & 3,10 & 2,10 & 5,19 & 3,19 \\
\hline 11 & 1.104 & 3,35 & 2,20 & 0,44 & 0,43 & 3,78 & 2,64 & 6,42 & 3,94 \\
\hline 12 & 1.046 & 3,74 & 2,82 & 0,59 & 0,46 & 4,20 & 3,41 & 7,61 & 4,66 \\
\hline 13 & ' 869 & 4,31 & 3,57 & 0,78 & 0,57 & 4,87 & 4,25 & 9,23 & 5,32 \\
\hline 14 & 714 & 4,85 & 4,28 & 0,91 & 0,68 & 5,53 & 5,19 & 10,72 & 5,76 \\
\hline
\end{tabular}


QLADRO 15 - NOMERO DE ESCOLARES EXAMINADOS, CPO MEDIO, COMPONENTES, NECESSIDADES DE TRATAMENTO E DESVIO PADRÃO, SEGUNDO A IDADE, NA REGIÃO DE SOROCABA, EM 1980.

\begin{tabular}{|c|c|c|c|c|c|c|c|c|c|}
\hline Idades & $\begin{array}{l}\text { Nümero de } \\
\text { Escolares } \\
\text { Examinados }\end{array}$ & $\overline{\mathrm{C}}$ & $\overline{0}$ & $\overline{\mathrm{E}}$ & $\bar{E} \bar{I}$ & $\overline{C+E I}$ & $\overline{O+E}$ & $\overline{\mathrm{CPO}}$ & $\begin{array}{l}\text { Desvio } \\
\text { Padrão }\end{array}$ \\
\hline 7 & 1.969 & 2,29 & 0,17 & 0,02 & 0,10 & 2,38 & 0,19 & 2,58 & 1,65 \\
\hline 8 & 2.004 & 2,11 & 1,00 & 0,08 & 0,20 & 2,31 & 1,08 & 3,39 & 1,66 \\
\hline 9 & 2.006 & 2,12 & 1,46 & 0,13 & 0,25 & 2,37 & 1,59 & 3,96 & 2,11 \\
\hline 10 & 2.028 & 2,69 & 1,74 & 0,29 & 0,38 & 3,07 & 2,03 & 5,10 & 2,96 \\
\hline 11 & 1.9 .36 & 3,13 & 2,20 & 0,34 & 0,42 & 3,55 & 2,54 & 6,09 & 3,53 \\
\hline 12 & 1.877 & 3,78 & 2,71 & 0,45 & 0,46 & 4,24 & 3,16 & 7,40 & 4,10 \\
\hline 13 & 1.670 & 3,99 & 3,29 & 0,59 & 0,49 & 4,48 & 3,88 & 8,36 & 4,36 \\
\hline 14 & 1.406 & 4,32 & 4,08 & 0,62 & 0,40 & 4,72 & 4,70 & 9,42 & 4,53 \\
\hline
\end{tabular}


QUADRO 16 - NOMERO DE ESCOLARES EXAMINADOS, CPO MEDIO, COMPONENTES, NECESSIDADES DE TRATAMENTO E DESVIO PADRÃO, SEGUNDO A IDADE, NA REGIÃO DE SOROCABA, EM 1982.

\begin{tabular}{|c|c|c|c|c|c|c|c|c|c|}
\hline Idades & $\begin{array}{l}\text { Numero de } \\
\text { Escolares } \\
\text { Examinados }\end{array}$ & $\tau$ & $\delta$ & $\bar{E}$ & $\overline{E I}$ & $\overline{C+E I}$ & $\overline{O+E}$ & $\bar{C} \overline{P O}$ & $\begin{array}{l}\text { Desvio } \\
\text { Padrão }\end{array}$ \\
\hline 7 & 1.026 & 2,43 & 0,18 & 0,04 & 0,16 & 2,59 & 0,22 & 2,81 & 1,56 \\
\hline 8 & 1.040 & 2,17 & 1,08 & 0,09 & 0,24 & 2,41 & 1,17 & 3,58 & 1,62 \\
\hline 9 & 1.042 & 2,74 & 1,41 & 0,22 & 0,34 & 3,08 & 1,63 & 4,71 & 2,45 \\
\hline 10 & 1.023 & 2,98 & 1,76 & 0,34 & 0,41 & 3,39 & 2,10 & 5,49 & 3,12 \\
\hline 11 & 948 & 3,63 & 2,10 & 0,51 & 0,46 & 4,09 & 2,61 & 6,70 & 3,60 \\
\hline 12 & 888 & 4,35 & 2,55 & 0,63 & 0,51 & 4,86 & 3,18 & 8,04 & 4,31 \\
\hline 13 & 776 & 4,82 & 3,08 & 0,80 & 0,63 & 5,45 & 3,88 & 9,33 & 4,72 \\
\hline 14 & 700 & 4,77 & 4,04 & 1,04 & 0,58 & 5,35 & 5,08 & 10,43 & 4,77 \\
\hline
\end{tabular}


QUADRO 17 - NUMERO DE ESCOLARES EXAMINADOS, CPO MEDIO, COMPONENTES, NECESSIDADES DE TRATAMENTO E DESVIO PADRÃO, SEGUNDO A IDADE, NA REGIÃO DE CAMPINAS, EM 1980.

\begin{tabular}{|c|c|c|c|c|c|c|c|c|c|}
\hline Idades & $\begin{array}{l}\text { Número de } \\
\text { Escolares } \\
\text { Examinados }\end{array}$ & $\bar{C}$ & $\overline{0}$ & $\bar{E}$ & $\overline{E I}$ & $\overline{C+E I}$ & $\overrightarrow{O+E}$ & $\overline{\mathrm{CPO}}$ & $\begin{array}{l}\text { Desvio } \\
\text { Padrão }\end{array}$ \\
\hline 7 & 7.133 & 1,87 & 0,20 & 0,02 & 0,10 & 1,97 & 0,22 & 2,19 & 1,66 \\
\hline 8 & 7.168 & 1,85 & 0,86 & 0,06 & 0,18 & 2,03 & 0,92 & 2,95 & 1,75 \\
\hline 9 & 7.205 & 2,02 & 1,29 & 0,13 & 0,25 & 2,27 & 1,42 & 3,69 & 2,21 \\
\hline 10 & 7.170 & 2,48 & 1,58 & 0,22 & 0,32 & 2,80 & 1,80 & 4,60 & 2,94 \\
\hline 11 & 6,788 & 3,02 & 2,12 & 0,33 & 0,40 & 3,42 & 2,45 & 5,87 & 3,90 \\
\hline 12 & 6.405 & 3,46 & 2,68 & 0,42 & 0,42 & 3,88 & 3,10 & 6,98 & 4,47 \\
\hline 13 & 5.633 & 3,52 & 3,70 & 0,51 & 0,39 & 3,91 & 4,21 & 8,12 & 4,80 \\
\hline 14 & 4.501 & 3,46 & 4,80 & 0,64 & 0,42 & 3,88 & 5,44 & 9,32 & 5,18 \\
\hline
\end{tabular}


QUADRO 18 - NOMERO DE ESCOLARES EXAMINADOS, CPO MEDIO, COMPONENTES, NECESSIDADES DE TRATAMENIO E DESVIO PADRÃO, SEGUNDO A IDADE, NA REGIẼO DE CAMPINAS, EM 1982.

\begin{tabular}{|c|c|c|c|c|c|c|c|c|c|}
\hline Idades & $\begin{array}{l}\text { Nümero de } \\
\text { Escolares } \\
\text { Examinados }\end{array}$ & $\overline{\mathrm{C}}$ & $\overline{0}$ & $\bar{E}$ & $\bar{E} \bar{I}$ & $\bar{C}+\bar{E} \bar{I}$ & $\overline{O+E}$ & $\overline{\mathrm{CPO}}$ & $\begin{array}{l}\text { Desvio } \\
\text { Padrão }\end{array}$ \\
\hline 7 & 1.811 & 2,09 & 0,23 & 0,02 & 0,11 & 2,20 & 0,25 & 2,45 & 1,61 \\
\hline 8 & 1.810 & 2,02 & 0,95 & 0,08 & 0,18 & 2,19 & 1,03 & 3,23 & 1,76 \\
\hline 9 & 1.824 & 2,22 & 1,35 & 0,12 & 0,25 & 2,47 & 1,47 & 3,94 & 2,12 \\
\hline 10 & 1.809 & 2,66 & 1,70 & 0,25 & 0,33 & 3,00 & 1,95 & 4,94 & 2,96 \\
\hline$I I$ & 1.737 & 3,10 & 2,07 & 0,34 & 0,38 & 3,48 & 2,41 & 5,89 & 3,60 \\
\hline 12 & 1.524 & 3,43 & 2,86 & 0,43 & 0,39 & 3,82 & 3,29 & 7,11 & 4,30 \\
\hline 13 & 1.283 & 3,38 & 3,66 & 0,48 & 0,37 & 3,75 & 4,14 & 7,89 & 4,69 \\
\hline 14 & 937 & 3,20 & 4,64 & 0,63 & 0,40 & 3,60 & 5,27 & 8,87 & 4,92 \\
\hline
\end{tabular}


QUADRO 19 - NOMERO DE ESCOLARES EXAMINADOS, CPO MEDIO, COMPONENTES, NECESSIDADES DE TRATAMENTO E DESVIO PADRÃO, SEGUNDO A IDADE, NA REGIÃO DE RIBEIRÃO PRETO, EM 1980.

\begin{tabular}{|c|c|c|c|c|c|c|c|c|c|}
\hline Idades & $\begin{array}{l}\text { Nümero de } \\
\text { Escolares } \\
\text { Examinados }\end{array}$ & $\bar{C}$ & $\overline{0}$ & $\bar{E}$ & $\overline{E I}$ & $\overline{\mathrm{C}+\overline{\mathrm{EI}}}$ & $\overline{O+E}$ & $\overline{\mathrm{CPO}}$ & $\begin{array}{l}\text { Desvio } \\
\text { Padrão }\end{array}$ \\
\hline 7 & 4.918 & 2,22 & 0,22 & 0,01 & 0,07 & 2,29 & 0,23 & 2,52 & 1,58 \\
\hline 8 & 4.977 & $2,0.9$ & 1,14 & 0,05 & 0,14 & 2,23 & 1,19 & 3,42 & 1,66 \\
\hline 9 & 5.105 & 2,13 & 1,61 & 0,11 & 0,22 & 2,36 & 1,72 & 4,07 & 2,11 \\
\hline 10 & 5.098 & 2,58 & 2,02 & 0,17 & 0,26 & 2,84 & 2,19 & 5,03 & 2,95 \\
\hline 11 & 4.978 & 3,15 & 2,68 & 0,27 & 0,32 & 3,47 & 2,95 & 6,42 & 3,75 \\
\hline 12 & 4,730 & 3,58 & 3,35 & 0,32 & 0,33 & 3,91 & 3,67 & 7,58 & 4,27 \\
\hline 13 & 4.350 & 3,59 & 4,50 & 0,41 & 0,32 & 3,91 & 4,91 & 8,82 & 4,56 \\
\hline 14 & 3.443 & 3,56 & 5,51 & 0,49 & 0,32 & 3,88 & 6,00 & 9,88 & 4,60 \\
\hline
\end{tabular}




\section{ANEXO 21}

QUADRO 20 - NUMERO DE ESCOLARES EXAMINADOS, CPO MEDIO, COMPONENTES, NECESSIDADES DE TRATAMENTO E DESVIO PADRÃO, SEGUNDO A IDADE, NA REGIÃO DE, RIBEIRÃO PRETO, EM 1982.

\begin{tabular}{|c|c|c|c|c|c|c|c|c|c|}
\hline Idades & $\begin{array}{l}\text { Número de } \\
\text { Escolares } \\
\text { Examinados }\end{array}$ & $\overline{\mathrm{C}}$ & $\overline{0}$ & $\widetilde{\mathrm{E}}$ & $E I$ & $\overline{C+E I}$ & $\overrightarrow{O+E}$ & CPO & $\begin{array}{l}\text { Desvio } \\
\text { Padrão }\end{array}$ \\
\hline 7 & 1.959 & 2,43 & 0,23 & 0,02 & 0,11 & 2,54 & 0,25 & 2,79 & 1,50 \\
\hline 8 & 1.933 & 2,04 & 1,36 & 0,07 & 0,17 & 2,21 & 1,43 & 3,64 & 1,58 \\
\hline 9 & 1.941 & 2,36 & $\bar{I}, 8 \mathrm{I}$ & 0,12 & 0,26 & 2,61 & 1,93 & 4,55 & 2,25 \\
\hline 10 & 1.955 & 2,76 & 2,15 & 0,20 & 0,28 & 3,05 & 2,35 & 5,39 & 2,88 \\
\hline 11 & 1.937 & 3,39 & 2,71 & 0,34 & 0,33 & 3,72 & 3,05 & 6,77 & 3,87 \\
\hline 12 & 1.876 & 3,52 & 3,47 & 0,39 & 0,34 & 3,86 & 3,86 & 7,72 & 4,29 \\
\hline 13 & 1.633 & 3,79 & 4,45 & 0,54 & 0,37 & 4,15 & 4,99 & 9,15 & 4,79 \\
\hline 14 & 1.330 & 3,73 & 5,30 & 0,54 & 0,65 & 4,38 & 5,84 & 10,22 & 5,26 \\
\hline
\end{tabular}


QUADRO 21 - NUMERO DE ESCOLARES EXAMINADOS, CPO MEDIO, COMPONENTES, NECESSIDADES DE TRATAMENTO E E DESVIO PADRÃO, SEGUNDO A IDADE, NA REGIÃO DE BAURU, EM 1980.

\begin{tabular}{|c|c|c|c|c|c|c|c|c|c|}
\hline Idades & $\begin{array}{l}\text { Nümero de } \\
\text { Escolares } \\
\text { Examinados }\end{array}$ & $\bar{C}$ & $\overline{0}$ & $\bar{E}$ & $\overline{E I}$ & $\bar{C}+\bar{E} \bar{I}$ & $\overrightarrow{O+E}$ & CQO & $\begin{array}{l}\text { Desvio } \\
\text { Padrão }\end{array}$ \\
\hline 7 & 2.054 & 2,05 & 0,20 & 0.02 & 0,09 & 2,14 & 0,22 & 2,35 & 1,70 \\
\hline 8 & 2,001 & 1,99 & 1,09 & 0,05 & 0,14 & 2,13 & 1,14 & 3,27 & 1,75 \\
\hline g & 2.091 & 2,00 & 1,62 & 0,11 & 0,21 & 2,22 & 1,73 & 3,94 & 1,99 \\
\hline 10 & 2.125 & 2,54 & 1,96 & 0,19 & 0,28 & 2,82 & 2,15 & 4,97 & 2,91 \\
\hline 11 & 2.019 & 3,15 & 2,43 & 0,31 & 0,37 & 3,52 & 2,74 & 6,26 & 3,65 \\
\hline 12 & 1.975 & 3,79 & $\hat{0}, 11$ & 0,44 & 0,43 & 4,23 & 3,55 & 7,77 & 4,20 \\
\hline 13 & 1.848 & 4,01 & 4,12 & 0,60 & 0,41 & 4,41 & 4,72 & 9,14 & 4,44 \\
\hline 14 & 1.583 & 4,35 & 5,11 & 0,72 & 0,44 & 4,80 & 5,83 & 10,62 & 4,76 \\
\hline
\end{tabular}


QUADRO 22 - NÜMERO DE ESCOLARES EXAMINADOS, CPO MEDIO, COMPONENTES, NECESSTDADES DE TRATAMENTO E DESVIO PADRÃO, SEGUNDO A IDADE, NA REGIÃO DE BAURU, EM 1982.

\begin{tabular}{|c|c|c|c|c|c|c|c|c|c|}
\hline Idades & $\begin{array}{l}\text { Nümero de } \\
\text { Escolares } \\
\text { Examinados }\end{array}$ & $\overline{\mathrm{C}}$ & $\overline{0}$ & $\overline{\mathrm{E}}$ & $\overline{\mathrm{EI}}$ & $\overline{\mathrm{C}+\mathrm{EI}}$ & $\overline{O+E}$ & $\overline{\mathrm{CPO}}$ & $\begin{array}{l}\text { Desvio } \\
\text { Padrão }\end{array}$ \\
\hline 7 & 1.280 & 1,91 & 0,16 & 0,00 & 0,06 & 1.97 & 0,16 & 2,13 & 1,54 \\
\hline 8 & 1.253 & 1,73 & 1,04 & 0,05 & 0,15 & 1,88 & 1,09 & 2,97 & 1,68 \\
\hline 9 & 1.246 & 1,93 & 1,46 & 0.07 & 0,21 & 2,14 & 1,53 & 3,67 & 2,01 \\
\hline 10 & 1.240 & $2,1.1$ & 1,63 & 0,17 & 0,33 & 2,44 & 1,80 & 4,24 & 2,74 \\
\hline 11 & 1.243 & 2,61 & 2,07 & 0,29 & 0,40 & 3,01 & 2,36 & 5,37 & 3,45 \\
\hline 12 & 1.222 & 2,95 & 2,53 & 0,34 & 0,40 & 3,35 & 2,87 & 6,21 & 4,17 \\
\hline 13 & 1.125 & 3,15 & 3,39 & 0,41 & 0,37 & 3,52 & 3,80 & 7,32 & 4,62 \\
\hline 14 & 975 & 3,07 & 4,46 & 0,64 & 0,36 & 3,43 & 5,10 & 8,53 & 4,98 \\
\hline
\end{tabular}


ANEXO 24

QUADRO 23 - NUMERO DE ESCOLARES EXAMINADOS, CPO MEDIO, COMPONENTES, IECESSIDADES DE TRATAMENTO E DESVIO PADRÃO, SEGUNDO A IDADE, NA REGIÃO DE SÃO JOSE DO RIO PRETO, EM 1980.

\begin{tabular}{|c|c|c|c|c|c|c|c|c|c|}
\hline Idades & $\begin{array}{l}\text { Nümero de } \\
\text { Escolares } \\
\text { Examinados }\end{array}$ & $\overline{\mathrm{C}}$ & $\overline{0}$ & $\bar{E}$ & $\overline{E I}$ & $\overline{C+E I}$ & $\overline{O+E}$ & $\overline{\mathrm{CPO}}$ & $\begin{array}{l}\text { Desvio } \\
\text { Padrão }\end{array}$ \\
\hline 7 & 3.547 & 1,97 & 0,25 & 0,01 & 0,07 & 2,04 & 0,26 & 2,30 & 1,62 \\
\hline 8 & 3.609 & 1,82 & 1,18 & 0,05 & 0,11 & 1,93 & 1,23 & 3,16 & 1,77 \\
\hline 9 & 3.564 & 1,94 & 1,58 & 0,11 & 0,20 & 2,14 & $i, 69$ & 3,83 & 2,17 \\
\hline 10 & 3,531 & 2,31 & 1,94 & 0,21 & 0,24 & 2,55 & 2,15 & 4,70 & 2,91 \\
\hline 11 & 3.454 & 2,93 & 2,44 & 0,29 & 0,31 & 3,24 & 2,73 & 5,97 & 3,74 \\
\hline 12 & 3.335 & 3,18 & 3,23 & 0,35 & 0,29 & 3,47 & 3,58 & 7,05 & 4,23 \\
\hline 13 & 3.170 & 3,41 & 4,29 & 0,51 & 0,29 & 3,71 & 4,80 & 8,50 & 4,63 \\
\hline 14 & 2,402 & 3,33 & 5,46 & 0,63 & 0,30 & 3,62 & 6,09 & 9,72 & 4,93 \\
\hline
\end{tabular}


QMARO 24 - MOMERO DE ESCOLARES EXAMINADOS, CPO MEDIO, COMPONENTES, NECESSIDADES DE TRATAMENTO E DESVIO PADRÃO, SEGUNDO A IDADE, NA REGIÃO DE SÄO JOSÉ DO RIO PRETO, EM 1982.

\begin{tabular}{|c|c|c|c|c|c|c|c|c|c|}
\hline Idades & $\begin{array}{l}\text { Número de } \\
\text { Escolares } \\
\text { Examinados }\end{array}$ & $\overline{\mathrm{C}}$ & $\overline{0}$ & $\overline{\mathrm{E}}$ & $\overrightarrow{\mathrm{EI}}$ & $\overline{\mathrm{C}+\mathrm{EI}}$ & $\overline{O+E}$ & $\overline{\mathrm{CPO}}$ & $\begin{array}{l}\text { Desvio } \\
\text { Padrão }\end{array}$ \\
\hline 7 & 1.593 & 2,13 & 0,27 & 0,01 & 0,06 & 2,18 & 0,28 & 2,47 & 1,60 \\
\hline 8 & 1.531 & 1,63 & 1,42 & 0,05 & 0,10 & 1,72 & 1,47 & 3,20 & 1,66 \\
\hline 9 & 1.537 & 1,74 & 1,91 & 0,13 & 0,15 & 1,89 & 2,04 & 3,93 & 2,09 \\
\hline 10 & 1.549 & 2,15 & 2,21 & 0,22 & 0,24 & 2,39 & 2,43 & 4,82 & 2,81 \\
\hline 11 & 1.521 & 2,80 & 2,36 & 0,33 & 0,28 & 3,07 & 2,69 & 5,77 & 3,37 \\
\hline 12 & 1.438 & 3,30 & 3,05 & 0,45 & 0,28 & 3,58 & 3,50 & 7,08 & 3,97 \\
\hline 13 & 1.293 & 3,57 & 3,87 & 0,55 & 0,31 & 3,88 & 4,42 & 8,30 & 4,33 \\
\hline 14 & 984 & 3,46 & 4,86 & 0,64 & 0,32 & 3,77 & 5,50 & 9,28 & 4,68 \\
\hline
\end{tabular}


QUADRO 25 - NOMERO DE ESCOLARES EXAMINADOS, CPO MEDIO, COMPONENTES, NECESSIDADES DE TRATAMENTO E DESVIO PADRÃO, SEGUNDO A IDADE, NA REGIT̃O DE ARAÇATUBA, EM 1980.

\begin{tabular}{|c|c|c|c|c|c|c|c|c|c|}
\hline Idades & $\begin{array}{l}\text { Nümero de } \\
\text { Escolares } \\
\text { Examinados }\end{array}$ & $\overline{\mathrm{C}}$ & $\overline{0}$ & $\overline{\mathrm{E}}$ & $\overline{E I}$ & $\overline{\mathrm{C}+\overline{E I}}$ & $\overline{O+E}$ & $\overline{\mathrm{CPO}}$ & $\begin{array}{l}\text { Desvio } \\
\text { Padrão }\end{array}$ \\
\hline 7 & 1.050 & 2,12 & 0,31 & 0,02 & 0,07 & 2,19 & 0,33 & 2,52 & 1,60 \\
\hline 8 & 1.052 & 1,98 & 1,33 & 0,05 & 0,09 & 2,07 & 1,38 & 3,45 & 1,37 \\
\hline 9 & 1.039 & 2,02 & 1,96 & 0,08 & 0,18 & 2,20 & 2,04 & 4,24 & 1,95 \\
\hline 10 & 1.089 & 2,59 & 2,46 & 0,18 & 0,19 & 2,78 & 2,64 & 5,42 & 3,00 \\
\hline 11 & 1.092 & 3,34 & 2,92 & 0,25 & 0,21 & 3,55 & 3,17 & 6,72 & 3,77 \\
\hline 12 & 1.005 & 4,11 & 3,68 & 0,37 & 0,32 & 4,44 & 4,05 & 8,48 & 4,51 \\
\hline 13 & 990 & 4,61 & 4,51 & 0,56 & 0,28 & 4,89 & 5,07 & 9,96 & 4,73 \\
\hline 14 & 704 & 4,73 & 5,87 & 0,82 & 0,37 & 5,10 & 6,69 & 11,79 & 5,16 \\
\hline
\end{tabular}


QUADRO 26 - NUMERO DE ESCOLARES EXAMIIADOS, CPO MEDIO, COMPONENTES, NECESSIDADES DE TRATAMENTO E E DESVIO PADRÃO, SEGUNDO A IDADE, NA REGIT̃O DE ARAÇATUBA, EM 1982.

\begin{tabular}{|c|c|c|c|c|c|c|c|c|c|}
\hline Idades & $\begin{array}{l}\text { Número de } \\
\text { Escolares } \\
\text { Examinados }\end{array}$ & $\bar{C}$ & $\overline{0}$ & $\bar{E}$ & $\overline{E I}$ & $\overline{\mathrm{C}+\mathrm{EI}}$ & $\overline{O+E}$ & $\overline{\mathrm{CPO}}$ & $\begin{array}{l}\text { Desvio } \\
\text { Padrão }\end{array}$ \\
\hline 7 & 1.326 & 2,23 & 0,27 & 0,01 & 0,47 & 2,69 & 0,28 & 2,98 & 2,31 \\
\hline 8 & 1.279 & 1,65 & 1,71 & 0,04 & 0,46 & 2,11 & 1,75 & 3,86 & 2,27 \\
\hline 9 & 1.286 & 2,06 & 1,94 & 0,11 & 0,75 & 2,81 & 2,05 & 4,86 & 3,62 \\
\hline 10 & 1.282 & 2,60 & 2,33 & 0,19 & 0,95 & 3,55 & 2,52 & 6,07 & 4,52 \\
\hline 11 & 1.259 & 3,74 & 2,53 & 0,27 & 0,96 & 4,71 & 2,80 & 7,50 & 4,97 \\
\hline 12 & 1.238 & 4,56 & 2,98 & $a, 43$ & 1,03 & 5,59 & 3,41 & 9,00 & 5,52 \\
\hline 13 & 1.129 & 5,27 & 3,64 & 0,48 & 1,11 & 6,38 & 4,12 & 10,50 & 5,97 \\
\hline 14 & 894 & 5,13 & 5,02 & 0,68 & 1,20 & 6,32 & 5,70 & 12,03 & 6,01 \\
\hline
\end{tabular}


QUADRO 27 - IUMERO DE ESCOLARES EXAMINADOS, CPO MEDIO, COMPONENTES, NECESSIDADES DE TRATAMENTO E JESVIO PADRÃO, SEGUNDO A IDADE, NA REGIÃO DE PRESIDENTE PRUDENTE, EM 1980.

\begin{tabular}{|c|c|c|c|c|c|c|c|c|c|}
\hline Idades & $\begin{array}{l}\text { Número de } \\
\text { Escolares } \\
\text { Examinados }\end{array}$ & $\bar{C}$ & $\overline{0}$ & $\overrightarrow{\mathrm{E}}$ & $\bar{E} \bar{I}$ & $\overline{C+E I}$ & $\overline{O+E}$ & $\overline{\mathrm{CPO}}$ & $\begin{array}{l}\text { Desvio } \\
\text { Padrão }\end{array}$ \\
\hline 7 & 995 & 1.73 & 0,32 & 0,01 & 0,06 & 1,79 & 0,33 & 2,12 & 1,73 \\
\hline 8 & 960 & 1,42 & 1,33 & 0,05 & 0,10 & 1,52 & 1,38 & 2,90 & 1,77 \\
\hline 9 & 1.064 & 1,46 & 1,80 & 0,10 & 0,13 & 1,60 & 1,90 & 3,49 & 2,09 \\
\hline 10 & 1.076 & 1,89 & 2,30 & 0,15 & 0,20 & 2,09 & 2,45 & 4,54 & 2,95 \\
\hline 11 & 1.066 & 2,39 & 2,61 & 0,31 & 0,23 & 2,62 & 2,92 & 5,54 & 3,72 \\
\hline 12 & 1.023 & 3,29 & 3,31 & 0,43 & 0,29 & 3,58 & 3,74 & 7,32 & $4,5 I$ \\
\hline 13 & 918 & 3,24 & 4,32 & 0,57 & 0,32 & 3,56 & 4,89 & 8,45 & 4,99 \\
\hline 14 & 766 & 3,76 & 5,76 & 0,60 & 0,35 & 4,11 & 6,36 & 10,47 & 5,72 \\
\hline
\end{tabular}


QUADRO 28 - NTMERO DE ESCOLARES EXAMINADOS, CPO MEDIO, COMPONENTES, NECESSIDADES DE TRATAMENTO E E DESVIO PADRÃO, SEGUNDO A IDADE, NA REGIÃO DE PRESIDENTE PRUDENTE, EM 1982.

\begin{tabular}{|c|c|c|c|c|c|c|c|c|c|}
\hline Idades & $\begin{array}{l}\text { Numero de } \\
\text { Escolares } \\
\text { Examinados }\end{array}$ & $\overline{\mathrm{C}}$ & $\overline{0}$ & $\dddot{\mathrm{E}}$ & $\overline{\mathrm{EI}}$ & $\overline{\mathrm{C}+\overline{\mathrm{EI}}}$ & $\overline{O+E}$ & $\overline{\mathrm{CPO}}$ & $\begin{array}{l}\text { Desvio } \\
\text { Padrão }\end{array}$ \\
\hline 7 & 1.101 & 2,00 & 0,26 & 0,02 & 0,06 & 2,06 & 0,28 & 2,34 & 1,60 \\
\hline 8 & 1.067 & 1,81 & 1,20 & 0,05 & 0,16 & 1,97 & 1,25 & 3,22 & 1,77 \\
\hline 9 & 1.065 & 2,13 & 1,66 & 0,12 & 0,20 & 2,33 & 1,78 & 4,11 & 2,10 \\
\hline 10 & 1.063 & 2,86 & 1,76 & 0,21 & 0,31 & 3,17 & 1,97 & 5,14 & 3,09 \\
\hline 11 & 1.039 & 3,95 & 1,88 & 0,30 & 0,39 & 4,33 & 2,18 & 6,52 & 4,05 \\
\hline 12 & 977 & 4,85 & 2,37 & 0,45 & 0,47 & 5,33 & 2,85 & 8,14 & 4,62 \\
\hline 13 & 796 & 5,11 & 3,20 & 0,62 & 0,49 & 5,60 & 3,82 & 9,42 & 4,96 \\
\hline 14 & 649 & 5,72 & 4,00 & 0,74 & 0,51 & 6,23 & 4,74 & 10,97 & 5,19 \\
\hline
\end{tabular}


QUADRO 29 - UMERO DE ESCOLARES EXAMINADOS, CPO MEDIO, COMPONENTES, NECESSIDADES DE TRATAMENTO E DESVIO PADRÃO, SEGUNDO A IDADE, NA REGIÃO DE MARILIA, EM 1980.

\begin{tabular}{|c|c|c|c|c|c|c|c|c|c|}
\hline Idades & $\begin{array}{l}\text { Número de } \\
\text { Escolares } \\
\text { Examinados }\end{array}$ & $\bar{C}$ & $\overline{0}$ & $\overline{\mathrm{E}}$ & $\overline{E I}$ & $\overline{\mathrm{C}+\mathrm{E}}$ & $\overline{O+E}$ & $\overline{\mathrm{CPO}}$ & $\begin{array}{l}\text { Desvio } \\
\text { Padrão }\end{array}$ \\
\hline 7 & 2.371 & 2,08 & 0,27 & 0,01 & 0,09 & 2,17 & 0,28 & 2,45 & 1,67 \\
\hline 8 & 2.378 & 1,89 & 1,21 & 0,06 & 0,16 & 2,05 & 1,27 & 3,32 & 1.76 \\
\hline 9 & 2.392 & 2,26 & 1,59 & 0,15 & 0,24 & 2,50 & 1,74 & 4,24 & 2,31 \\
\hline 10 & 2.447 & 2,76 & 1,84 & 0,24 & 0,36 & 3,12 & 2,12 & 5,20 & 3,12 \\
\hline 11 & 2.369 & 3,61 & 2,25 & 0,41 & 0,46 & 4,07 & 2,66 & 6,73 & 4,08 \\
\hline 12 & 2.248 & 4,19 & 2,81 & 0,56 & 0,46 & 4,65 & 3,37 & 8,02 & 4,64 \\
\hline 13 & 2.131 & 4,75 & 4,05 & 0,77 & 0,54 & 5,29 & 4,82 & 10,11 & 5,16 \\
\hline 14 & 1.732 & 4,80 & 4,64 & 0,82 & 0,61 & 5,41 & 5,46 & 10,87 & 5,16 \\
\hline
\end{tabular}


QMDRO 30 - NUMERO DE ESCOLARES EXAMIMADOS, CPO MEDIO, COMPONENTES, NECESSIDADES DE TRATAMENTO E DESVIO PADRÃO, SEGUNDO A IDADE, NA REGIÃO DE MARILIA, EM 1982.

\begin{tabular}{|c|c|c|c|c|c|c|c|c|c|}
\hline Idades & $\begin{array}{l}\text { Número de } \\
\text { Escolares } \\
\text { Examinados }\end{array}$ & $\overline{\mathrm{C}}$ & $\overline{0}$ & $\overline{\mathrm{E}}$ & $\overline{E I}$ & $\overline{C+E \bar{I}}$ & $\overline{O+E}$ & $\overline{\mathrm{CPO}}$ & $\begin{array}{l}\text { Desvio } \\
\text { Padrão }\end{array}$ \\
\hline 7 & I. 158 & 2,14 & 0,23 & 0,01 & 0,10 & 2,24 & 0,24 & 2,48 & 1,61 \\
\hline 8 & 1.148 & 1,74 & 1,31 & 0,06 & 0,13 & 1,86 & 1,37 & 3,24 & 1,55 \\
\hline 9 & 1.135 & 1,93 & 1,58 & 0,15 & 0,23 & 2,16 & 1,73 & 3,89 & 2,05 \\
\hline 10 & 1.148 & 2,60 & 1,89 & 0,26 & 0,32 & 2,92 & 2,15 & 5,07 & 2,94 \\
\hline 11 & 1.137 & 3,41 & 2,20 & 0,38 & 0,43 & 3,84 & 2,58 & 6,42 & 3,80 \\
\hline 12 & 1.107 & 4,04 & 2,60 & 0,57 & 0,47 & 4,51 & 3,17 & 7,68 & 4,37 \\
\hline 13 & 1.009 & 4,46 & 3,48 & 0,62 & 0,53 & 4,99 & 4,10 & 9,09 & 4,74 \\
\hline 14 & 905 & 4,42 & 4,34 & 0,83 & 0,50 & 4,92 & 5,17 & 10,09 & 4,84 \\
\hline
\end{tabular}


OLADRO 31.- NUMERO DE ESCOLARES EXAMINADOS, CPO MEDIO, COMPONENTES, NECESSIDADES DE TRATAMENTO E DESVIO PADRÃO, SEGUNDO A IDADE NA REGIÃO DO VALE DO RIBEIRA, EM 1980.

\begin{tabular}{|c|c|c|c|c|c|c|c|c|c|}
\hline Idades & $\begin{array}{l}\text { Número de } \\
\text { Escolares } \\
\text { Examinados }\end{array}$ & $\bar{c}$ & $\overrightarrow{0}$ & $\overline{\mathrm{E}}$ & $\overline{\mathrm{EI}}$ & $\overline{\mathrm{C}+\mathrm{EI}}$ & $\overline{\mathrm{O+E}}$ & $\overline{\mathrm{CPO}}$ & $\begin{array}{l}\text { Desvio } \\
\text { Padrão }\end{array}$ \\
\hline 7 & 150 & 2,29 & 0,08 & 0,02 & 0,10 & 2,39 & 0,10 & 2,49 & 1,54 \\
\hline 8 & 150 & 1,86 & 1,25 & 0,03 & 0,31 & 2,17 & 1,28 & 3,45 & 1,56 \\
\hline 9 & 150 & 1,73 & 1,98 & 0,16 & 0,35 & 2,09 & 2,14 & 4,22 & 1,88 \\
\hline 10 & 150 & 2,61 & 1,98 & $a, 34$ & 0,53 & 3,14 & 2,32 & 5,46 & 2,91 \\
\hline 11 & 150 & 3,47 & 2,59 & 0,37 & 0,55 & 4,02 & 2,96 & 6,98 & 3,50 \\
\hline 12 & 150 & 4,76 & 2,63 & 0,68 & 0,67 & 5,43 & 3,31 & 8,74 & 4,03 \\
\hline 13 & 120 & 4,99 & 3,74 & 1,09 & 0,57 & 5,56 & 4,83 & 10,39 & 4,51 \\
\hline 14 & 105 & 5,72 & 4,30 & 1,30 & 0,55 & 6,28 & 5,60 & 11,87 & 5,18 \\
\hline
\end{tabular}


QUADRO 32 - NOMERO DE ESCOLARES EXAMINADOS, CPO MEDIO, COMPONENTES, NECESSIDADES DE: TRATAMENTO E DESVIO PADRÃO, SEGUNDO A IDADE, NA REGIÃO DO VALE DO RIBEIRA, EM 1982.

\begin{tabular}{|c|c|c|c|c|c|c|c|c|c|}
\hline Idades & $\begin{array}{l}\text { Número de } \\
\text { Escolares } \\
\text { Examinados }\end{array}$ & $\bar{C}$ & $\overline{0}$ & $\vec{E}$ & $\widetilde{\mathrm{EI}}$ & $\overline{\mathrm{C}+E \bar{I}}$ & $\overline{O+E}$ & $\overline{\mathrm{CPO}}$ & $\begin{array}{l}\text { Desvio } \\
\text { Padrão }\end{array}$ \\
\hline 7 & 205 & 1,84 & 0,29 & 0,02 & $0,0.6$ & 1,90 & 0,31 & 2,21 & 1,58 \\
\hline 8 & 202 & 1,48 & 1,43 & 0,02 & 0,12 & 1,60 & 1,45 & 3,05 & 1,47 \\
\hline 9 & 20.1 & 1,61 & 1,85 & 0,11 & 0,27 & 1,88 & 1,96 & 3,84 & 1,50 \\
\hline 10 & 197 & 2,41 & 1,91 & 0,17 & 0,31 & 2,72 & 2,08 & 4,80 & 2,27 \\
\hline 11 & 19.9 & 2,84 & 2,77 & 0,50 & 0,39 & 3,23 & 3,27 & 6,50 & 3,44 \\
\hline 12 & 208 & 3,33 & 3,22 & 0,60 & 0,63 & 3,97 & 3,82 & 7,78 & 4,12 \\
\hline 13 & 187 & 3,88 & 3,96 & 0,81 & 0,53 & 4,41 & 4,77 & 9,18 & 4,53 \\
\hline 14 & 157 & 4,30 & 4,42 & 1,15 & 0,59 & 4,89 & 5,57 & 10,46 & 4,53 \\
\hline
\end{tabular}

